\section{Application of Fracture Mechanics to Cementitious Composites}

edited by

\section{S.P. Shah}

Department of Civil Engineering

Northwestern University

Evanston. Illinois

USA

\section{Martinus Nijhoff Publishers}

Dordrecht / Boston / Lancaster

Published in cooperation with NATO Scientific Affars Division
APPLICATION OF FRACTURE MECHANICS TO CEMENTITIOUS COMPOSITES

NATO-ARW - September 4-7, 1984

Northwestern University, U.S.A.

S. P. Shah, Editor

CONTINUUM MODEL FOR PROGRESSIVE CRACKING AND IDENTIFICATION OF NONLINEAR FRACTURE PARAMETERS

\author{
Zdeněk P. Ražant ${ }^{a}$, Jin-Keun Kim ${ }^{b}$, and Phillip Pfeiffer ${ }^{c}$ \\ Center for Concrete and Geomaterials \\ The Technological Institute, Northwestern Univeristy \\ Evanston, Ilitinois 60?0I, U.S.A.
}

ARSTRACT

Fracture of concrete as well as other materials such as rocks or sea ice is preceded hy progressive distributed cracking. On the macroscale, this behavior calls for a continuum model, and the crack tip biunting due to distributed cracking necessitates a nonlinear fracture mechanics approach.

The first part of this lecture gives a review of a recentiy formulated nonlocal continuum model which permits distributed cracking to occur in a stable manner over finite-size zones of the material, and summarizes the finite element crack band model, which is a special case of the nonlocal continuum approach. The size effect in blunt fracture is also briefly reviewed.

The second part of this lecture presents in detail a new method of identifying the material parameters for propagation of fractures blunted by a cracking zone. This method exploits the recently derived size effect law for blunt fracture for determining the parameters of the R-curve and the parameters of the finite
Proceedings of the NATO Advanced Research Workshop on Application of Fracture Mechanics to Cementitious Composites. Northwestern University, Evansion. Illincs. USA. September 4-7. 1984

\footnotetext{
aProfessor of Civil Engineering and Center Director

b Graduate Research Assistant

${ }^{C}$ Graduate Research Assistant; presentiy Resident Student Associate at Argonne National Laboratory
} 
element crack band model (as well as Hillerborg's fictitious crack model). No measurements of the crack length or of the unloaring compliance are needed, and it suffices to measure only the maximum load vaiues for a set of geometrically similar notched specimens of different sizes. From these data, the parameters of the size effect law are identified by linear regression in certain transformed variables. The inverse slope of the regression iine yieids the fracture energy. The regression has further a two-fold benefit: it smoothes statistically scattered data according to a theoretically known law, and it extends the range of the data, so that fewer tests are needed than without the use of the size effect law. Using the experimentaliy calibrated size effect law, the R-curve may then be obtained as the envelope of family of curves representing fracture equilibrium for different specimen sizes. A simple aigehraic formula for the R-curve, which closely agrees with the size effect law, is also presented. In the case of the crack band model, the size effect regression plot makes it again possible to determine all material parameters, particulariy the fracture energy, the crack band width and the strain-softening moduius. Formulas for that purpose may he set up for each fracture specimen geometry, and some are presented here. The parameters of Hillerhorg's fictitious crack model can be also easily identified from the size effect regression plot.

\section{INTRODUCTION}

Structures made of a heterogeneous brittle material such as concrete often exhibit brittle failures in which the materiai fractures progressiveiy and the fracturing is distrihuted over a zone of finite size. In the macroscopic continum approximation, the behavior of the fracturing zone is characterized by strainsoftening, i.e., a stress-strain relation in which the maximum principal stress decreases at increasing strain. Strain-softening may be easily implemented in a finite element code, however, problems are encountered in convergence as the mesh is refined. Using a finite element discretization of the classical, local continuum, the failure zone always localizes into a zone of vanishing thickness, which means that in the 1 imit of an infinitely small mesh size the structure is indicated to dissipate zero energy during failure. This aspect is obviousiy unrealistic, and it causes an incorrect spurious sensitivity of the results to the chosen element size $[3,7,9.10,16\rceil$.

An expedient remedy is possible with the crack hand mode?, in which the cracking front is forced to have a fixed width which is a material property. This type of analysis has been shown to yieid good agreement with all important fracture test data for concrete, as well as rock $[3,16]$. However, a disconcerting feature remains. The mesh cannot be refiner to sizes smaller than a certain charactristic length, and so one does not have a limiting continuum which the finite element model is supposed to approximate. Furthermore, the size of the strain-softening zone and the strain distribution over the zone, which must he known if the energy dissipated hy cracking should he correctly calculated, is unknown. To overcome these limitations, it is necessary to abandon the classical idea of a local continuum, as will now be shown in the first part of the lecture, in which a recently established $[5,7,12,13]$ nonlocal continuum model is described.

The existence of a characteristic length in the noniocal continuum model impijes a size effect which differs from hoth the failure criteria of limit analysis and the inear elastic fracture mechanics. After reviewing the recentiy derived size effect law [6] that is associated with the nonlocai continuum approach, the second part of the lecture deals with the problem of determination of the material parameters for propagation of fractures blunted by a cracking zone. A new method of their determination, which uses experimental data on the size effect, is presented in detail.

\section{CONTINUUM MODEL FOR DISTRIRUTED CRACKING}

\subsection{Imbricate Nonlocal Continuum}

From the works of Kroner, Kunin, Krumhans 7 , Levin and others $[21-2,27-31]$, it is known that in a statisticaliy heterogeneous medium which is not in a macroscopically homogeneous state of strain, the averaged (smoothed) stress at a certain point depends not oniy on the gradient of the averaged displacements at that same point (local properties), hut also on the averaged displacements within a certain characteristic finite neighborhood of that point. The properties of such a medium cannot be said to he local, and the medium is, therefore, called nonincal.

The nonlocal displacement gradient may be defined hy the relation

$$
D_{i} u_{j}(\underset{\sim}{x})=\frac{1}{V} \int_{V(\underline{x})} \frac{\partial u_{j}\left(\underline{x}^{\prime}\right)}{\partial x_{i}} d V^{\prime}=\frac{1}{V} \int_{S(\underset{\sim}{x})} u_{j}\left(\underline{\sim}^{\prime}\right) n_{i}\left(\underline{x}^{\prime}\right) d S^{\prime}
$$

in which $u_{j}$ are the cartesian displacement components $(j=1,2,3)$, $x$ is the coordinate vector of the given point characterized by cartesian coordinates $x_{i}, V(\underset{z}{x})$ is the characteristic volume (Fig. 1 ) of the material centêred at point $\underset{\tilde{f}}{x} S(\underset{\tilde{s}}{)}$, is the surface of this volume, $n_{i}\left(x^{*}\right)$ is the unit normal of this surface at point $x^{\prime}$, and $D_{j}$ is the gradient averaging operator. The surface integral in Eq. 1 follows from the volume integral by application of the Gauss integrai theorem. More generaliy, a weighting function can be introduced in Eq. ?. Using the gradient averaging operator, 


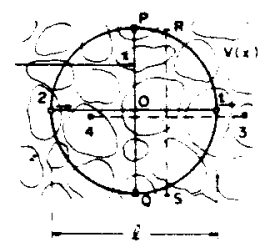

Fig. 1 - Representative Volume of an Aggregate Material

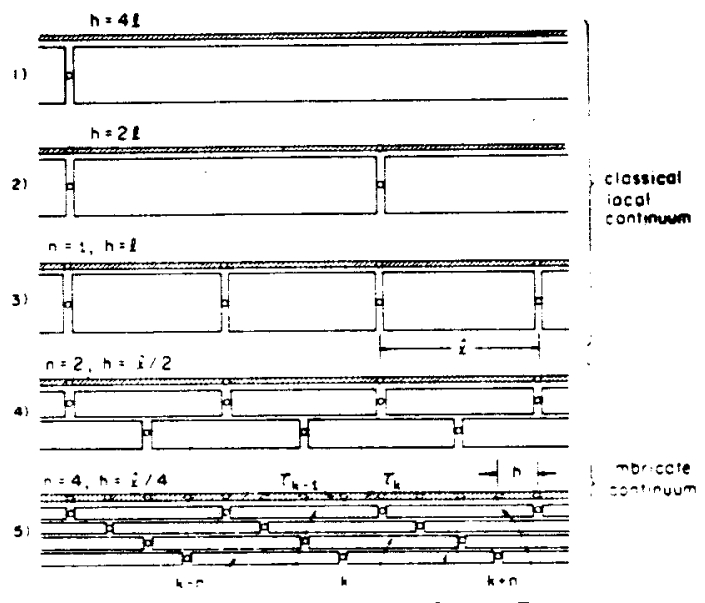

$\sigma_{k-n} \quad \sigma_{k-n: 1} \quad \sigma_{k-1} \quad \sigma_{k} \quad \sigma_{k+1}$

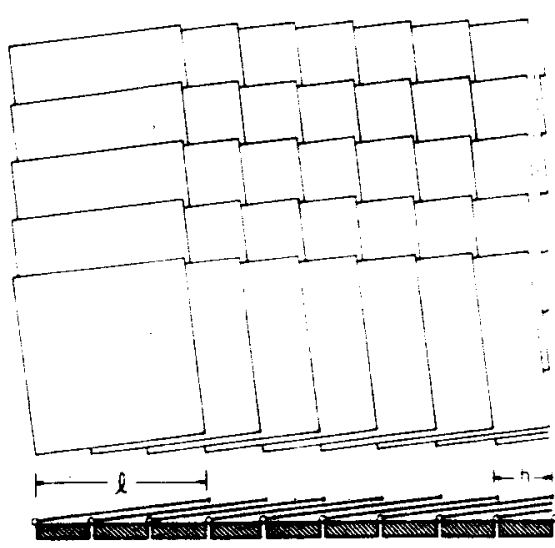

Fig. 2 - Finite Element Discretization of Imbricate Nonlocal Continuum for One Dimension and Two Dimensions (the continuum is the limiting case as the element size tending to zero) the mean strains may be defined as

$$
\bar{\varepsilon}_{i j}=\frac{1}{2}\left(D_{i} u_{j}+D_{j} u_{i}\right)
$$

In previous works dealing with nonlocal continua, it has been generaliy assumed that the continuum equation of motion has the form

$$
\frac{\partial}{a x_{j}} \bar{C}_{i j k m}(\underset{\sim}{\bar{\varepsilon}}) D_{m} u_{k}=\rho \ddot{u}_{i}
$$

in which $\bar{C}_{i j k}$ are secant elastic moduli which, in general, depend on the mean ikfrain, $\rho$ is the mass density, and superior dots refer to time derivatives. It is found, however, that $\mathrm{Eq} .3$ is incapable of describing a strain-softening continuum. It aiways leads to unstable response as soon as strain-softening begins. The difficulty has been traced to the asymmetry of these equations due to the combinatin of partial derivatives $\partial / \partial x_{j}$ with the gradient averaging operator $D_{m}$. This feature gives rise to nonsymmetric finite eiement matrices even if $\bar{c}_{\text {jikm }}$ are constant, i.e., if the medium is elastic. Such a nonsymmetry is certainly an unacceptable characteristic.

For this reason, a systematic derivation of the continuum equation of motion on the basis of $\mathrm{Eq} .1$ has been attempter, using the caicuius of variations. It has been found $[5,7\rceil$ that the proper form of the continuum equation of motion is

$$
(1-c) n_{j} C_{i j k m}(\bar{\varepsilon}) D_{m} u_{k}+C \cdot \frac{\partial}{\partial x_{j}} C_{i j k m}(\underset{\sim}{\varepsilon}) \frac{\partial}{\partial x_{m}} u_{k}=\rho \ddot{u}_{i}
$$

in which $c$ is an empirical coefficient between 0 and 1 , and

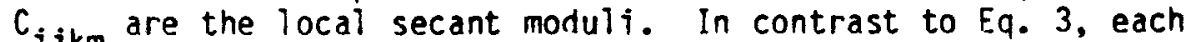
terink the last equation has a symmetric structure, and consequentiy, discretization by finite elements leads to symmetric stiffness matrices if the elastic moduli $C_{i j k m}$ and $C_{i j k m}$ are
symmetric.

Eq. 4 can be also written in the form

$$
(1-c) D_{j} \sigma_{i j}+c \tau_{i j, j}=\rho \ddot{u}_{i}
$$

in which

$$
\begin{aligned}
& \sigma_{i j}=C_{i j k m}\left(\underset{\underset{\varepsilon}{\bar{\varepsilon}})}{\varepsilon_{k m}}=C_{i j k m}(\underset{\sim}{\bar{\varepsilon}}) D_{m} u_{k}\right. \\
& \tau_{i j}=C_{i j k m} \varepsilon_{k m}=C_{i j k m} \frac{\partial u_{k}}{\partial x_{m}}
\end{aligned}
$$

in which $\tau_{i j}$ are the usual, local stresses, and $\sigma_{i j}$ are the 
stresses characterizing the stress state in the entire representative volume of the material and are called the broadrange stresses $[5,7]$.

When the continuum defined by Eq. 4 is discretized by finite elements the size of which is smaller than the size $\ell$ of the representative volume, one obtains a system of imbricated (regularly overiapping) finite elements visualized in Fig. 2. Therefore, the present type of nonlocal continuum has been called the imbricate continuum [4]. The finite elements keep a constant size $\ell$ as the mesh is refined, and the number of imbricated finite elements that cross a given point is inversely proportional to the mesh size, while the cross section of these elements diminishes so that all the imbricated finite elements have the same total cross section for any mesh size. It can be also shown that the limiting case of the finite difference equations describing such an imbricated system of finite elements is the differential equation in Eq. 4 [5,7]. If the finite element size $h$ is larger than the characteristic length $\ell$, then the finite element model of the imbricate nonlocal continuum becomes identical to that for the classical local continuum.

To assure convergence and stahility, the local stress-strain relations (Eq. 7) may not exhibit strain-softening, or eise unstabie response and spurious sensitivity to mesh size, along with incorrect convergence, may be obtained. The strain-softening properties must be described solely by the broad-range stressstrain relation in Eq. 6 .

Fig. 3 reproduces some of the results of explicit dynamic finite element calculations from Ref. 7 , in which wave propagation in a strain-softening bar of length $\&$ was analyzed [7]. Both ends of the bar are subjected to a constant outward velocity d beginning at time $t=0$. This loading produces step waves of strain propagating inward. When these waves meet at midlength, the strain suddeniy increases and strain-softening ensues. If this problem is analyzed with the usual finite element method for local continuum, it is found that strain-softening is always limited to a singleelement width. Thus, the width of the strain-softening zone reduces to zero as the element mesh is refined (Fig. 4). As a consequence, the energy $W$ consumed by fajlure decreases with decreasing mesh size and approaches zero as the mesh size tends to zero (Fig. 5). Moreover, the finite el ement model of local continuum exhibits a discontinuous dependence of response on the prescribed end velocities as well as on the slope $E_{f}$ of the strain-softening branch. The solution, however, converges to a unique exact solution, although this solution is unrealistic from the physical point of view.

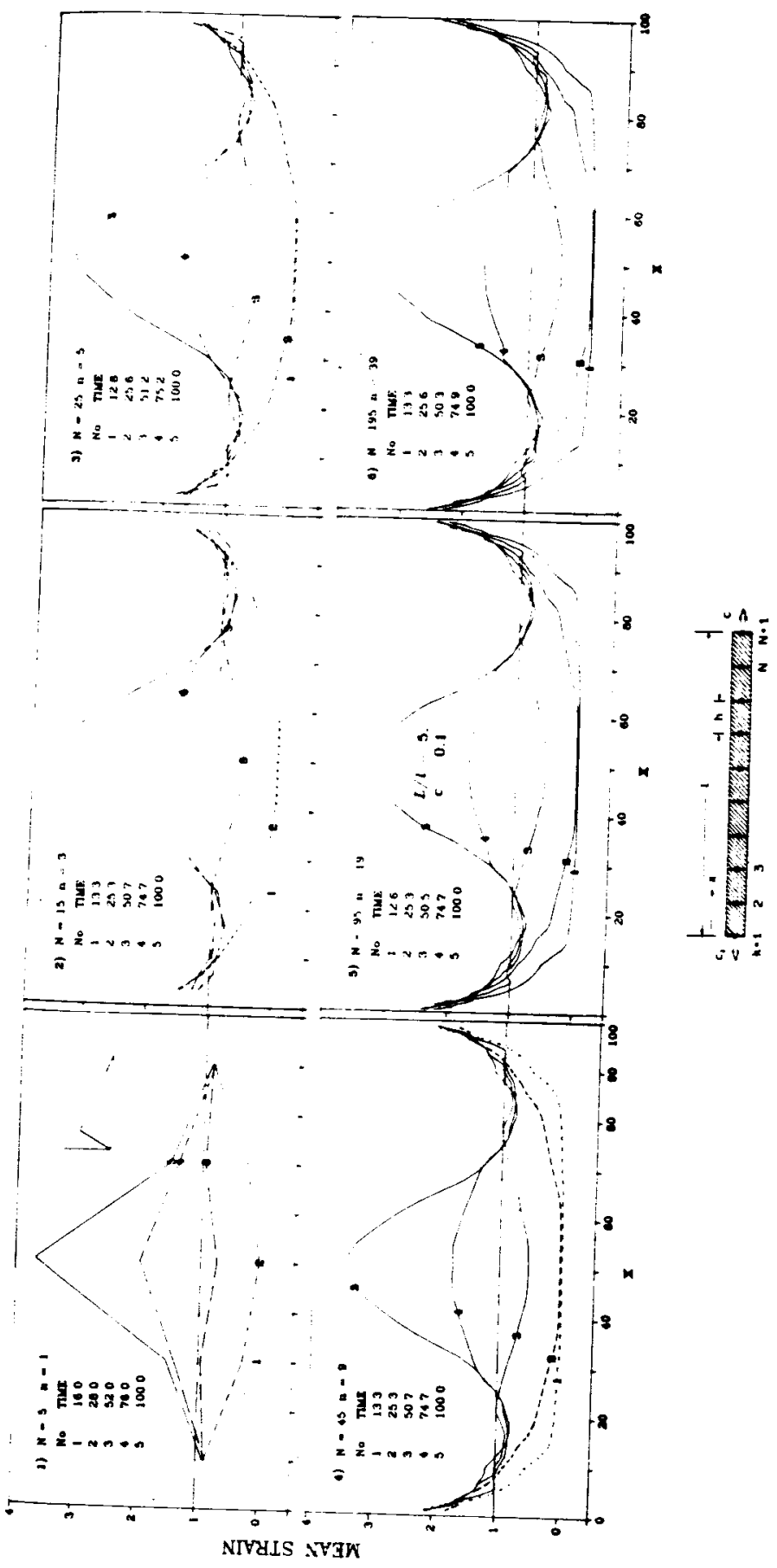




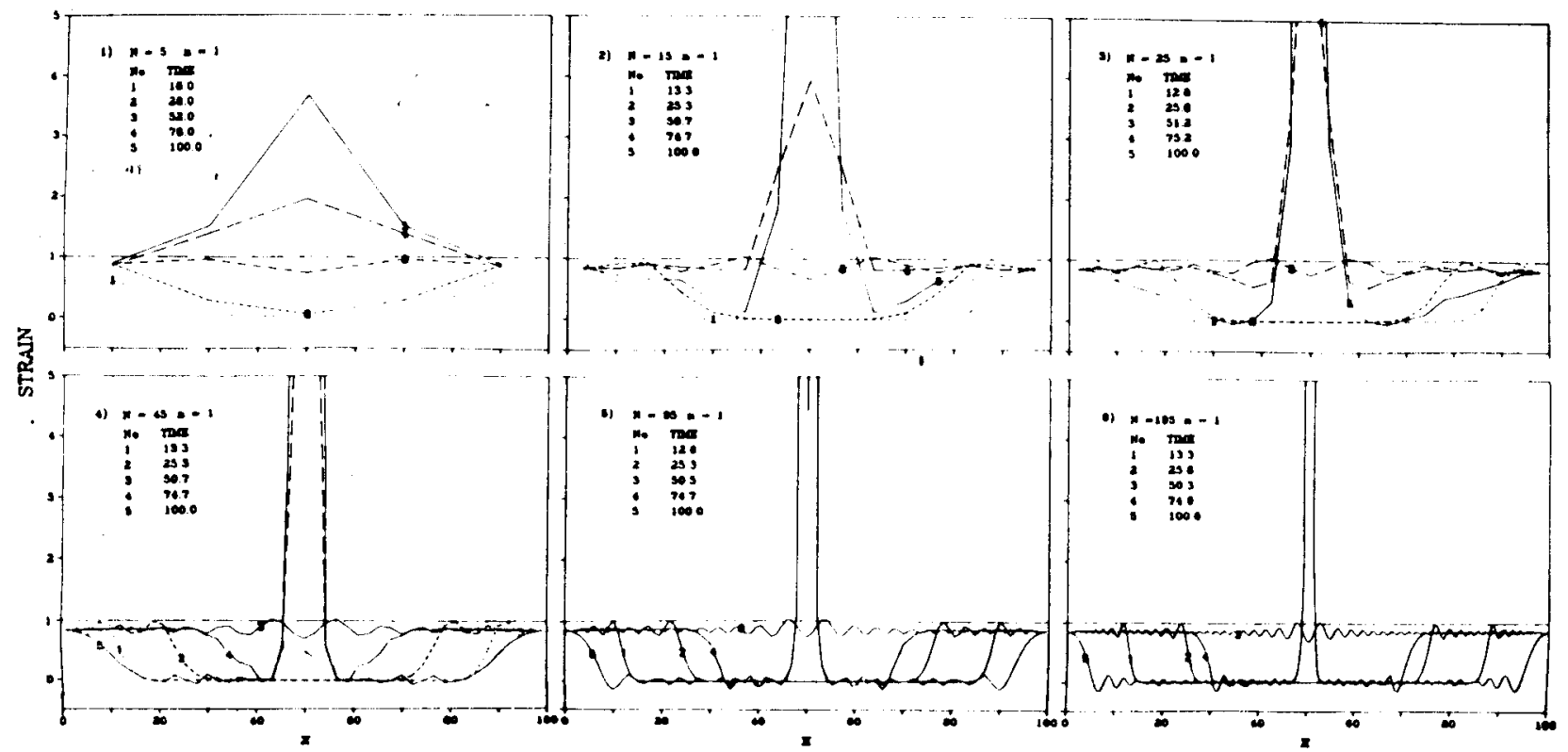

Fig. 4 - Numerical Results for the Same Problem as in Fig. 3 Obtained with Finite Elements of Classical Local Cont i nuum.

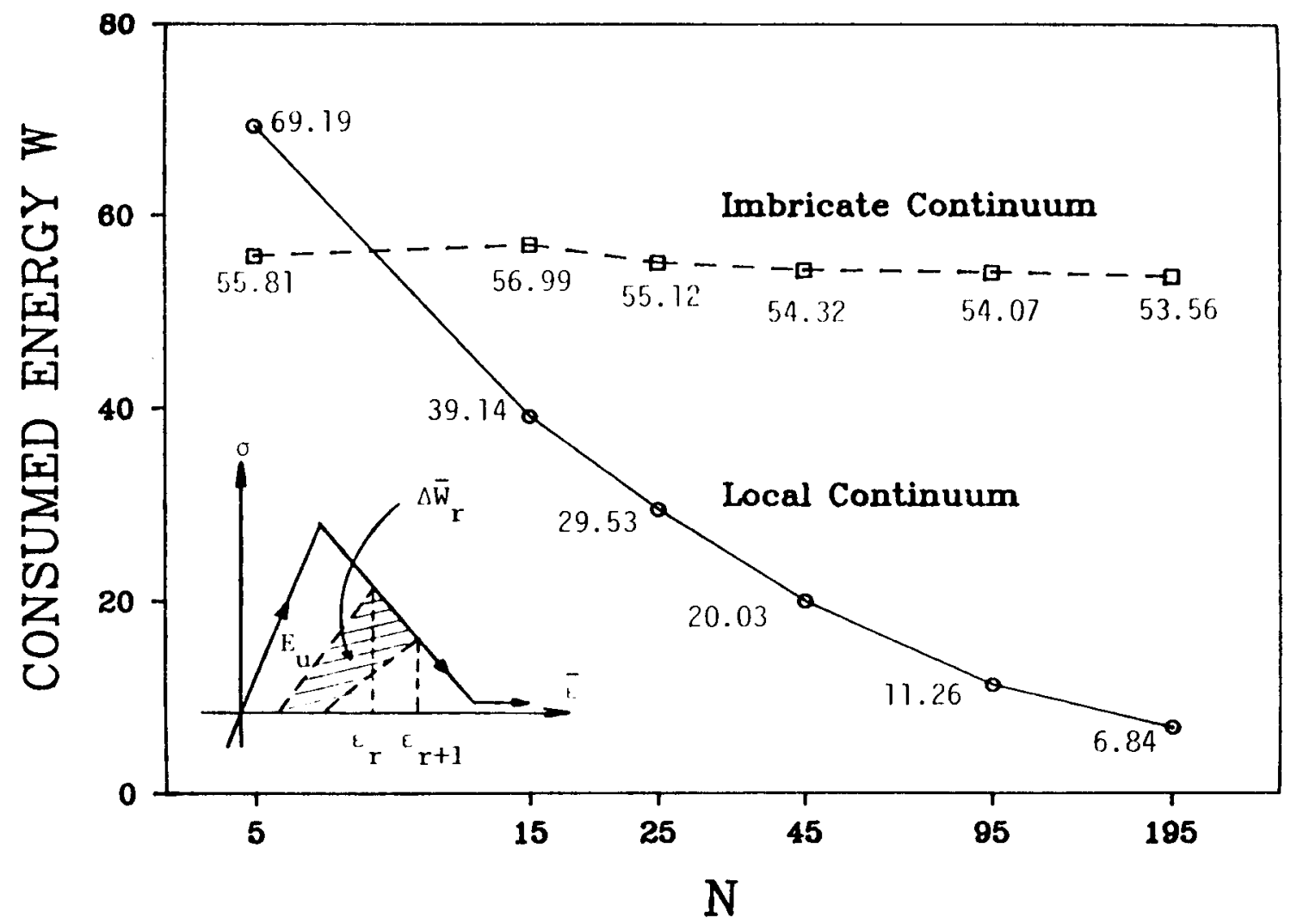

Fig. 5 - Numerical Results for Energy Consumed by Failure as a Function of Mesh Size, (a) for Classical Local Continuum, (b) -for Imbricate Nonlocal Continuum (wave propagation in a bar, element arrangement shown in Fig. 3) (after Bazant, Chang, and Belytschko, 1983). 
For the present imbricate continuum, by contrast, the solution of wave propagation in the strain-softening bar (Fig. 3) exhibits correct convergence, with a strain-softening zone of a finite size in the limit [7]. Also, the energy consumed hy failure in the har converges to a finite value, as shown in Fig. 5. The

characteristic length in these computations has been considered as $\ell=L / 5$.

\subsection{Differential Approximation of Imbricate Noniocal Continuum}

For the purpose of analytical solutions it may be useful to approximate the integral operator that defines the mean strain by a differential operator. To this end, we expand the integrand of $\mathrm{Eq}$ 1 into Taylor series:

$u_{j, j}\left(\underline{x}^{\prime}\right)=u_{j, i}(\underset{\sim}{x})+u_{j, j k}(\underset{\sim}{x}) x_{k}^{\prime}+\frac{1}{2} u_{j, i k m}\left(x_{\sim}\right) x_{k}^{\prime} x_{m}^{\prime} x_{m}^{\prime}$

This yields

$D_{i} u_{j}(\underline{x})=u_{j, i}(\underset{\sim}{x})+\frac{1}{2 !} A_{k m} u_{j, i k m}(\underset{\sim}{x})+\frac{1}{4 !} B_{k m p q} u_{j, i k m p q}(\underset{\sim}{)}+\ldots(8)$

where

$A_{k m}=\frac{1}{V} \int_{V} x_{k} x_{m} d V=\frac{\ell^{2}}{20} \quad \delta_{k m}$

and $B_{k m q}=\frac{1}{V} \int_{V} x_{k} x_{m} x d v$, provided that the representative

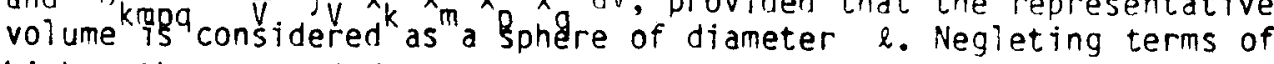
higher than second degree, we obtain

$$
n_{i} u_{j}=u_{j, i}+\lambda^{2} u_{j, i k k}=\left(\gamma+\lambda^{2} \nabla^{2}\right) \frac{\partial u_{j}}{\partial x_{j}}
$$

in which $\lambda=\ell^{2} / 4 n$ and $\nabla^{2}=$ Laplace operator. Since $\&$ equals approximateiy $3 d$ where $d=$ maximum aggregate size, we note that $\lambda$ approximately êquals the maximum aggregate radius. In view of $\mathrm{Eq} .10$, the field equations for the imbricate nonlocal continuum (Eqs. 5-6) may now be written as follows 157 :

$$
(1-c)\left(i+\lambda^{2} \nabla^{2}\right) \sigma_{i j, j}+c \tau_{i j, j}=\rho \ddot{u}_{i}
$$

$\sigma_{i j}=\tau_{i j k m}(\underset{\sim}{\varepsilon}) \bar{\varepsilon}_{k m}, \quad \tau_{i j}=C_{i j k m}(\underset{\sim}{\varepsilon}) \varepsilon_{k m}$

$\bar{\varepsilon}_{k m}=\left(1+\lambda^{2} \nabla^{2}\right) \varepsilon_{k m}, \quad \varepsilon_{k m}=\frac{1}{2}\left(u_{k, m}+u_{m, k}\right)$

The principal of virtual work for a body (whose domain is $B$ and surface is S) made of the imbricate continuum may be stated as follows:

$$
\delta W=\int_{B} \sigma_{i j} \delta \vec{\varepsilon}_{i j} d V-\int_{S} p_{i} \delta u_{i} d S+\int_{B} \rho \ddot{u}_{i} \delta u_{i} d V=0
$$

in which $\delta u_{j}(\underset{\sim}{x})$ is any kinematically admissible displacement variation, and $p_{j}$ are the given distrihuted surface loads. Substituting $\mathrm{Eq}$. $\left\{3\right.$ for $\bar{\varepsilon}_{j \mathrm{j}}$ and applying repeatediy Gauss integral theorem, one can derive the field equations (Eqs. 11-13) from the virtual work relation (Fq. 14). Moreover, the variationa? procedure yields the boundary conditions at surface $S$;

either

$$
u_{i}=0 \text { or } \bar{\sigma}_{i j} n_{j}=p_{i} \quad \text { (on } s \text { ) }
$$

where

$$
\bar{\sigma}_{i j}=\left(1+\lambda^{2} \nabla^{2}\right) \sigma_{i j}
$$

In the classicai nonlocal continuum theory, the mean strain is more generaily defined with the help of a certain given weighting function $w(\Sigma)$ where $r=x^{\prime}-\underset{x}{ }$, i.e.,

$$
D_{i} u_{j}(\underline{x})=\frac{1}{V} \int_{V(\underline{x})} w(\underline{\sim}) \frac{\partial u_{j}\left(\underline{x}^{\prime}\right)}{\partial x_{j}^{\prime}} d v^{\prime}
$$

in which $\int_{Y} w(\Sigma) d V^{\prime}=1$ (normalized weights). Introducing again the Taylor series expansion of $\partial u_{i} / \partial x_{j}^{\prime}$ and truncating it after the quadratic term, one finds that

$$
D_{i} u_{j}=\left(1+\alpha \lambda^{2} \nabla^{2}\right) \frac{\partial u_{j}}{\partial x_{j}}
$$

in which $\alpha=\frac{1}{2} \int_{V} w(\underset{\sim}{r}) x_{k}^{\prime} x_{k}^{\prime} d V^{\prime}$. However, as long as $\lambda$ is to be $\{a l i b r a t e d$ empiricaify, one can determine oniy the product $\alpha \lambda^{2}$, and not $\alpha$ and $\lambda^{2}$ separately. Thus, it does not matter which weighting function is used, and the simplest case $W(L)=I / V=$ const. may be chosen.

It is interesting to compare the equation

$$
\bar{\varepsilon}_{i j}=\left(1+\lambda^{2} \nabla^{2}\right) \varepsilon_{i j}=\varepsilon_{i j}+\frac{1}{2} \lambda^{2}\left(u_{i, j k k}+u_{j, i k k}\right)
$$

with the well-known couple stress theories or micropolar theories. In them, only first and second derivatives appear and the second derivatives are skipped. Moreover, there is no need to 
associate with the higher displacement derivative any special type of stress tensor of a higher rank, such as the couple stress tensor. Only one, second-rank stress tensor is used here.

Let us now check stability of the continuum. Consider linearly elastic properties, characterized by Young's modulus $E$, and the one-dimensional case, with $x_{j}=x, u_{i}=u$. From Eqs. 1113 we obtain the differential equation of motion

$$
(1-c)\left(1+\lambda^{2} \frac{\partial^{2}}{\partial x^{2}}\right)^{2} \frac{\partial^{2} u}{\partial x^{2}}=\frac{\rho}{E} \frac{\partial^{2} u}{\partial t^{2}}
$$

Now seek a solution of the form $u=A$ exp $[j \omega(x-v t)]$ where $y=$ wave velocity, $\omega=$ frequency. Substitution in Eq. 20 provides the condition

$$
v^{2}=\frac{E}{\rho}\left[(1-c)\left(1-\lambda^{2} \omega^{2}\right)^{2}+c\right]
$$

For stability, $v$ must always be real and positive, and so we must have $c>0$.

The chief advantage of the approximation by derivatives is that it facilitates anaiytical solutions, for which the houndary layer method known from fluid mechanics may be utilized. For computer programming, the use of imbricated finite elements (Fig. i) seems, however, the simpiest approach, since ordinary finite elements may be used and the nonlocal properties are entirely taken care of by the element imbrication (regular overlapping). Existing finite element codes and the usual element types can be used and the only change to be made in the existing finite element codes is to properly define the integer matrix giving the nodal numbers corresponding to each element number.

\subsection{Crack Band Theory for Progressive Fracturing}

For very fine meshes for which the element size $h$ is less than the characteristic length $\ell$ of the medium, the fracture front may be many elements in width. However, for many practical applications it is sufficient to use finite elements whose size is equal to the characteristic length or is larger. In such a case, the cracking zone is of a single-element width at its front, and the finite element model of the imbricate continuum then coincides with that of the classical local continuum. The fracture anaiysis then becomes identical to what has been previously developed as the crack band theory $[3,16]$.

Distributed cracking has been modeled in finite element analysis by adjustments in the material stiffness matrix since 1967 when Rashid [35] introduced this approach. Recently it has been demonstrated this approach yields consistent results, independent of the mesh size, oniy if the stress-strain relation with strainsoftening is associated with a certain fixed finite element size,

$\ell$. For concrete, this size appears to be roughily $\ell=3 d$ where $d=$ the maximum size of the aggregate. This size of finite elements is too small for many practical purposes. In the crack band theory it has been proposed and verified that consistent results can be obtained with iarger finite elements provided that the tensile strain-softening relation is adjusted so that it yields the same fracture energy regardiess of the mesh size $[10,16]$. The fracture energy is expressed as

$$
G_{f}=w_{c} \int \sigma_{33} d \varepsilon_{33}=\frac{w_{c}}{2}+f_{t}^{\prime} \text { ? }\left(\frac{1}{E_{0}}-\frac{1}{E_{t}}\right)
$$

in which $w_{c}$ now represents the width of the cracking front, $w \approx \ell$, $\sigma_{33}$ and $\varepsilon_{33}$ are the stress and strain in the finite element normal to the direction of cracking, $f^{\prime}$ is the direct tensile strength of the material, $E_{n}$ is the initial elastic Young's modulus, and $E_{t}$ is the mean downward siope of the strain-softening segment of the stress-strain diagram, which is negative (Fig. 6). If the finite element size is $h=l$, then $E q$. 8 with $l$ replaced by $h$ must yield the same value of $G_{f}$. This may be achieved by adjusting, first, the downward strain-softening slope $E_{t}$, and second, if the siope becomes vertical, by reducing the actual tensile strength $f_{t}^{\prime}$ to a certain equivalent strength $f_{\text {eq }}^{\prime}[3,8-10,16\rceil$.

The crack band theory has been shown to agree with essentially all fracture test data for concrete, inciuding the maximum load data and the R-curve data $[3,16]$.

It may be noted that approximately the same resuits may aiso be obtained if the cracking strain accumulated across the width of the crack band is expressed as a single cracking displacement, and a certain stress-displacement relation in the connections between the finite elements is introduced into the analysis. This has been the approach follower by Hillerborg, et at. [23].

\subsection{Constitutive Relations for Strain-Softening}

In the analysis of many practical situations, including all fracture tests, the principal stress direction in the fracture process zone remains constant during fracturing. Triaxial strainsoftening can then he introduced in the form

$$
\varepsilon=\mathbb{2} \underset{\sim}{q}+\xi
$$

in which $\varepsilon$ and $g$ are the column matrices of the components of strain and stress, $\underset{\sim}{D}$ is the $6 \times 6$ matrix of elastic constants, and $\xi$ is a column matrix representing additional smeared-out strains due to cracking, $\xi=\left(\xi_{11}, \xi_{22}, \xi_{33}, 0,0,0\right)^{\top}$. The normal 

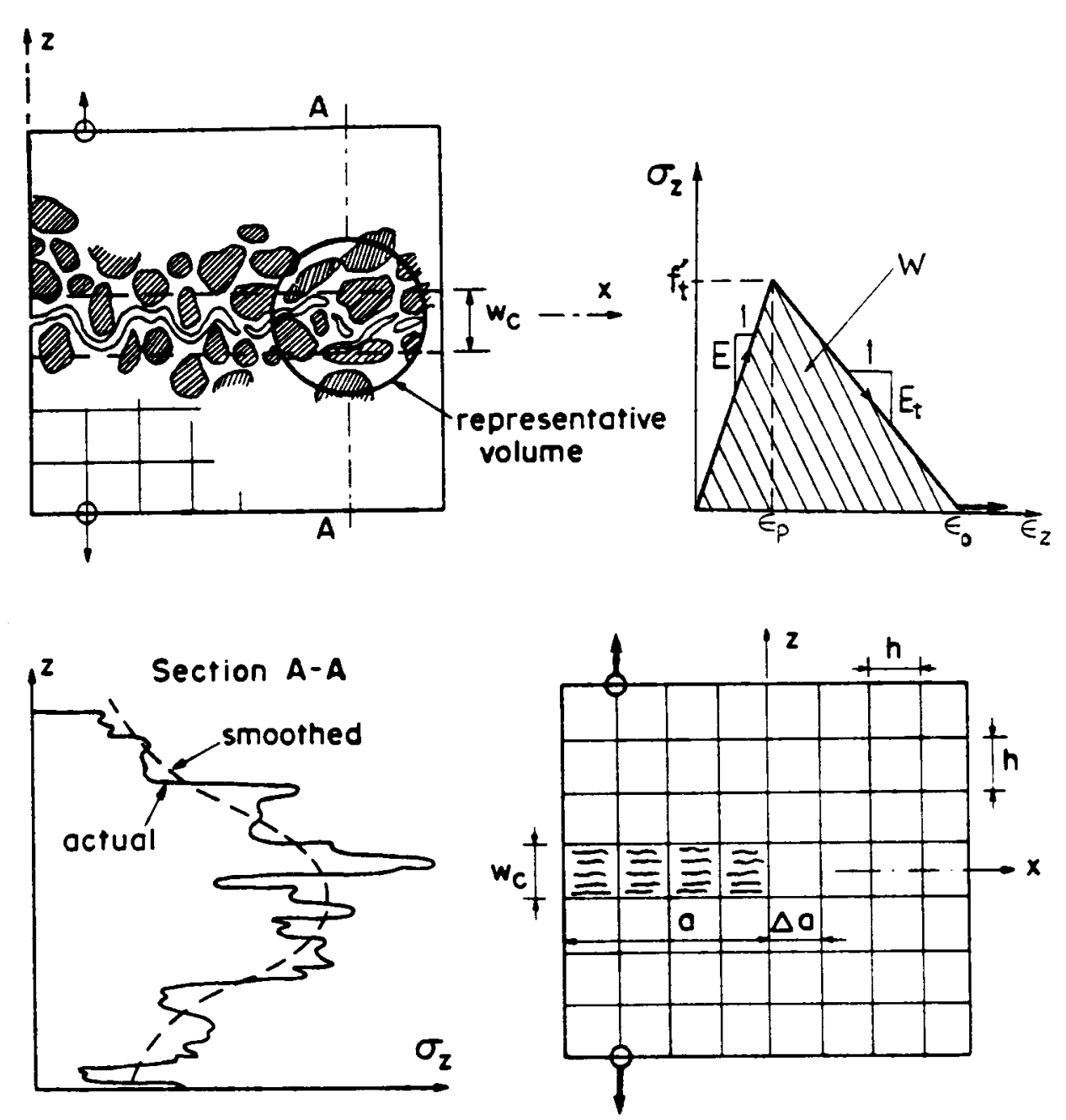

Fig. 6 - Crack Band Model and Corresponding Tensile Stress- Strain Relation with Strain-Softening. stresses may be assumed to be uniquely related to their associated cracking strains,

$$
\sigma_{11}=C\left(\xi_{11}\right) \xi_{11}, \quad \sigma_{22}=C\left(\xi_{22}\right) \xi_{22}, \quad \sigma_{33}=C\left(\xi_{33}\right) \xi_{33}
$$

in which $C$ is the secant moduius which reduces to zero at very large cracking strains and may be calibrated from direct tensile test data which cover strain-softening $[1,4,19,33,34,36,39,41]$. Different algebraic relations must, of course, be user for unloading.

For some situations, especially in dynamics, it is necessary to describe progressive formation of fracture during which the principal stress directions rotate. In such a case, the foregoing model is inadequate. A satisfactory formulation can be obtained with an analog of the slip theory of plasticity, which is called the microplane model $[4,18]$. In this model it is assumed that the strain on a plane of any inclination within the macroscopic smoothing continuum consists of the resolved components of one and the same macroscopic strain tensor $\varepsilon_{j j}$. Using the condition that the energy dissipation calculated in terms of the stresses and strains on all such planes and in terms of the macroscopic stress and strain tensors must be equal, one may obtain the stress-strain relation

$$
d \sigma_{i j}=D_{i j k m}^{c} d \varepsilon_{i j}
$$

in which

$$
D_{i j k m}^{c}=\int_{0}^{2 \pi} \int_{0}^{\pi / 2} n_{i} n_{j} n_{k} n_{m} F^{\prime}\left(e_{n}\right) \sin \phi d \theta d \phi
$$

This equation superimposes contributions to inelastic stress relaxations from planes of all directions within the material, defined hy spherical coordinates $\theta$ and $\phi: n$ are the direction cosines for all such directions, and $F(e)$ is a function

characterizing the constitutive properties and representing the stress-strain relation for one particular microplane within the material; $e_{n}=n_{i} n_{j} \varepsilon_{i j}=$ normal strain on a plane with direction

It has been demonstrated that the microplane model allows describing tensile strain-softening under general stress or strain histories and always leads to a reduction of stress to zero at sufficiently large tensile strain. 
3. SIZE EFFECT AND ITS USE IN DETERMINATION OF FRACTURF. PARAMETERS

\subsection{Problem of Experimental Determination of Material Parameters}

Anaiysis of distributed fracturing by noniocal continuum, crack band theory or other methods is feasible only if the material parameters involved can be identified from test data. This question will now be addressed and a novei method which exploits the size effect will be presented in detail. Since this method can be closely linked with the concept of R-curves, the use of R-curves for characteizing nonlinear fracture associated with progressive cracking will now be analyzed.

Fracture anaiysis of brittle heterogeneous materials, as well as ductile metals, must take into account the biunting of the crack front caused by microcracking or yielding. In consequence, the fracture properties of these materials are not completely described by a single parameter, the fracture energy, and at least two further parameters are required. Several mathematical models with additional parameters have been recenty formulater

$\lceil 3,4,11,16,23,34,4\}\rceil$ and shown capable of closely representing the available experimental evidence. These models, however, are practically useful only if their fracture parameters can he easily determined from tests of a given material.

The simplest, although crudest, method consists of an approximate lineariy elastic fracture analysis using an equivalent crack length (which is unrelated to the actual crack length) and a function describing how the energy, $R$, required for crack growth (per unit crack length and unit thickness) depends on the length $c$ of the crack extension from the notch. Irwin and $\mathrm{Krafft}$, et al., $[24,26]$, proposed that this function, called the resistance curve or the R-curve, may be considered to be unique even though this is not exactly true. Shah and co-workers $[39,40]$, introduced the Rcurve concept to fracture analysis of concrete.

The existing gethod for determining the R-curve utilizes the relation $R=k_{1} p^{2} a /\left(E_{c} b^{2} d^{2}\right)$ in which $k_{1}$ is a known coefficient for a given Specimen geometry, $E_{c}$ is the Young's elastic modulus, $b=$ specimen thickness, $d=$ characteristic dimension of the specimen, $a=$ the length of crack plus notch, and $P=$ load at which the crack extends. A series of $R$-values is determined either on a single specimen from the crack iengths, a, corresponding to various loads $P$, or on a series of specimens from their critical values of $P$ and the corresponding critical values of crack length a. In both cases, however, the crack length needs to be measured. This is a considerable obstacle in the case of a material like concrete, for two reasons: First, the crack length is hard to define since the crack tip is blurred by a microcracking zone, and second, even if one succeeds to measure the location of the crack tip, the mesurement is of dubious significance since the $R$-curve is actualiy a function of a certain equivaient crack length which yieids the correct remote elastic stress field rather than the actua? crack length.

In view of these difficulties, it has been attempted to determine the crack iength indirectiy, by measuring specimen compliance, either at unloading or at reloading. However, this approach is also questionable because at unioading or reloading the microcracks within the fracture process zone do not completely close (due to rubbie and fragments within the crack space, as well as irreversibility of material deformation at microcrack tips). Thus, the compliance for unloading and reloading is smaller than the compliance for continued loading, which, however, cannot be measured since the crack growth cannot be arrested. Therefore, the compliance measurements tend to yieid crack iengths which are much too small.

The R-curve is in essence a device to make possible an approximate linearly elastic solution even though the material behaves noniineariy [11]. A nonlinear fracture analysis, which is more realistic, may be carried out with the finite element blunt crack band model $[3,16,17]$, in which a certain fixed triaxial tensile strain-softening constitutive relation is used, and the crack front is assumed to have a certain characteristic width $w_{c}$ which is a material property (and equals about three maximum aggregate sizes of concrete). A similar finite element model for nonlinear fracture analysis of concrete, due to Hillerborg, et a) $[23,24]$, utilizes, instead of a softening stress-strain relation, a softening stress-displacement relation for the relative displacement between two finite elements. The material parameters for these finite element models can be determined $\lceil 16,17\rceil$ by optimization or trial-and-error procedures using a finite element program; but this is not exactly simple for every-day applications. The fracture energy can, in theory, be aiso determined by measuring the area under the complete load-deflection diagram of a single specimen $[34,387$. This approach, however, has certain disadvantages (see Section 3.9), and it does not yield the nonlinear fracture parameters other than the fracture energy. Thus, there is a need for another model, for which we propose here to exploit the size effect, following an idea briefly outlined in Ref. 6 .

\subsection{Review of Structural Size Effect}

For blunt fracture one can generally introduce the hypothesis $[4,7]$ that the total potential energy release $W$ caused by fracture in a given structure depends on both: 
1) the length a of the fracture, and

2) the area traversed by the fracture process zone, such that the size of the fracture process zone at failure is constant, independent of the size of the structure.

Dimensional analysis and similitude arguments then show that the structural size effect for geometrically similar specimens or structures made of the same material (and having the same

thickness) is governed by the simpie law [6]:

$$
\sigma_{N}=B f_{t}^{\prime}\left(1+\frac{d}{d_{0}}\right)^{-1 / 2}
$$

in which $\sigma_{N}=P /$ d $=$ nominal stress at failure, $P=\operatorname{maximum}$ load (i.e., failure load, $b=$ thickness, $d$ = characteristic dimension of the specimen or structure (e.g., the beam's depth), $f_{1}^{\prime}=\operatorname{direct}$ tensile strength: and $\mathrm{B}, \mathrm{d}_{0}=$ empiricai constants, $\mathrm{d}_{0}$ heing a certain multiple of the maximum aggregate size, $d$. The vaiues of $B$ and of ratio $\lambda_{0}=d_{0} / d_{a}$ depend on the geometricai shape of the structure, but not on its size. In the graph of iog $\sigma_{N}$ versus $\log$ d, Eq. 27 is plotted in Fig. 7a.

If the structure is very small, then the second term in the parenthesis in Eq. 27 is negligibie comprared to 1 and then $\sigma_{N}=B f^{\prime}$ in the failure condition, which represents the strength (or yiefd) criterion and corresponds to a horizontal line in Fig.

$7 a$. If the structure is very large, then 1 is negliginie comparen to the second term in the parenthesis of $\mathrm{Eq}$. 27, and then

$\sigma_{0}=$ const. $/ \sqrt{d}$. This is the type of a size effect typical of

Iinear elastic fracture mechanics: it corresponds to the inclined straight line in Fig. 7a, having the slope $-1 / 2$.

The size effect 1 aw according to Eq. 27 represents a gradual transition from the strength (or yieid) criterion to the energy criterion of linear elastic fracture mechanics. This law is approximate because the hypothesis of a constant size of the fracture process zone at failure cannot be considered to be exact. However, the errors due to this approximation appear to be insignificant compared to inevitable random scatter of material properties. Statistical errors due to this scatter are, of course, superimposed on Eq. 27, which describes only the mean behavior.

Let us now summarize the dimensional analysis from Ref. 6 that leads to Eq. 27. To take the dispersed and progressive nature of cracking at the fracture front into account, the following
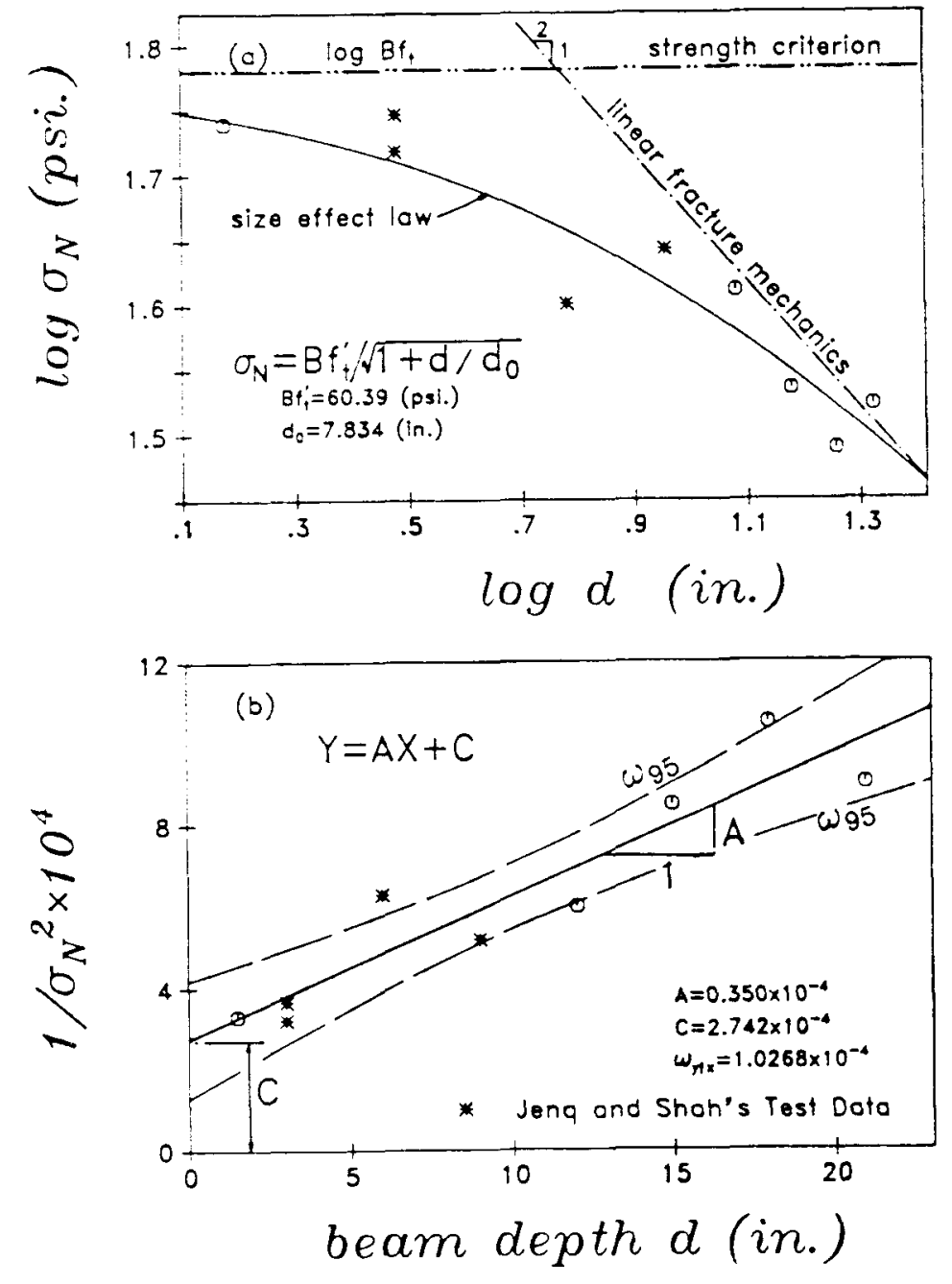

Fig. 7 - Size Effect Law and Regression Analysis of Maximum Load Data. 
hypothesis may be introduced:

The total potential energy release $W$ caused by fracture in a given structure is a function of both:

(1) the length of the fracture $a$, and

(2) the area of the cracked zone and $a$.

Here $m$ = material constant characterizing the width of the cracking zone at the fracture front. Under part (1) of this hypothesis we understand the part of energy that is reieased from the uncracked regions of the structures into the fracture front.

Variables a and amd are not nondimensional. They are, however, allowed to appear only in a nondimensional form. This form is given by the following variables

$$
\alpha_{1}=\frac{a}{d}, \quad \alpha_{2}=\frac{a m d}{d^{2}}
$$

representing the nondimensional fracture length and the nondimensional area of the cracked zone. Furthermore, $w$ must be proportional to volume $d^{2} b$ of the structure (where $b=$ thickness) and to the characteristic energy density

$\sigma_{N}^{2} / 2 E$ in which $\sigma_{N}=P / b d=$ nominal stress at failure, $P=$ given applied load, and $d=$ characteristic dimension of the structures. Consequentiy, we must have

$$
W=\frac{1}{2 E_{c}}\left(\frac{p}{b d}\right)^{2} b d^{2} f\left(a_{1}, \alpha_{2}, \xi_{j}\right)
$$

in which $f$ is a certain continuous and continuously differentiable positive function, and parameters $\xi_{j}$ represent ratios of the structure dimensions characterizing the geometrical shape of the structure. For similar structures, $\xi_{\text {j }}$ are constant. The condition for the fracture to propagdte is

$$
\frac{\partial W}{\partial a}=G_{f} b
$$

in which $G_{f}$ is the fracture energy - - a material property characterizing the energy consumed per unit extension of the fracture, per unit thickness.

Consider now geometrically similar structures, for which parameters $\xi_{j}$ are constant and only the characteristic dimension varies. According to the chain rule of differentiation,

$\partial f / \partial a=f_{1}\left(\partial \alpha_{1} / \partial a\right)+f_{2}\left(\partial \alpha_{2} / \partial \alpha\right)$, in which we introduce the notations $f_{1}=\partial_{f} / \partial \alpha_{1}, f_{2}=\partial f / \partial \alpha_{2}$. Thus, substitution of Eq. 29 into Eq. $3 n$ yields

$$
\left(\frac{f}{d}+\frac{f_{2}^{m d} a}{d^{2}}\right) \frac{p^{2}}{2 b E}=G_{f} h
$$

Furthermore, the fracture energy may be expressed as the area under the complete tensile stress-strain curve, including the strainsoftening down to zero stress, times the width of the cracking front $\mathrm{md}_{\mathbf{a}}$ :

$$
G_{f}=m d a\left(i-\frac{E_{c}}{E_{t}}\right) \frac{f_{t}^{\prime 2}}{{ }^{2} E_{c}}
$$

in which $E_{c}$ is the initial elastic modulus of concrete, $E_{t}$ is the mean strain-softening modulus, which is negative, and $f:$ is the direct tensile strength of concrete. Substituting Eq. 32 andP $=\sigma_{N}$ bd into Eq. 31, we may obtain:

$\sigma_{N}=B f_{t}^{\prime}\left(1+\frac{d}{\lambda_{0} d_{a}}\right)-1 / 2$

in which $B=\left[\left(1-E_{f} / E_{f}\right) / f_{2}\right]^{1 / 2}$ and $\lambda_{0}=m f_{2} / f f_{1}$. B and $\lambda_{0}$ are constants when geometficaliy similar structures of different sizes are considered. Thus, Eq. 33 proves our starting equation, E.q. 27.

\subsection{Equivalent Linear Fracture Analysis and R-Curves}

Frequently the nonlinear fracture process zone is small compared to the structure dimensions and the stress and strain fieids remote from the fracture process zone are then almost the same as the elastic ones. The fracture may then be approximately treated as an equivalent line crack which produces the same remote elastic stress and strain fields. For this equivalent crack. however, the energy, $R$, required for crack growth (also called the fracture resistance) may not be assumed constant (as is done in linear elastic fracture mechanics) but must be considered as a function of the crack extension $c$ from the notch or smoothed surface, i.e., $R=R(c)$ in which $c=a-a_{0}, a_{0}=$ length of the notch, and $a=$ total length of the crack plus notch; see Fig. 8 . The energy that must be supplied to the structure to produce the crack is $U=b S R(c)$ da $-W(a)$ where $W(a)=$ the total release of 
strain energy from the structure. An equilibrium state of fracture occurs if no energy needs to be supplied to change a by $\delta a$ and none is released, i.e., if $\delta U=0$. Since $\delta U=(\partial U / \partial a) \delta a=0$, in which $\partial U / \partial a=b(R-G)=0$ and $b G=W^{\prime}=\partial W / \partial a$, it follows that fracture equilibrium takes place if

$G(a)=R(c) \quad$ (equilibrium)

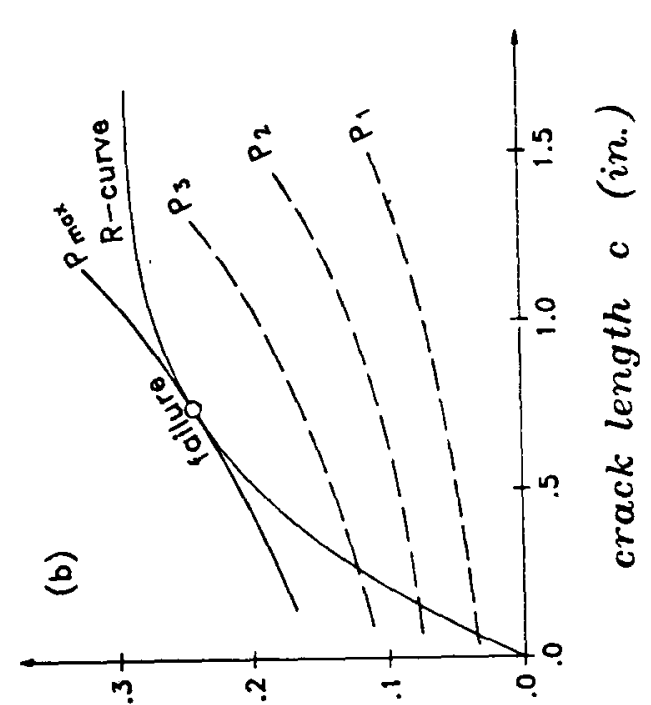

$(\cdot u ? / \cdot 91)(0) d$

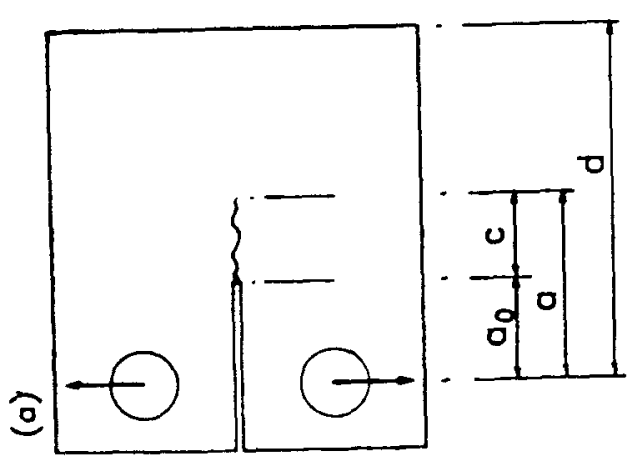

in which $a=a_{0}+c, G$ is the energy release rate of the structure and $R$ is its critical value characterizing the material. The equilibrium fracture state is stable if the second variation

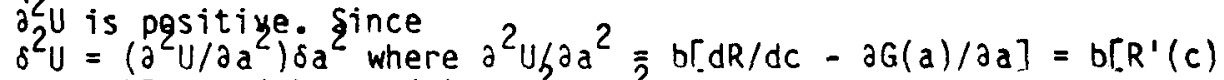
- $\left.G^{\prime}(a)\right], b G^{\prime}(a)=W^{\prime \prime}(a)=\partial^{2} W / \partial a^{2}$, the following conditions ensue

$$
\begin{aligned}
R^{\prime}(c)-G^{\prime}(a) & >0 & & (\text { stable) } \\
& =0 & & \text { (criticai) }
\end{aligned}
$$

Considering structures that are geometrically similar but could have dissimilar notches, and using dimensional analysis for the equivalent linear problem, one can show that

$$
\begin{aligned}
& G(a)=\frac{W^{\prime}(a)}{b}=\frac{p^{2} g(a)}{E_{c} b^{2} d} \\
& G^{\prime}(a)=\frac{W^{\prime \prime}(a)}{b}=\frac{p^{2} g^{\prime}(a)}{E_{c} b^{2} d^{2}}
\end{aligned}
$$

in which $d$ is the characteristic dimension of the structure, $\alpha=a / d, g^{\prime}(\alpha)=d g(\alpha) / d \alpha, E_{f}=$ Young's elastic modulus; and $g(\alpha)$ is a nondimensional function that characterizes the geometry of the structure. It can be determined by linear finite element analysis and it can be also found for typical shapes in handbooks $[37]$, which ysually give the stress intensity factor $K_{1}$, from which $G=K^{2} / E^{\prime}, E_{c}^{\prime}=E$ for piane stress and $E^{\prime}=E^{\prime}\left(1-\nu^{2}\right)$ for piane strain ' $v^{C}=$ Pofsson ratio; since $\nu^{2} \approx 6.03$ the distinction between plane stress and plane strain is not very important for concrete. Plane stress usually describes test conditions better than plane strain.

Substitution of Eqs. 34,36 and 37 into Eq. 35 leads to the conditions 


$$
\begin{aligned}
R(c) g^{\prime}(\alpha)-R^{\prime}(c) g(\alpha) d & >0 & & \text { (stable) } \\
& =0 & & \text { (critical) }
\end{aligned}
$$

Alternatively, since $d g / d c=d g / d a=g^{\prime}(\alpha) / d$, the last condition is equivalent to

$\frac{R(c)}{g(a)}=\operatorname{Max}$

in which $\alpha=\left(a_{0}+c\right) / d$. So the critical state of failure may be found by maximizing the ratio $R(c) / g(\alpha)$. This can be easily done by evaluating Eq. 39 for many values of $c$.

The foregoing relations are generaliy true for any equivalent linear analysis of nonlinear fracture. However, the function $R(c)$ is generally not the same for different specimen shapes and different notch length. The R-curve concept of fracture anaiysis rests on the hypothesis $[24,26]$ that function $R(c)$ may be approximately considered as a unique material property, the same for different notch length and different specimen shapes.

\subsection{Identification of Fracture Energy from Size Effect}

As an example, consider now three-point bent fracture tests on specimens of various depth $d$, all with $b=1$ in., span to depth ratio $L / d=4$, and initial notch depth $a_{0}=d / 3$; also, $E_{c}=4.3 \times$ $10^{6}$ psi and $f^{\prime}=3650$ psi [25]. According to Tada's handbook [37], for $L / d \cong 4$ :

$$
g(\alpha)=16 \pi \alpha\left(1.635-2.603 \alpha+12.30 \alpha^{2}-21.27 \alpha^{3}+21.86 \alpha^{4}\right)^{2}
$$

The following experimental data for the maximum loads are considered for specimens of various depths $d$ :

$d=1.5, \quad 3^{*}, \quad 6^{*}, 9^{*}, 12,15, \quad 18,21$ in.

$P=82.4,156.9^{*}$ and $167.4^{\star}, 239.6^{\star}, 395.6,49 n .0,514.5,555.5,700 \mathrm{lb}$.

(asterisks label the values taken from Jeng and Shah's measurements ${ }^{\circ}$ Ref. 25). Inevitably, the data are statistically scattered. They may be smoothed out using the size effect law in Eq. 27. This equation may be algebraically transformed to a linear form,

$Y=A X+C$

$$
x=d, y=\frac{1}{\sigma_{N}^{2}}=\frac{b^{2} d^{2}}{p^{2}}, A=\frac{c}{d_{0}}, c=\frac{1}{B^{2} f_{c}^{2}}
$$

Thus, coefficients $A$ and $C$ can be determined hy linear regression, either by computer or hy hand; see $F i g, 7 b$. This yields

$C=2.742 \times 10^{-4}$, and $A=0.350 \times 10^{-4}$. The coefficient of variation $\omega$ of the deviations from the regression line and the corresponding $95 \%$ confidence limits are also shown in Fig. $7 \mathrm{~b}$.

As mentioned before, for very large specimen sizes $(d+\infty)$ iinear elastic fracture mechanics applies, and the corresponding value of $R$, calied the fracture energy $G_{f}$, may be obtained from the inclined asymptote in Fig. la, i.e., from Eq. 27 when $l$ is neglected, in which case $Y=A X=\sigma_{N}{ }^{2}$. Noting that $\alpha+\alpha_{0}$ for failure of very large specimens, and substituting here $X=d$ and $\sigma_{N}=G_{f} E / g\left(\alpha_{p}\right) d$, which follows from Eq. 36 by seting $G$ $=G_{f}$ and $P=\sigma_{N} b d$, we obtain:

$$
G_{f}=\frac{g\left(\alpha_{0}\right)}{A E_{c}}
$$

in which $\alpha_{0}=a / d$. So the fracture energy is inverseiy proportiona? to the slope, $A$, of the regression line of size effect. Substituting $A$ and $g\left(\alpha_{0}\right)=43.76$ from $\mathrm{Eq} .40$, Fq. 44 yields the result $G_{f}=0.291 \mathrm{ib} . \mathrm{Iin}$.

The test data used (Eq. 4i, asterisk labeled) are those of Jeng and Shah $[257$. They measurer the R-curve hy a certain novel method not exploiting the size effect, and the asymptotic value of their measured $R$-curve was $G_{f}=0.42 \mathrm{ib} . / \mathrm{in}$. This is not very different from the value found here, in view of the radicaliy different methods of evaluation which must he influenced by different sources of errors.

Evaluating Eq. 42 for various values of $d$, we may further obtain smoothed values of maximum load data

$$
d=1.5, \quad 3, \quad 6, \quad 9, \quad 12, \quad 15, \quad 18,21 \text { in. }
$$

$P=83.0,154.7,272.7,370.8,455.4,530.6,598.6,661.0$ ibs.

(This same smoothed data would be obtained even if the measurements included only the three asterisk-marked values in Eq. 4l.) Thus, the size effect law in Eq. 42 ailows substantially increasing the range of d-values compared to the range of measurements, which will be useful for determining the R-curve. 
Geometric similarity is required oniy in two dimensions, and thus the specimens couid have different thicknesses h. However, the fracture energy is not constant along the front edge of the crack, and thus the thickness has some effect on the mean $i_{f}$ for the whole thickness. There are two effects causing the thickness effect. One is the disturbance of the free surface houndary conditions due to Poisson effect and surface point singuiarity of elastic solution [14], and another one is the different infiuence of the aggregate size near the surface and the interior on the microcracking zone size. The former effect is eliminated if $\mathrm{b} / \mathrm{d}$ is constant, and the latter one if $b$ is constant. Thus, no perfect answer exists for the choice of thickness. The condition $b=$ constant seems, nevertheless, preferable.

Eq. 44 is valid for all equivalent inear analysis of fracture. In particular, it does not depend on the hypothes is that the R-curve is unique.

The fact that the size effect plot of $\log \sigma_{\text {v }}$ versus iog $d$ possesses an inclined straight line asymotote implies that the $R$ curve must have a horizontai asymptote, a property previousiy sometimes regarded as uncertain. The fracture energy. Gf - a term reserved here strictly for the final asymptotic vaiue of the energy required for crack growth (per unit crack iength and unit thickness) - is uniqueiy defined by the straight iine asymptote of the size effect piot of log $\sigma$ versus log $d$ ( $F i g .7 a)$. Thus, the vaiue of the fracture energy must he considered size independent. Worrying about its size dependence wouid be meaningiess, just like saying that a value of some function $F(x)$ at $x$, depends on $x_{2}\left(\neq x_{2}\right)$ or the values of $F(x)$ at $x_{2}$. It is important to realize this with regard to the current debates on the size dependence of fracture energy. In these debates, other determinations of fracture energy that are not based on the size effect law have been considered. For such other definitions, the fracture energy vaiues are in general different from the present one and can indeed depend on the size of the structure; but this cannot he so for the present definition. In this light the present definition of $f_{f}$, based on the asymptote of the size effect regression plot, seems to be preferable and circumvents the question of size dependence of fracture energy for its other definitions. The present definition relates most directiy to the failure loads at different sizes of a structure - usually the main concern of a structural anaiyst.

If three-point bent fracture specimens are sufficientiy slender, i.e., $L / A$ is sufficiently large, the failure is governed primarily by the bending moment $M$ in the notched cross section, an the effect of the shear force may he negiecter. Then it is not necessary for the specimens of different sizes to he geometrically similar. It suffices if the notched cross sections are similar, i.e. hae the same ratios $a_{0} / d$.

Let the reference specimen be characterized by $d=d_{1}$ and $L=$ $L_{1}$. Then the maximum ioad $P_{2}$ measured for a dissimilar specimen of dimensions $L_{2}$, $d_{2}$ such that $\left[2 / d_{2}\right.$ the maximum load $p_{2}$ corresponding to span the bending moments, Equating

$$
p_{2}^{*}=p_{2} \frac{L_{2} d_{1}}{L_{1} d_{2}}
$$

specimen of span $L_{2}^{\star}$ and the actual, dissimilar specimen of span $L_{2}$ have the same cross section, and therefore, they may be assumed to fail at the same crack length $c$, i.e.., at the same a or the same $\alpha(\alpha=a / d)$. Thus, the energy release rates $G$ at maximum load must be the same for both specimens, and so (according to Eq. 36)

$$
G=P_{2}^{?} g\left(\alpha_{2}\right) / E_{c} h^{2} d_{2}^{2}=P_{2}^{* 2} g^{*}\left(\alpha_{2}\right) / E_{c} b^{2} d_{2}^{2} \text { where } \alpha_{2}=a_{2} / d_{2}=a_{2}^{*} / d_{2} \text { : }
$$

this yieids

$$
P_{2}^{\star}=p, \sqrt{\frac{g\left(\alpha_{2}\right)}{g\left(\alpha_{2}\right)}}
$$

It may be checked numericaliy that if hoth $L_{2} / H_{2}$ are large Fa. 47 reduces to $\mathrm{Eq}$. 46 .

Eq. 47 has an inconvenient feature in that the crack length at faiiure must be estimated hefore $P_{2}^{*} c$ an he calculated $\left(a_{2}=\left(a_{0}+c\right) / d_{2}\right)$. The estimate, however, can he improved iteratively. For this purpose one has to soive also the R-curve as described in the next section, and then solve $\alpha_{2 \star}$ from $\mathrm{Fq} .37$, upon which one may obtain an improved value of $\beta_{2}$ from Eq. 47 .

\subsection{Determination of R-Curve as an Envelope}

Consider again that a series of geometricaliy similar specimens (of the same thickness b) has been tested and the maximum load $P=P_{\max }$ has been measured for each of them. However, the crack length $c$ corresponding to each failure load in each of these specimens is unknown (its measurement, no matter how careful, would not reaily heip since $c$ should he considered as the equivalent crack length giving the same remote elastic stress field, rather than the actual crack length). Using function $g(\alpha)$, which is common to all specimens, we can plot accorting to F.q. 36 the equilibrium curves of $G$ versus $C$ for each of these specimens, as is shown in Fig. 9a. Mniy one point on each of these equilihrium 

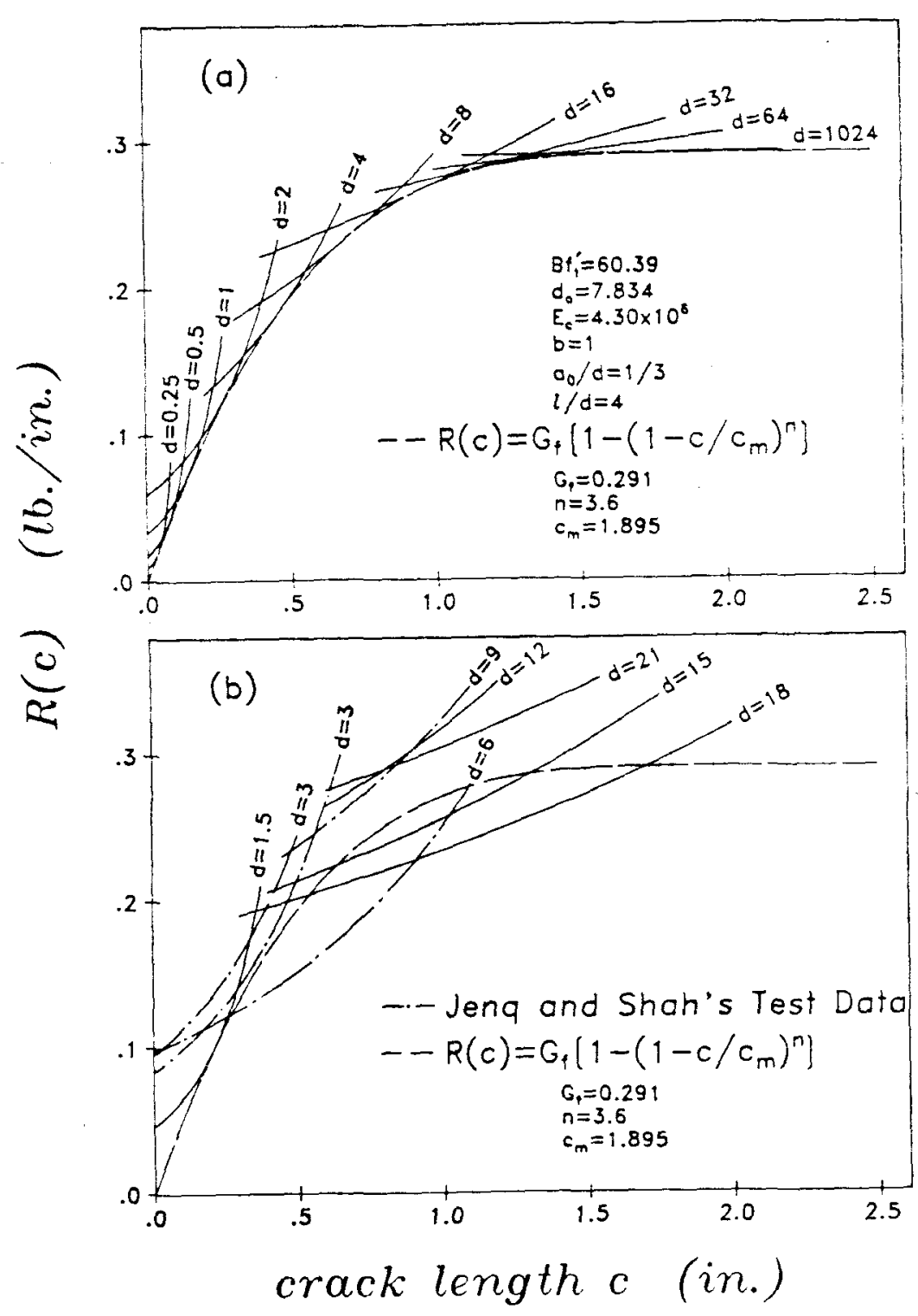

Fig. 9 - R-Curve as an Envelope for (a) Smoothed Data (b) Unsmoothed Data. curves is the failure state. Now, each equilibrium curve of $G$ versus $c$ must contain a failure point, and so this curve shouid be tangent to the R-curve, as seen in Fig. $9 a$. This leads to the following conciusion:

The R-curve is the envelope of all equibrium curves of $G$ versus $c$ for the failure ioads of specimens of different sizes.

To prove it rigorousiy, the curves in Fig. 9a are considered as a one-parameter family of curves (with parameter $\lambda$ ) described by the equation

$$
f(c, G, \lambda)=0
$$

in which

$$
f(c, G, \lambda)=R(c)-G\left(a_{0}+c, \lambda\right)
$$

Differentiation of Eq. 48 yieids

$$
\frac{\partial f}{\partial C}+\frac{\partial f}{\partial G} G^{\prime}+\frac{\partial f}{\partial \lambda} \frac{\partial \lambda}{\partial c}=R^{\prime}-G^{\prime}+\frac{\partial f}{\partial \lambda} \frac{\partial \lambda}{\partial C}=0
$$

The envelope of the family of all curves is given by $E q .5 n$ with the condition $a f / \partial \lambda=0$. This leads then to the relation $R^{\prime}(c)$ $G^{\prime}=0$, which is the same as Eq. 35 for the critical state. So the envelope of the curve represents the critical states.

It may now seem that the R-curve couid be constructed as an envelope directiy from measured data (Eq. 41) by piotting fo versus c according to Eq. 36. In practice, however, such an approach does not work. This is because of inevitahle statistical scatter of test resuits (see subsequent comments on fig. 9b). Therefore, one needs some simple law for the mean behavior which couid he used to smooth out the experimental data before construction of the envelope is attempted. Eq. 27 for the size effect provides such a law. So we use the smoothed data from Eq. 45, and for each pair d and $P$ we plot the equilibrium curve of $G$ versus $c$ according to $E q$. 36. This yields the family of curves shown in Fig. 9a. The envelope, representing the R-curve, may he graphically plotted with ease. To obtain the envelope numerically, it is simplest to locate from the graph the approximate c-values of the points on the envelope, then evaluate for each of them the G-value from Eq. 36, and then fit these values of $G$ with a suitable formula.

Aithough, from the viewpoint of representation of the original measured data, many different formulas are about equaliy good [.5] 
(due to large scatter of data), the choice of formulas hecomes more limited if one wants to closely match the size effect law (F.qs. 27 or 42). From this viewpoint, the following formula appears to work best

$$
R(c)=G_{f}\left[1-\left(1-\frac{c}{c_{m}}\right)^{n}\right] \text { for } c<c_{m}, \quad R(c)=G_{f} \text { for } c \geqslant c_{m}
$$

Its parameters are found, according to the values in Eq. 45 , as $G_{f}$ $=0.291 \mathrm{lb} . / \mathrm{in} ., c_{m}=1.895 \mathrm{in} .$, and $n=3.6$. This formula, plotted graphicaliy in Fig. 9 a, appears to be a perfect envelope.

Aiternativeiy, one can also use the formula

$$
R(c)=G_{f}\left(1+\frac{k_{0}}{c+k_{1} c^{n}}\right)^{-m}
$$

with coefficients $G_{f}, k_{0}, k_{1}, m$ and $n$. It so happens that the approximations of the envelope remain quite good if $m$ and $n$ in $F$. 52 are fixed as $m=0.19$ and $n=4.24$. Then Eq. 52 has the advantage that parameters $k_{n}$ and $k$ may he determiner by inear regression. Indeed, Eq. 52 can be transformed to the form $y=A^{\prime} x+C^{\prime}$, in which

$$
x=c^{n-1}, y=\left[\left(G_{f} R^{-1}\right)^{1 / m}-1\right]^{-1} / c, A^{\prime}=k_{1} C^{\prime}, c^{\prime}=1 / k_{1} .
$$

For the values in Eq. 45 , one obtains $k_{n}=1.53 \times$ in 10 , and $k_{1}=$

For comparison, let us see what we would get if the size effect law (Eq. 1) were not available to us. Then, piotting the curves of $G$ vesus $C$ (Eq. 36 ) on the basis of the measured maximum loads (Eq. 4l), we would get the family of curves shown in Fig. 9b. This family of curves has no common envelope, and since the failure points (i.e., the values of $c$ at failure) for each of the curves are unknown, it is not even possible to deduce any R-curve by statistical regression. Thus, knowledge of the size effect law (Eq. 27) is crucial for being abie to determine the R-curve without having to measure the crack lengths at failure states, a task notorious for its difficulty and ambiguity. For comparison, Fig. $9 b$ a so shows the R-curve which is obtained if the measured maximum loads are first smoothed with the size effect law, Eq. 27. (The fact that the R-curve is oniy an approximate concept and is not strictly unique for different specimen shapes is not the cause of the lack of a common envelope in Fig. 9b; indeed, if the curves in Fig. 9b are calculated from fixed material properties, a smooth common envelope always exists.)
Instead of constructing the envelope graphically (Fig. 9a), one can define it analytically. For this purpose, we insert $P=$ $\sigma_{N}$ bd in $E q .36$, and we set equal 0 the partial derivative of this equation with respect to $\lambda$ at constant $G$, which is the condition for an enveiope. This yields

$$
\begin{aligned}
& G=\frac{d_{0}}{E_{c}} \lambda \sigma_{N}^{2}(\lambda) g(\alpha), \quad \alpha=\frac{a_{0}+c}{\lambda d_{0}} \\
& \frac{a_{0}+c}{d_{0}} \frac{1}{g(\alpha)} \frac{d g(\alpha)}{d \alpha}=\lambda+\frac{2 \lambda^{2}}{\sigma_{N}(\lambda)} \frac{d \sigma_{N}(\lambda)}{d \lambda}
\end{aligned}
$$

in which functions $\sigma_{v}(\lambda)$ and $g(\alpha)$ are defined by Eqs. 27 and 40 . Eqs. 53-54 represent a parametric equation of the R-curve, with $\lambda$ as a parameter. To calculate points on the R-curve, a series of $\lambda$-values is chosen, and for each $\lambda$ the value of $c$ is solved from Eq. 54 by Newton iterative methor. G then results by suhstitution in Eq. $5 i$ (in which $c=a \lambda d_{n}-a_{n}$ ).

It is interesting to caicuiate the size effect curve $\sigma_{N}(\lambda)$ from the $R$-curve $R(c)$ that has previousiy heen calculated from the size effect curve according to Eq. 27 . Since Eqs. 41 or 42 for the R-curve are oniy approximate, the resulting curve $\sigma_{N}(\lambda)$ cannot be exactiy the same as Eq. 27 , but it should he almost the same. The calculations are carried out for the present example $(\mathrm{Eq} .50)$, and the R-curve in $\mathrm{Eq} .51$ is obtained hy maximizing the ratio in Eq. 38 in which $d=\lambda d$, with $g(\alpha)$ given by $\mathrm{Eq} .40$. After solving $C$ from $\mathrm{Eq} .39, \mathrm{G}$ is obtained from $\mathrm{Eq} .34$ and $P$ (or $\sigma_{N}$ ) is obtained from $E q .36$. The resuits are plotted in Fig. 10 and tabulated in Table 1. We see that the size effect curves thus obtained are indeed very close to the size effect law (Eq. 27).

As is well known, the R-curve concept is only approximate. For different specimen geometries different R-curves must be obtained, in theory, aithough usualiy the differences are not large (especialiy when compared to the scatter of test data). To check it, we follow the procedure from Eq. 34 to Eq. 51 and calculate the R-curves for three-point bent specimens of various span-to-depth ratios, various notch length-to-depth ratios, and also for a different type of specimen - the compact tension specimen. The corresponding functions for these geometries were taken from Tada's handbook [377. The shapes of the resulting R-curves $R(c)$ are plotted in Fig. 4b (the R-curves were scaled hoth vertically and horizontally so that the final value be 1.0 and the point where one-half of the final value is reached be common to all the $R$ curves). It is interesting to note how small are the differences among the shapes of the R-curves for different specimen shapes. 

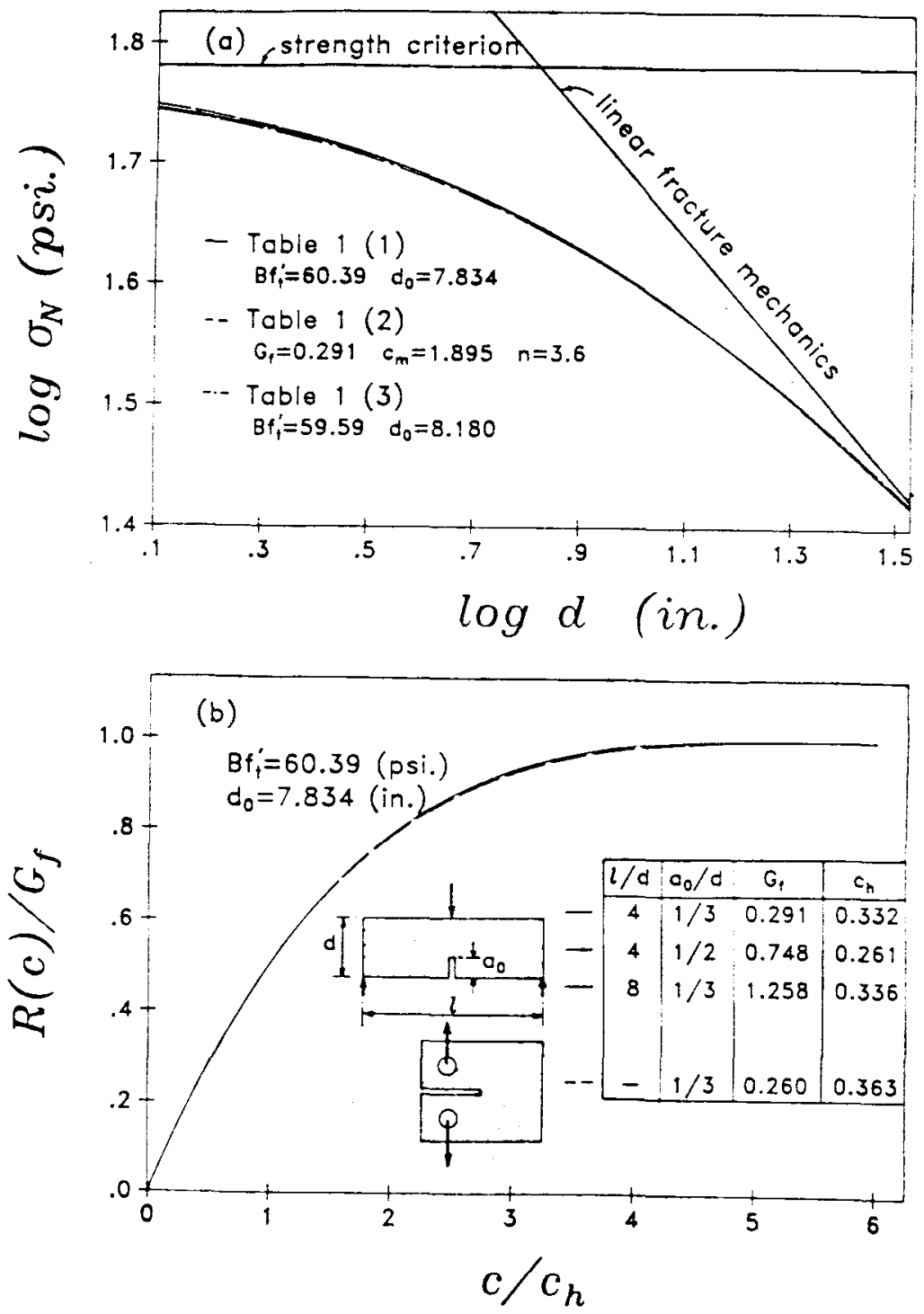

Fig. 10 - Shape of R-Curve and Corresponding Size Effect Curve
They are so small that they are hardly distinguishable graphically. Therefore, the R-curves from Fig. 10 are also tabulated in Table 2. (The parameters for the three columns in this Table are $G_{f}=0.291,0.748,1.258,0.260 \mathrm{hh} . / \mathrm{in} ., \mathrm{c}_{\mathrm{m}}=1.895$, $1.491,1.919,2.280 \mathrm{in.}, \mathrm{c}_{\mathrm{h}}=0.332,0.26 \mathrm{i}, 0.336,0.363 \mathrm{in}$. , respectively.)

In consequence of these considerations, it may be concluded that the relationship between the size effect iaw and the R-curve for a given specimen geometry may he considered as approximately unique.

In the size effect law (Eq. 27), there are two independent parameters, $B f^{\prime}$ and $d_{0}$. For the relative values of $R$-curve $R(c) / G_{f}$ in Eq. 47 , there are aiso only two parameters, $n$ and $c_{m}$ ( $G_{f}$ is obtained by linear regression from $\mathrm{Eq}$. 44). Hence, for all specimens for which the values of Bfi and $A_{0}$ are the same, the values of nondimensional parameters $n{ }^{t}$ and $c_{m}$ shouid also he the same. This means that all geometricaliy similar specimens of different sizes should be characterized by the same values of $n$ and $c_{m} / d_{0}$. This property is verified by numericai exampies. We may, therefore, construct a table of $n$ and $c_{m} / d_{n}$ for various typical specimen geometries, see Fig. 11 . For the specimen geometries included in Fig. $1 \mathrm{i}$, it is not necessary to construct the R-curve as an envelope. It suffices to carry out the iinear regression shown in Fig. 7b, and then take $n$ and $c_{m} / d_{0}$ from $F i g . ~ 19$.

\subsection{Determination of Crack Rand Model Parameters}

The size effect law (Eq. 27) may be aiso exploited to identify the material parameters for the finite element crack hand more? $[3,16]$. This may be done in two ways - either with or without an equivalent linear elastic fracture analysis. Consider the latter approach first.

In the crack band model, the cracking, assumed to he uniformily distributed throughout the finite element, is descrihed by a triaxial constitutive relation with tensile strain-softening. Under the assumption that the principai stress directions do not rotate significantiy during the passage of the fracture process zone through a given point, the strain-softening may be defined by a total stress-strain relation $\underset{\sim}{\varepsilon}=\underset{\sim}{\underset{\sim}{\sigma}} \underset{\sim}{ }+\xi$, in which $\underset{\sim}{\sigma}=$ column matrix of stress components $=\left(\sigma_{11}, \sigma_{22}, \sigma_{33}, \sigma_{12}, \sigma_{23}, \sigma_{31}\right)$, where $T$ denotes a transpose of a matrix and the subscripts refer to cartesian coordinates $x_{j}(i=1,2,3)$, of which $x_{1}$ is the direction of crack propagation and $x_{3}$ is normal to the crack plane: $\underset{\sim}{\varepsilon}=\operatorname{similar}$ column matrix of strain components, $\underset{\tilde{C}}{\mathcal{C}}=6 \times 6$ matrix of elastic compiances (constants), and $\xi=$ coiumn matrix of 


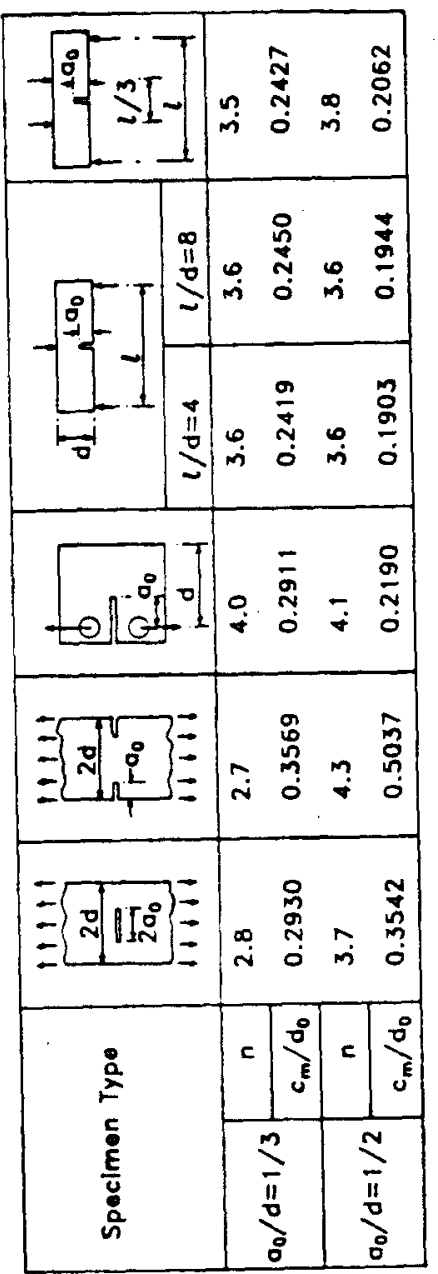

additional averaged strains due to cracking. Only the normal components of $\xi$ are nonzero and they are defined as $\xi_{1}=\phi\left(\sigma_{11}\right), \xi_{22}=\phi\left(\sigma_{22}\right), \xi_{33}=\phi\left(\sigma_{33}\right)$, in which $\phi$ is a certain function. The precise shape of this function is not important, and in the preceding work $[3,16]$ this function is taken as bilinear. It is calibrated according to the bilinear uniaxial tensile stressstrain diagram shown in Fig. 12, characterized by negative tangent modulus $E_{t}$ for the strain-softening segment, and by tensile strength $f^{\prime}$. For unioading (decreasing strain), a different stress-strain diagram is considered.

It must be emphasized that the foregoing stress-strain relation is valid oniy for a certain element size which corresponds to the representative volume of the heterogeneous material and to a certain width $w_{c}$ of the cracking front. If a different element size has to be used, the stress-strain reiation must be adjusted so as to yield the same fracture energy, $G_{f}$.

The fracture energy is equal to the area under the tensile uniaxial stress-strain diagram in fig. 12a, times the width of cracking front, $w_{c}$;

$$
G_{f}=\frac{W_{C}}{2 E} f_{t}^{\prime 2}\left(1-\frac{E}{E_{t}}\right)
$$

Approximately, $w_{c}=3 d_{a}$ where $d_{a}=$ maximum aggregate size.

For geometrically similar specimens, the finite element solution of the nominal stress at failure $\sigma_{y}$ shouid depend oniy on the material parameters. There are four of them, $f \prime, E, G$, and $w$. Parameter $E_{t}$ is not independent since it must satisfy Eq. 55. Eonsequently, for geometrically similar specimens

$$
{ }_{\text {bं }}^{P}=\sigma_{N}=\phi_{1}\left(f_{t}^{\prime}, E, G_{f}, w_{C}\right)
$$

in which $\phi$ is a certain function. Now, according to Buckingham's II theorem of dimensional analysis [2], the number $n_{s}$ of independent nondimensional governing parameters should be $n_{p}-n_{d}$ where $n_{p}=4=$ number of governing parameters in Eq. 56 and $n_{d}=2$ = numbef of independent dimensions in these parameters. Since there are among them only two independent dimensions, namely those of length and of force, $n_{s}=4-2=2$. So there can be only two independent nondimensional governing parameters. Along with the nondimensional function, they may be introduced as

$$
s=\frac{\sigma_{N}}{f_{t}^{\prime}}, \quad \theta=\frac{d}{w_{c}}, \quad k=\frac{E G_{f}}{w_{c} f_{t}^{\prime 2}}
$$


and the governing $\mathrm{Eq} .56$ reduces to

$$
s=\Phi(\theta, k)
$$

Eqs. 57-58, describing the similitude of blunt fracture, greatiy reduce the number of cases that have to be solved by finite eiements in order to cover all possible situations.

For identifying the material parameters of the crack hand model, the following approach may be adopted. We choose a certain specimen geometry, and by testing specimens of different sizes we determine, by inear regression, parameters $B$ and $d_{0}$ of the size effect law, Eq. 27. Then, by carrying out finite element soiutions for specimens of different sizes and similar geometry, we determine the size effect $i a w$ as a function of the governing parameters

$\theta$ and $k(E q .57)$. Finaliy, we determine those material parameter values for which both size effect iaws are matched. The interjection of the size effect law not oniy facilitates analysis, but aiso has the effect of smoothing and extending randomi scattered measured data. The detailed procedure is as foliows.

1. Set $w_{C}=E=f_{t}^{\prime}=b=1$.

2. Fix the value of $k\left(k=G_{f}\right)$.

3. Fix the value of $\theta(\theta=d)$ and solve hy a finite eiement program with incrementai loading the maximum ioad $p$ (the ioadpoint displacements are prescribed and $D$ is caiculated as the reaction). From this, calculate $s=P / \theta$.

4. Repeat 2 step 3 for various values of $\theta$ and construct the piot of $s^{-2}$ versus $\theta$.

5. Now, according to the size effect law in Eq. 27, this piot shouid ideally agree with $s=B[\}+(\theta / r)]=1 / 2$, which is equivalent to $y$ - $\overline{\bar{I}} A x+C^{\prime}$ where $x=\theta, y=$ $s^{-2}, A=\left(B^{2} r\right)^{-1}, C^{\prime}=B^{-2}$ and $r=d_{0} / w_{C}$. Determine the regression line of this plot; its $y$-intercept is $C^{\prime}$, from which $B=1 / \sqrt{C^{\prime}}$, and its siope is $A$, from which $r=C^{\prime} / A$. These values of $B$ and $r$ correspond to the previously fixed value of K.

6. Repeat steps 2 - 5 for various values of $k$ and construct the graphs $B(k)$ and $r(k)$ to be used for interpretation of test data.

The calculation results show that the graphs of
$B(k)$ and $r(k)$ are linear. Thus, calculation of only two points on each graph is sufficient, and the values may generaliy be calculated as

$$
B(k)=k_{1}+k_{2} k, \quad r(k)=k_{3}+k_{4} k
$$

Fig. 13 shows the caiculation results for several typicai fracture specimens.

We are now ready to give an exampie using the data from Eq. 45 for similar specimens of different sizes. The test resuits are plotted as $1 / \sigma^{2}$ versus $d(F i g .7 h)$, and from the slope and the intercept of the regression line we get the values of $R$ and $d_{n}$ for the size effect law as measured (Eq. 27). For the data in Fig. 7h we have $B=0.18 i 7$ and $d_{0}=7.834$. Then, for this value of $R$, we calculate from Eq. 59, using the values from Fig. i3, that $k_{m}=$ 8.9 and $r=11.9$. From this we finaily obtain

$$
w_{c}=\frac{a_{0}}{r\left(k_{m}\right)}, \quad G_{f}=\frac{{ }_{c}}{E} f_{t}^{2}{ }^{2}, \quad E_{t}=\frac{1}{E}-\frac{2 G_{f}}{w_{c} f_{t}^{2}}
$$

For specimen geometries other than those in Fig. 13 the analyst needs to calculate first (with the help of finite element solutions) the values of $k_{1}$ and $k_{2}$

Exploiting the size effect law (Eq. 27) makes it possible to do with a iesser amount of measurements. If the values of maximum loads for oniy a few specimens are fitted directly with the finite element program for the crack band theory, the values of material parameters which give good fits of data are quite ambiguous; even very different material parameter values yield equaliy good fits. This ambiguity and uncertainty is removed by the size effect law, which has the effect of smoothing and extrapolating the measured data.

If a smoothly curved tensile strain-softening constitutive equation is used, one may calibrate it accorting to the value $f_{f}$ obtained as ahove. Instead of caiculating $F_{t}$ one needs to adjust the tensile strain-softening uniaxial curve so that the area under the strain-softening segment and under the unloading diagram emanating from the peak stress point wouid be equal to $\hat{i}_{f}$.

Construction of the graphs in Fig. 13 requires the use of a noniinear finite element program with step-hy-step loading for the crack band theory. Such a program is not needed, however, if equivalent linear fracture analysis is used. The value of $f_{f}$ may then be calculated from Eq. 12 on the basis of the slope of the 
size effect regression piot and the value of $g\left(a_{n}\right)$ ohtained hy an analytical or finite element solution according to linear elastic fracture mechanics.

In the preceding procedure based on Eq. $6 n$, the value of $w_{c}$ has been considered as unknown. As a rough approximation, however, w $\sim 3 \mathrm{~d}$ where $d=$ maximum aggregate size $[167$. If this approximation is adopted, and if $f^{\prime}$ is known, then the identification of material parameters of crack hand mode: hecomes much simpier: $G_{f}$ is obtained from $E q .44$ on the basis of the siope of the regression piot for the size effect (Fig. 7b), and $E_{t}$ is then simpiy solyed from the relation $G_{f}=w_{C}$ $\left(E^{-1}-E_{t}^{-1}\right) f_{t}^{\prime 2} / 2$, i.e.

$$
E_{t}=\left(\frac{1}{E}-\frac{2 G_{f}}{w_{c} f_{t}^{T}}\right)
$$

\subsection{Fracture Modeis with Stress-Dispiacement Reiation}

Through a simpie extension of the foregoing anaiysis, it is possibie to determine the material parameters for noniinear fracture models, such as Hilierborg's modei for concrete $[23,34]$, in which a sharp iine fracture is assumed and a relation between the reiative dispiacement $\delta$ and normal stress $\sigma$ across the iine is introduced as a material property. The displacement $\delta$ iumps into a ine the accumulaten normal strain due to cracking across the crack band width $w_{C}$, and so

$$
\delta(\sigma)=w_{c}\left\lceil\varepsilon(\sigma)-\frac{\sigma}{E}\right\rceil
$$

where $\varepsilon(\sigma)$ describes the tensile stress-strain diagram for the equivalent crack band model. Most simpiy, the $\sigma$ - o reiation may be considered as a straight i ine of negative siope $C_{f}(F i g .1 ? c)$, described as $\delta(\sigma)=\left(f_{t}^{\prime}-\sigma\right) / C_{f}$ if $\sigma \geqslant 0$ and $\delta \geqslant 0$, and $\sigma=0$ if $\delta>f_{t}^{\prime} / c_{f}^{t}$.

Equating the totai relative displacement across the crack band according to =both models and assuming the stress at the crack front (in a thin plate) to be approximately uniaxiai, we have the relation

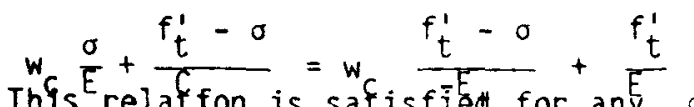

$$
\frac{1}{C_{f}}=w_{c}\left(\frac{1}{E}-\frac{1}{E_{t}}\right)
$$

Thus, if $E_{t}$ has been determined from measurement, $C_{f}$ can be found aiso.

Aiternativeiy, we may use the fondition of equal fracture energy for both theories: $G_{f}=f^{\prime}{ }^{2} / 2 C_{f}=w_{c}\left(E^{-T}-E_{t}\right)^{1} f_{t}^{\prime 2} / 2$.
From this, Eq. 64 is again obtained.

\subsection{On Materiai Parameter Identification without the Size Effect}

To further ii iustrate the advantage derived from the use of the size effect $: a w$, consiter a series of tests of specimens of the same dimension d but different notch iengths $a_{n}$. If one wishes to use the enveiope property, one would piot for each pair of an and $D$ the curve of $c_{2}$ versus $c$ where $c_{a}=p^{2} g(\alpha) /\left(E b^{2} d\right)$ and $\alpha=a_{n}+$ c) $/ d$. If the measurements were perfect, with no error, then these piots would yieid a family of curves such as iliustrater in Fig. $14 a$, for which the envelope representing the R-curve can be, in theory, constructed. In practice, this does not work, for two reasons: 1) If $d$ is constant, oniy a smail portion of the R-curve is covered by the failure states for various an-values. 2) There is always statistical scatter, which causes that these plots yield a family of curves such as illustrated in Fig. 14b. Obviousiy, no envelope can he constructed for this famiiy, and thus smoothing of the data is imperative before the envelope could be traced. However, for the effect of the notch length $a_{n}$ at a constant cross section dimension d, there is no simple law which could be used for smoothing the data. Such a law is known only for the size effect.

Nevertheiess, a more sophisticated procedure similar to that employed in Ref. 11, can be used. It consists of the following steps:

1. Choose a certain formula for the R-curve, such as Eq. 51 or 52.

2. Choose certain values of the material parameters in the formula.

3. Choose a certain value of initial notch iength $a_{n}$. 

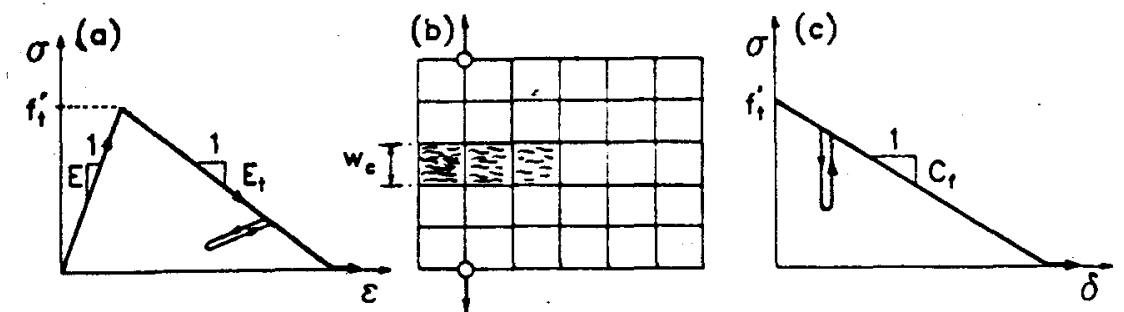

(d)

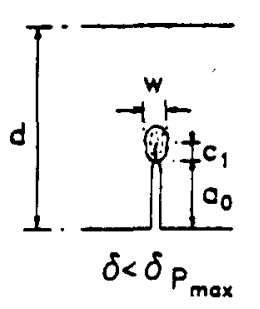

(e)

(4)

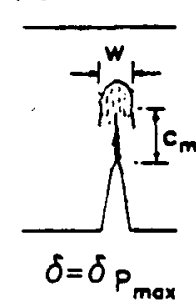

(4)

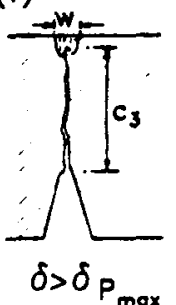

(g)

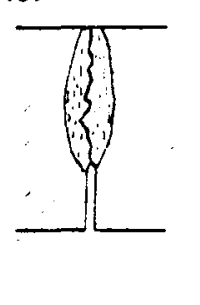

(h) $\bar{G} \quad$ ic

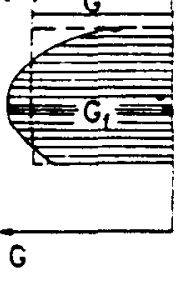

Fig. 12 - (a) Uniaxial Stress-Strain Relation for Crack Band Model (b) Finite Element for Crack Band Model, (c) - 0 Relation for Fictitious Crack Model of Hillerborg, (d-h) Explanation of Energy Dissipation During Crack Growth.

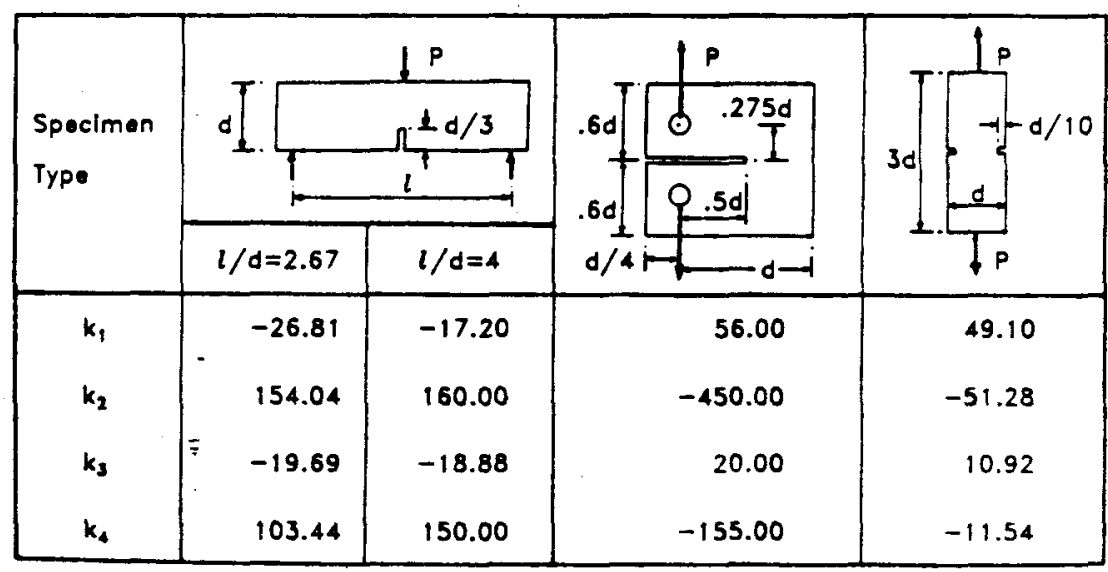

Fig. 13 - Coefficients for Determining Crack Band Model Parameter.
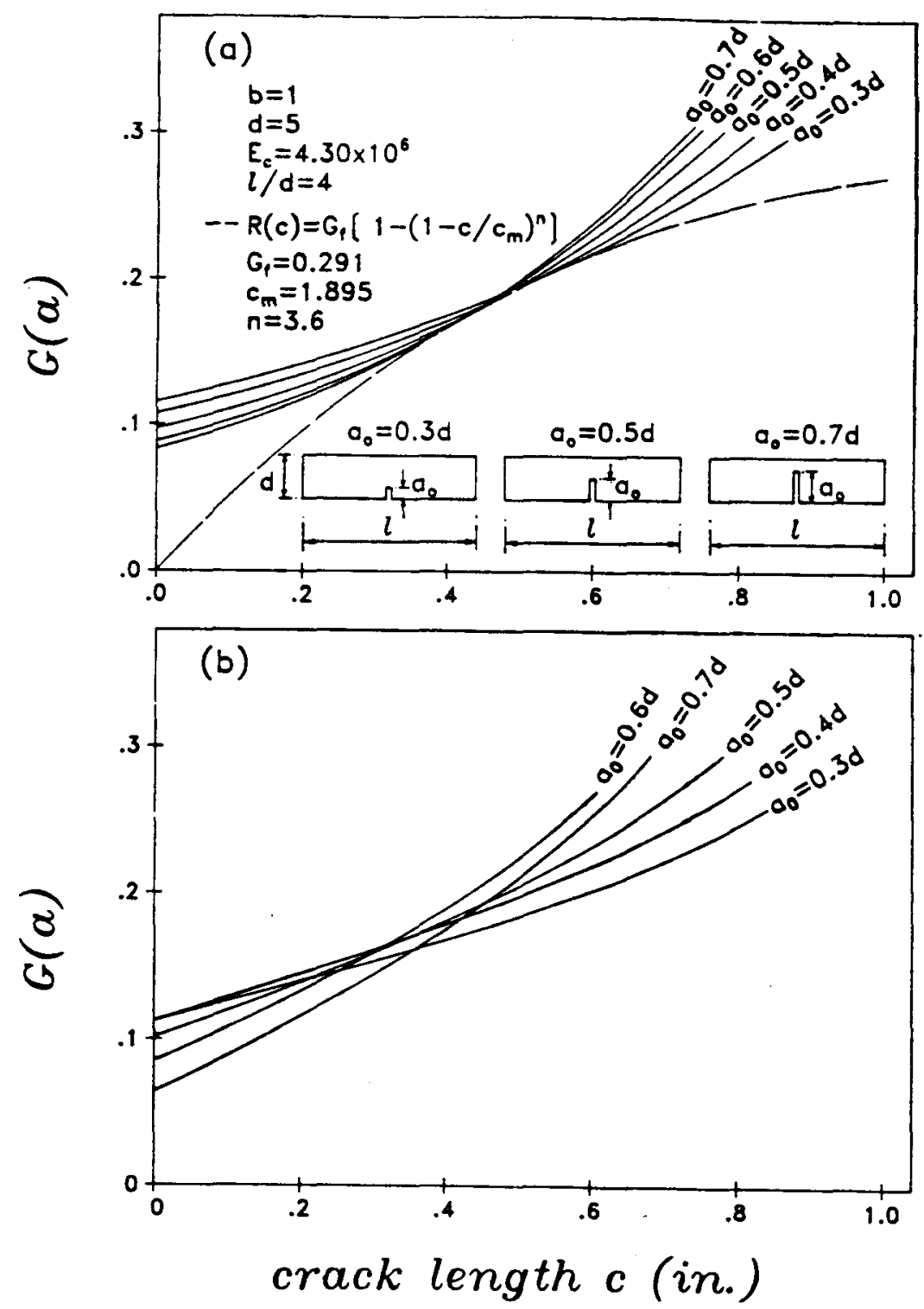

Fig. 14 - R-Curve as an Envelope for Various Notch Lengths in Specimen of One Size; (a) Smoothed, (b) Unsmoothed Data. 
4. For this value of an, solve crack extension at failure, $c$, from the condition $G_{G}(\xi)\left\{g(\alpha)=\operatorname{Max}\left(=f_{\max }\right)\right.$, and then evaluate $P=\left(f_{\max } E_{c} b \mathcal{d}\right)$

5. Repeat steps 2-4 for various values of $a_{0}$ between 0 and $d$.

6. Evaluate a suitable objective function to be minimized, such as $\Phi=\Sigma\left[\left(P-P_{\text {test }}\right) / P_{\text {test }}\right]^{2}$.

7. Repeat steps 1-6 to find which R-curve parameters yieid minimum $\Phi$. A computer optimization subroutine, such as the MarquardtLevenberg algorithm may be used for this purpose [111.

This type of algorithm works well 1111 , but requires more complicated optimization procedures - nonlinear optimization instead of innear regression. In nonitinear optimization it is not always guaranteed that a solution will be found. Moreover the minimum of $\Phi$ is not very sharp, which causes that aimost equaliy good fits of test data are obtained with rather different material parameter values $[11]$. This is, of course. due to lack of data smoothing by a law known in advance. Consequentiy, a larger amount of experimental results is needer if this approach is used [11].

\subsection{On Determining $G_{f}$ from Complete Load-Deflection Diagram}

It has been suggested that the fracture energy $G_{f}$ can be determined as the area under the complete load-deflection diagram for complete fracture of specimen $[32,34,38]$. However, the $\mathrm{G}_{\mathrm{f}}$ values obtained in this manner are frequentiy inconsistent and scattered. One likely source of error is that energy dissipation which does not produce fracture may happen in the system. The basic difference from the present approach is that the load values for all crack lengths affect the result, while here only the peak load value matters. The question then is whether the fracture pocess zone at other than peak load values dissipates energy at the same rate as it does at the peak load. This would certainly be true if the fracture were a straight line, with a sharp tip and a fracture process zone of negijgible size. This is not so, however. It is likely that the width and the length of the microcracking zone at the fracture front are different than they are at the peak load, and the fact that $G_{f}$ is far larger than double the theoretical specific surface Gibbs' free energy of the solid serves as the proof that much energy dissipation must occur due to microcracking on the sides of the final continuous crack.

The width of the microcracking zone ahead of the fracture front is assumed to be constant in the crack band model as well as
Hillerborg's fictitious crack model, but this is no douht a simplification (the nonlocal continuum approach points to that, too). In fact it is likely that the width $w$ of this zone varies (Fig. 12g), and especially that the widths at crack initiation (Fig. 12d) and at crack termination ( $F i g .12 f$ ) may be quite different from the width at the peak load (Fig. 12), at which the fracture front is remote from both the notch and the opposite face. Consequentiy, G along the crack path is variable (Fig. 12h) and the mean vaiue $\bar{G}$ lobtained by dividing the area under the load-deflection curve by the iigament length $\left.d-a_{0}\right)$ need not be the same as the value $G_{f}$ at maximum load (Fig. 12h).

Now, of the values $\bar{G}$ and $G_{f}$ (Fig. 12h) which one is more usefui? That depends. If the goa? is to predict the peak ioads or the response near the peak ioads, then it is more reasonable to use only peak load vaiues for determining $G_{f}$. Besides, they are easier to measure.

In the iight of Fig. 14, there might also be another difficuity. From this figure it is apparent that the use of a singie size specimen with different crack lengths cannot, due to inevitable random scatter, give information on the complete Rcurve, or the complete size-effect curve. It pertains only to a portion of these curves, and does not indicate unambiguousiy the limiting value of the R-curve, which represents $G_{f}$ (Fig. 14). If tests on singie size specimens (without crack length measurements) do not give sufficient data on the R-curve, how can they unambiguousiy yieid the R-curve asymptote?

R-Curves for Different Specimen Shapes. - Although this is not the main objective of this study, the use of the present resuits for the R-curves requires knowing to what extent the $R$-curve may be considered unique. This is a strictly theoretical question, which is hard to answer experimentally because the random scatter of materiai properties and other measurement difficulties obfuscate the comparisons of various experimentaliy determined R-curves. Therefore, it is preferable to make comparisons of R-curves which are calculated for specimens of different shapes using the same materiai properties. Such calculations have been carried out as described in Ref. 16 for specimens of various typical geometries. The calculated $R$-curves are plotted and compared in Fig. 15. The differences between some of these curves may seem iarge, however. they are not large compared to the inevitabie statistical scatter of measured R-curve values. Therefore, the hypothesis of a unique R-curve appears to be an acceptable approximation for the purposes of crude structural analysis. 
1. The macroscopic continuum description of dispersed cracking should properiy be hased on the nonlocal continuum concept. A suitable type of noniocal continuum is the imbricate continuum, representing the limit of an imbricated element system. This model is capable of describing stable strain-softening zones of a finite size. For large finite elements, this modei reduces to the previously formulated crack band theory. The existance of a characteristic length implies a simple size effect law for failures due to progressive cracking, which results from dimensional analysis and represents a transition from iimit analysis (strength or yield criterion) to linear elastic fracture mechanics.

2. The size effect law of blunt fracture (Eq. 27) is usefui for identifying the material parameters for noniinear fracture, regardiess of whether the R-curve approach, or the strainsoftening crack band model, or the stress-displacement relation (Hillerborg's model) is used. The basic idea is to transform the size effect law to a linear piot and netermine in this plot the regression line for the measured data obtained hy tests of geometrically similar specimens of different sizes. The slope of this regression line then yields the fracture energy (the value of which is, by definition, size-indepentent). The method can he also extended to certain dissimilar specimens of similar cross sections. The remaining noniinear fracture parameters for the R-curve or the crack band model (or Hilierborg's model) may then be identified hy finding a matching size effect regression line for this modei.

3. The R-curve may be obtained as the envelope of a family of fracture equilibrium curves determined on the basis of maximum load data smoothed with the size effect law. Without this smoothing, no envelope exists.

4. The size effect $l a w$ and the parameters of the crack band model are uniquely related. If one of them is specified, the other one may then be calculated. The same is true of the R-curve for specimens of given shape.

5. Exploiting the size effect law has important advantages: Statistically scattered measurements are smoothed with a known law permitting linear regression (Fig. 1b). The range of the test data is extended, thus reducing ambiguity of data fitting and uncertainty in the material parameter values.

Consequently, the experimentalist can get by with fewer tests covering a narrower range of conditions. nata smoothing enables constructing an envelope. A simpler measurement

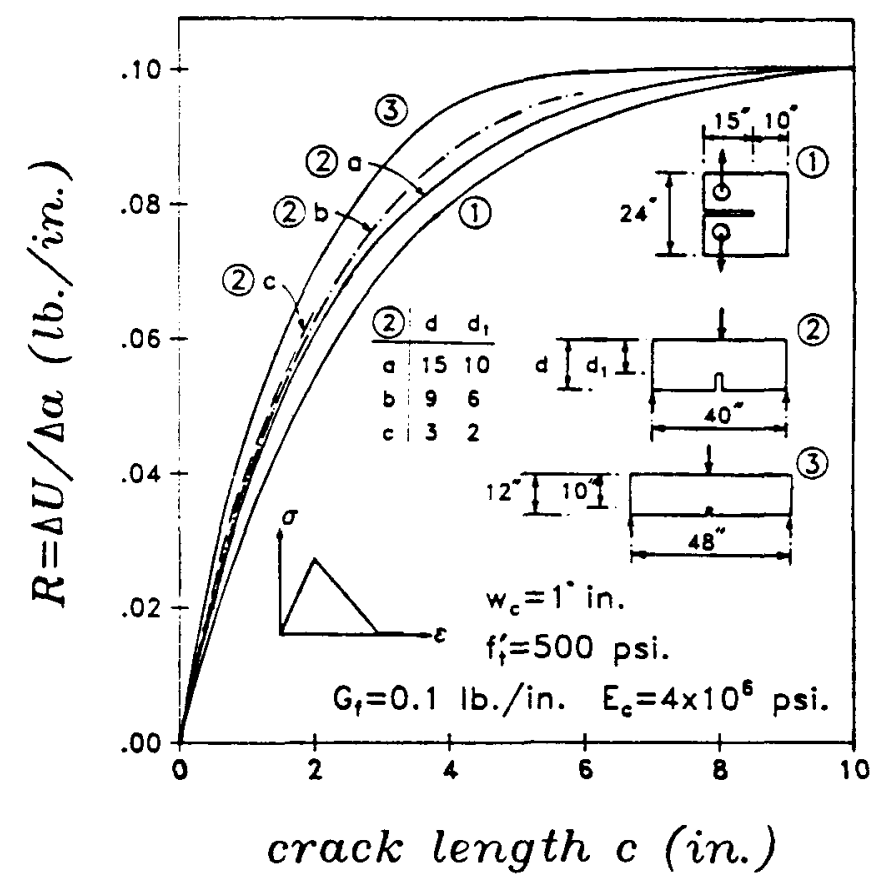

Fig. 15 - R-Curves Calculated by Crack Band Model for Same Material Parameters and Different Specimens. 
procedure than with the existing methods is made possible. Only maximum load values are needed. They can be obtained even in a laboratory with the most rudimentary equipment. There is no need to measure the crack length, which avoids the ambiguity in defining the location of the crack tip and the difficulty of its observation. No measurement of unloading or reloading compliance is needed. Since the size effect iaw for biunt fracture is applicable to diverse materials such as concrete, rock, or ductile metals [6], the present method of

identification of materiai parameters should he applicahle to ail these materials as well.

6. When the purpose of applying nonlinear fracture mechanjics in practice is the determination of the maximum load for monotonic loading, rather than the maximum load after a series of previous unloadings, it is more relistic to use only maximum loads also for the experimental calibration of the mathematical model.

7. Since material parameter identification is reduced to inear regressions, it would be possible to introduce statistics, and in particular, to determine the standard deviations of the material parameters from the statistical characteristics of the deviations from the regression line. As is generally agreed, statisticai aspects are very important for fracture predictions.

8. Measuring maximum loads of specimens that have notches of various lengths but are of the same size does not provide sufficient basis for determining the nonlinear fracture properties, e.g., the R-curve, accurately.

Acknowledgment. - Partial financial support under AFOSR Grant No. 830009 to Northwestern University is gratefully acknowledger. Marv Hill deserves thanks for her dedicated secretarial assistance.

\section{REFERENCES}

1. ASCF State-of-the-Art Report on "Finite Element Anaiys is of Reinforced Concrete," Prepared by a Task Committee chaired hy A. Nilson, Am. Soc. of Civil Engrs., New York, 1982.

2. Barenblatt, G. I.. "Similarity, Self-Similarity and Intermediate Asymptotics," Consultants Bureau, New York 1979 (trans?. from Russian).

3. Bazant, 2. P., "Crack Band Model for Fracture of Geomaterials," Proc., 4th Intern. Conf. on Numerical Methods in Geomechanics, heid in Edmonton, Alberta, Canada, June 1982 , ed. by Z. Eisenstein, Vor. 3 .

4. Bazant, Z. P., "Fracture in Concrete and Reinforced Concrele, Chapter 4 in "Mechanics of Geomaterials: Rocks, Concretes, Soils," John Wiley \& Sons, London, in press (Proc. of IUTAM W. Prager Symposium held at Northwestern University, Sept. 1983).

5. Bazant, 2. P., "Imbricate Continuum and Its Variational Formulation," Journal of Engineering Mechanics ASCE, Vol. 110 , No. 12, Dec. 1984, pp. 1693-1712.

6. Bazant, 2. P., "Size Effect in Blunt Fracture: Concrete, Rock, Metal," J of Engineering Mechanics, ASCE, Vol. Iin, i984, pp. 518-535.

7. Bazant, Z. P., Relytschko, T. R., and Chang, T. P... "Continuum Theory for Strain Softening," Journal of Engineering Mechanics ASCE, Vol. 110, No. 12, Dec. 1984, pp. 1666-1692.

8. Bazant, Z. P., and Certolin, L., "Rlunt Crack Band Propagation in Finite Element Analysis," Journal of the Engineering Mechanics Division, ASCE, Voi. 105, No. EM?, April 1979, pp. 297-315.

9. Bazant, Z. P., and Cedolin, L., "Fracture Mechanics of Reinforced Concrete," Journal of the Engineering Mechanics Division, ASCE, Vol. 106, No. EM6, Proc. Paper 15917, December 1980, pp. 1287-1306; with Discussion and Closure in Vol. 108, 1982, EM., pp. 364-471.

10. Bazant, Z. P., and Cedolin, L., "Finite Element Modeling of Crack Band Propagation," Journal of Structural Engineering, ASCE, Vol. 109, No. ST2, Feb. 1983, pp. 69-92. 
11. Bazant, Z. P., and Cedolin, L., "Approximate Linear Analysis of Concrete Fracture by R-Curves, ' Journal of Structura? Engineering, ASCE, Voi. 110, 1984, pp. 1336-i355.

12. Razant, Z. P., "Imbricate Continuum and Progressive Fracturing of Concrete and Geomaterials," Meccanica (Itaiy), Voi. 19, 1984, pp. 86-93.

13. Bazant, Z. P., "Numerical Simulation of Progressive Fracture in Concrete Structures: Recent Developments," Proceedings of the Sept. 1984 International Conference on "Computer-Aided Analysis and Design of Concrete Structures, heid in Spit, Yugosiavia, ed. by E. Hinton, R. Owen and F. Damjanic, Univ. of Wales, Swansea, U.K., Riveringe Press, Swansea, pp. 1-18.

14. Razant, Z. P., and Estenssoro, L. F., "Surface Singuiarity and Crack Propagation," International Journal of Solids and Structures, Voi. 15, 1979, pp. 405-426 and Voi. 16, 1980, pp. $479-487$.

15. Bazant, Z. P., and Kim, J. K., "Size Effect in Shear Fajiure of Longitudinaliy Reinforced Beams," Amer. Concrete Inst. Journal, Vol. 81, No. 5, 1984, pp. 456-468.

16. Bazant, Z. P., and Oh, R. H., "Crack Rand Theory for Fracture of Concrete," Materiaux et Constructions (Materials and Structures) RILEM, Paris, Vol. 16, 1983, pp. 155-i77.

17. Bazant, Z. P., and Oh, B. H., "Rock Fracture via StrainSoftening Finite Elements," Journal of Engineering Mechanics ASCE, Voi. 110, No. 7, Juiy 1984, pp. 1015-1035.

18. Bazant, Z. P., and Oh, B. H., "Microplane Model for Fracture Anaiysis of Concrete Structures, "Proc. Symp. on the "Interaction of Nonnuclear Munitions with Structures," U. S. Air Force Academy, Colorado Springs, May 1983, pp. 49-55.

19. Broek, D., "Elementary Engineering Fracture Mechanics," Noordhoff Internationa? Publishing, Leyden, Netherlands, 1974.

20. Eringen, A. C., and Edelen, D. C. R., "On Nonlocal Elasticity," International Journal of Engineering Science, Vol. 10, 1972 , pp. 233-248.

21. Eringen, A. C., and Ari, N., "Nonlocal Stress Field at Griffith Crack," Cryst. Latt. Mef. and Amorph. Mat., Vol. in, 1983, pp. 33-38.
22. Evans, R. H., and Marathe, M. S., "Microcracking and StressStrain Curves for Concrete in Tension," Materials and Stuctures (RILEM, Paris), No. 1, Jan.-Feb. 1968, pp. 61-54.

23. Hilierhorg, A., Modeer, M., and Petersson, P. E., "Analysis of Crack Formation and Crack Growth in Concrete by Means of Fracture Mechanics and Finite Elements," Cement and Concrete Research, Vol. 6, i967, pp. 773-782.

24. Irwin, G. R., Report of a Special Committee, "Fracture Testing of High Strength Sheet Material," ASTM Bulletin, Jan. 1960, p. 29 (aiso F. R. Irwin "Fracture Testing of High Strength Sheet Materials under Conditions Appropriate for Stress Anaiysis," Report No. 5486, Navai Research Lahoratory, July 1960).

25. Jenq, Y. S., and Shah, S. P., "Nonlinear Fracture Parameters for Cement Based Composites: Theory and Experiments". Preprints, NATO Advanced Research Workshop on "Applications of Fracture Mechanics to Cementitious Composites," ed. by S. P. Shah, Northwestern Univeristy, Evanston, IL. 60201, U.S.A. Sept. 4-7, i984, pp. 2i3-253.

26. Krafft, J. M., Suliivan, A.M., Boyie, R. W. "Effect of Dimensions on Fast Fracture Instabii ity of Notched Sheets," Cranfieid Symposium 1961, Voi. 1 , pp. 8-28.

27. Kroner, E., "Elasticity Theory of Materials with Long-Range Cohesive Forces," International Journal of Solids Structures, Vol. 3, 1967, pp. 731-742.

28. Kroner, E., "Interrelations Between Various Branches of Continuum Mechanics," Mechanics of Generalized Continua, ed. by E. Kroner, Springer-Veriag, 1968, pp. 33n-34n.

29. Krumhans1, J. A., "Some Considerations for the Relation Between Solid State Physics and Generaiized Continuum Mechanics," Mechanics of Generatized Continua, er. by $F$. Kroner, Springer-Verlag, 1968, pp. 298-311.

30. Kunin, I. A., "The Theory of Elastic Media With Microstructure and the Theory of Dislocations," Mechanics of Generalized Continua, ed. by E. Kroner, Springer-Verlag, 1968, pp. 321328 .

31. Levin, V. M., "The Relation Between Mathematical Expectation of Stress and Strain Tensors in Elastic Microheterogeneous Media," Prikiadnaya Matematika i Mekhanika, Vol. 35, 1971, pp. $694-701$ (in Russian). 
32. Mai, Y. W., "Fracture Measurements of Cementitious Composites," Preprints," NATO Advanced Research Workshop on "Applications of Fracture Mechanics to Cementitious Composites," ed. by S. P. Shah, Northwestern University, Evanston, I1.. Sept. 1984, pp. 289-319.

33. Petersson, P. E., "Fracture Energy of Concrete," Cement and Concrete Research, Vol. 10, 1980, pp. 78-89 and 91-101.

34. Petersson, P. C., "Crack Growth and Development of Fracture Zones in Plain Concrete and Similar Materials," Doctoral Dissertation, Lund Institute of Technology, Lund, Sweden, Dec.
1981 .

35. Rashid, Y. R., "Analysis of Prestressed Concrete Pressure Vesseis," Nuciear Engng. and Design, Voi. 7, No. 4, April 1968, pp. 334-344.

36. Reinhardt, H. W., and Cornelissen, H. A. W., "Post-Peak Cyclic Rehavior of Concrete in Uniaxial Tensile and Alternating Tensile and Compressive Loading," Cement and Concrete Research, Vol. 14, 1984, pp. 263-270.

37. Tada, H., Paris, P. C., and Irwin, G. R., "The Stress Anaiysis of Cracks Handbook," Del Research Corp., Hellertown, Pa.,
1973 .

38. Tattersa11: H. G., and Tappin, G., "The Work of Fracture and Its Measurement in Metals, Ceramics and Other Materials," Journal of Materials Science, Vol. 1, i966, pp. 296-301.

39. Velazco, G., Visalvanich, K., and Shah, S. P., "Fracture Behavior and Analysis of Fiber Reinforced Concrete Reams," Cement and Concrete Research, Vol. 110, pp. 41-51, 1980.

40. Wecharatana, M., and Shah, S. P., "Slow Crack Growth in Cement Composites," Journal of the Structural Division, ASCE, Vol. 108, June 1982, pp. 1400-1413.

41. Wittmann, F. H. (Editor) "Fracture Mechanics of Concrete," Elsevier, Netherlands, 1983.
APPLICATION OF FRACTURE MECHANICS

\section{TO CEMENTITIOUS COMPOSITES}

NATO-ARW - September 4-7, 1984

Northwestern University, U.S.A. S. P. Shah, Editor

NON-LINEAR FRACTURE MODELS

FOR DISCRETE CRACK PROPAGATION

Anthony R. Ingraffea, Associate Professor

Walter H. Gerstle, Graduate Research Assistant

Department of Structural Engineering

Cornell University, Ithaca, New York, U.S.A.

\section{INTRODUCTION}

The proper fracture mechanics to be applied to crack propagation in concrete is determined by scale effects. To ascertain whether linear elastic fracture mechanics (LEFM) or a non-linear approach is more applicable to a particular problem, one must answer the following question:

- How large is the process zone compared to the smallest critical dimension of the structure under consideration?

The purpose of this paper is to address this question from the particular point-of-view of discrete representation of a crack in a finite element model. Before proceeding to outline the paper's approach and methods, it is essential that key terms used in the above question be defined and that important assumptions be stated:

- The process zone is that area accompanying crack propagation in which inelastic material response is occurring.

- The term crack is not used here in its classical sense, as a complete discontinuity in both traction and displacement fields. Rather, it is used to describe an effective crack which consists of a length of true crack (in the classical sense) preceded by its process zone.

- The critical dimension might be the length of the crack itself, including its process zone, or, if it is smaller, the distance from the true crack tip to the nearest free surface or reinforcing bar. 
These definitions are in the spirit of the approach to the fracture mechanics of metals first proposed by Irwin (1). In fact, throughout this paper comparisons and analogies will be drawn between the well-accepted formulations for process zone size in ductile metals and the estimates derived here for brittle non-metallics.

The basis for any process zone size estimate, whether it be for a zone of plastic deformation in a metal or for some form of inelastic response in concrete, is a constitutive model for the material in this zone. Whereas for metals a model might be composed of the von Mises yield criterion, to relate the effective stress to all the principal stresses, and a normality flow rule, to relate the effective stresses to elastic and plastic strains, a much simpler, yet analogous, constitutive model will be used in this paper. To describe the inelastic behavior in the process zone of a crack propagating in concrete the following assumptions are made:

1. The only constitutive modeling required for process zone description in pure Mode $I$ is the stress-versus-crackopening-displacement $(C O D)$ relation which can be obtained from a displacement-controlled direct tension test (2). This relation is, in fact, the post-peak stress-COD curve measured in such a test. A range of such process zone softening models used in the present analyses is shown in Figure 1.

2. The previous assumption implies that normal stress continues to be transferred across a displacement discontinuity which may or may not be visible to the naked eye. It is assumed that this stress transfer is due to aggregate bridging and the undulating, three-dimensional nature of the opposing crack surfaces (3).

3. It is assumed that the process zone localizes, due to the rapid softening behavior shown in the models of figure 1 , into a very narrow band ahead of the true crack tip. In fact, for the purposes of the present finite element analysis, all softening is confined to one-dimensional interface elements lying in the crack plane ahead of the true crack tip (4).

4. Although for metals the process zone size is especially influenced by the principal stress parallel to the true crack front, it is assumed that this stress has no influence on the process zone in geomaterials such as concrete and rock $(5,6)$.

Schematically, these assumptions combine to paint the picture shown in Figure 2. The constitutive model is defined by the direct

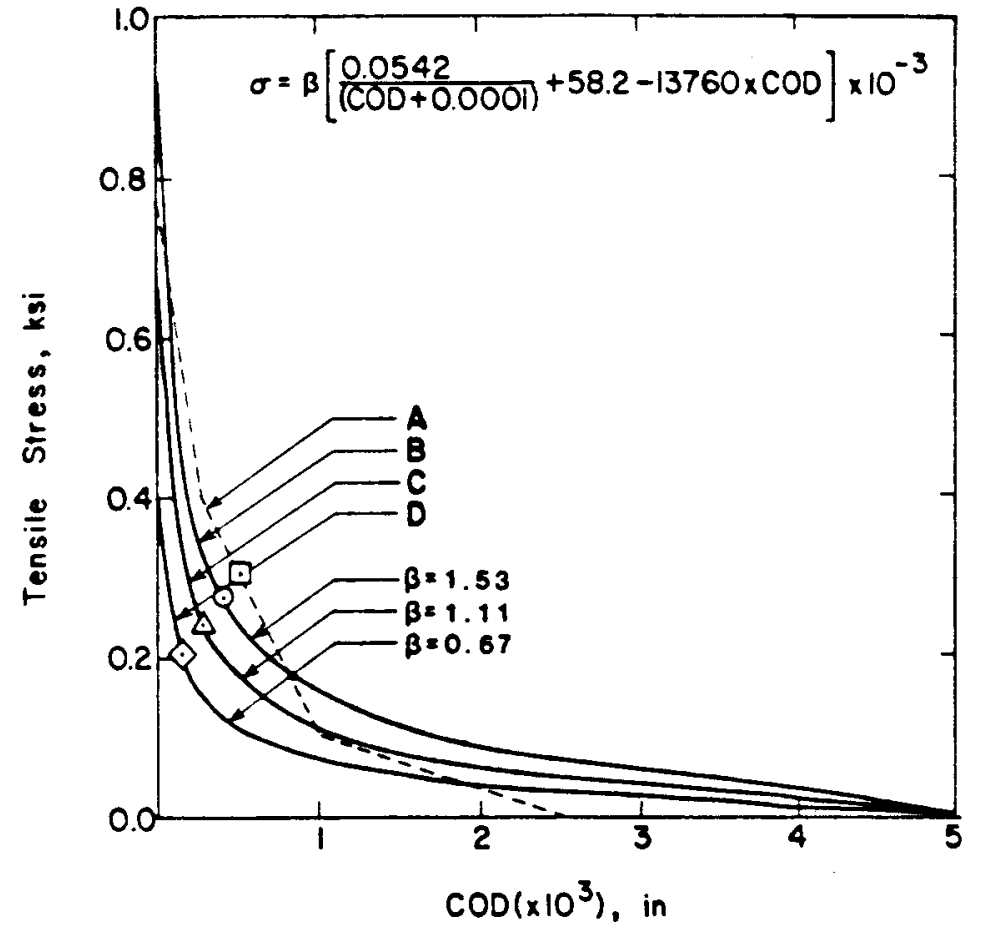

Figure 1. Various constitutive models for a discrete representation of the process zone in concrete.

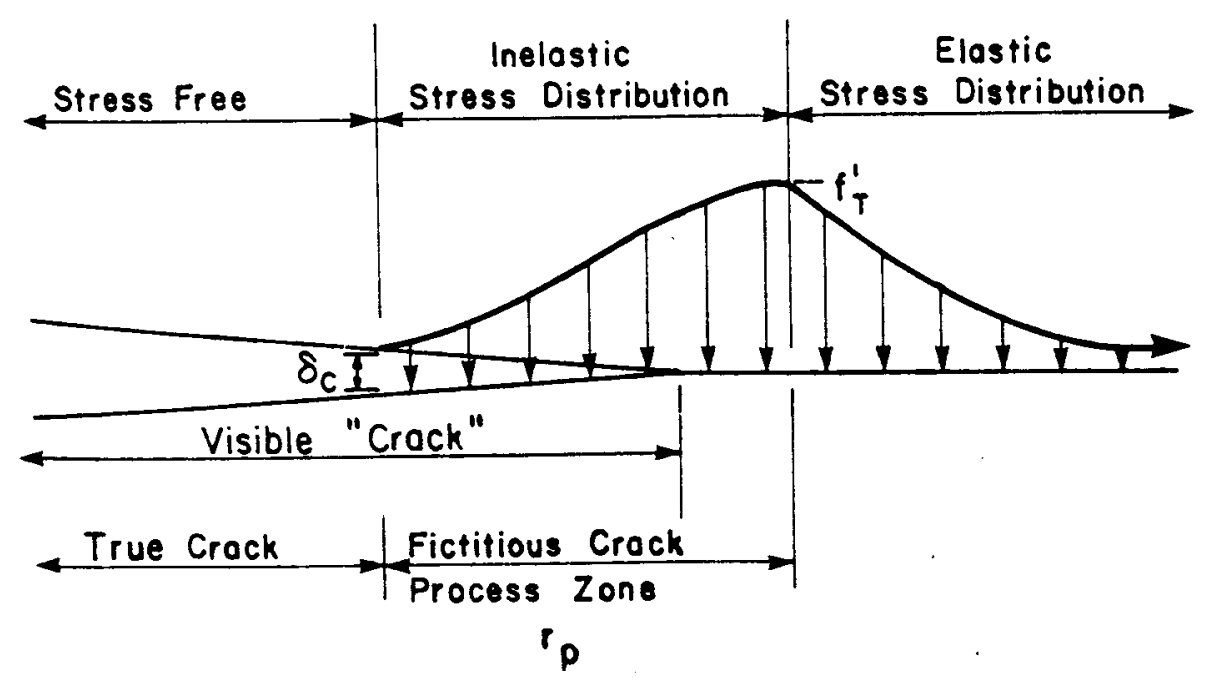

Figure 2. A schematic of the hypothesized process zone in concrete. 
tensile strength, $f_{T}^{\prime}$, which may be influenced by stress normal to the crack front, the shape of the postpeak stress $-C O D$ relationship, which, in conjunction with the COD-gradient characteristic of the problem at hand, produces the shape of the inelastic stress distribution, and finally, the characteristic COD, $\varepsilon_{c}$, which will occur at the true crack tip. Given these observations and assumptions, it is natural to ask:

- How large must the critical dimension be for the application of linear elastic fracture mechanics (LEFM) to be valid? Or, from the perspective of assumption 3, above, how long is the process zone?

- How sensitive is the process zone length, $r$, to structural geometry and the constitutive model which drives it?

- For a problem of effectively infinite domain, what is the steady-state process zone length for a given constitutive model?

The approach to answering these questions here will be a series of numerical analyses. All will be based on the well-known finite element method. The unique feature of all the analyses, however, will be the "discrete" representation of the crack in the mesh. The current state-of-the-practice for representing a crack in a finite element mesh is the "smeared" approach, originally proposed by Rashid (7). In that approach, the constitutive model is used to simulate the cracking process: the mesh is not changed as arbitrary cracking progresses, nor is a crack with a trajectory known a priori accommodated with special meshing.

In the discrete approach as used here, the mesh is itself modified, automatically, to represent the cracking process $(8,9)$. In the case of arbitrary cracking, local remeshing, the introduction of new elements and nodes and the modification of some previously existing elements, is performed for each crack at each increment of cracking. Singularity elements are introduced at a true crack tip under LEFM conditions. If the process zone, because of its length, requires representation, it too is modeled discretely as mentioned in assumption 3, above. If the crack trajectory is known, as will be the case in most of the test cases analyses to be reported here, special meshing is introduced to facilitate modeling of the complete fracture process. A thorough discussion of the general advantages and disadvantages of the two approaches is given, in an historical perspective, by Ingraffea and Saouma (9).

The differences between the "discrete" and "smeared" approaches are stark when true crack modeling is performed. However, the distinctions begin to blur when a process zone is being represented. It will be shown here that, under this condition, the only difference between the approaches lies in assumption 3, above.

Before beginning presentation of the finite element analyses which address the questions presented above, it is necessary to begin more simply, with hand calculations. These will enable one to relate process zone effects in strain-softening geomaterials to parallel processes in metals. Further they will offer a simple check for the acceptability of the finite element calculations to follow.

\section{PROCESS ZONE SIZE: SOME QUALITATIVE ASSESSMENTS}

Figure 3 , a complete stress-strain curve from a straincontrolled, direct-tension test on a strain-softening material, is the basis for the introductory calculations of this section. The constitutitve models shown in figure 1 can be derived from such a test. Evans and Marathe were first to observe (10), that, once the fracturing process of the test specimen has begun, nearly all the strain is due to the formation of a crack. That is, if the gage length were the specimen length, then the measured strain would be approximately equal to the COD divided by the gage length.

Alternatively, one can groove or so shape the test specimen so that the location of the fracture plane is known. The con can then be measured directly (2) as a function of applied stress.

For comparison, let's assume that two tests of the type shown schematically in figure 3 are performed, one on a concrete specimen leading to the response shown, the other on a metal specimen, with uniaxial yield stress $f_{y}$, exhibiting elastic-perfectly plastic behavior. We shall first seek to compare measures of process zone size for these materials based on very simple assumptions.

\subsection{Comparisons of Strain-Softening Versus Perfectly-Plastic}

\section{Behavior in the Process Zone}

Focus first on the region ahead of a crack tip in the metal. It is straightforward to show that a second-order measure of process zone size for the metal $r_{p_{\mathrm{m}}}$, is (11)

$$
r_{p_{m}}=\frac{1}{\pi}\left(\frac{k_{I c}}{f_{Y}}\right)^{2}
$$

where, 


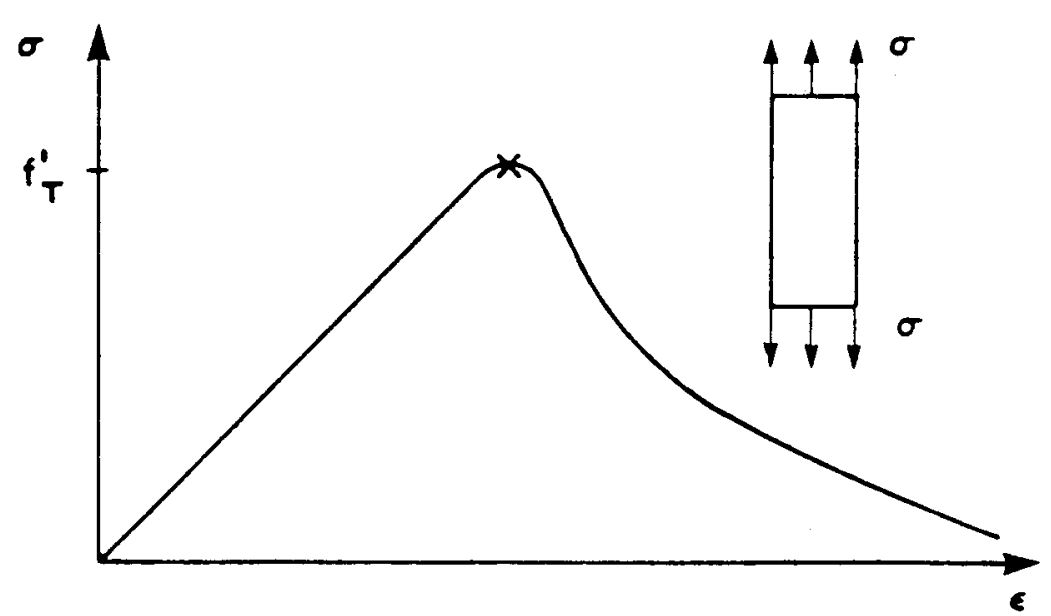

Figure 3. Idealized stress-strain curve for concrete loaded in uniaxial tension under strain control.

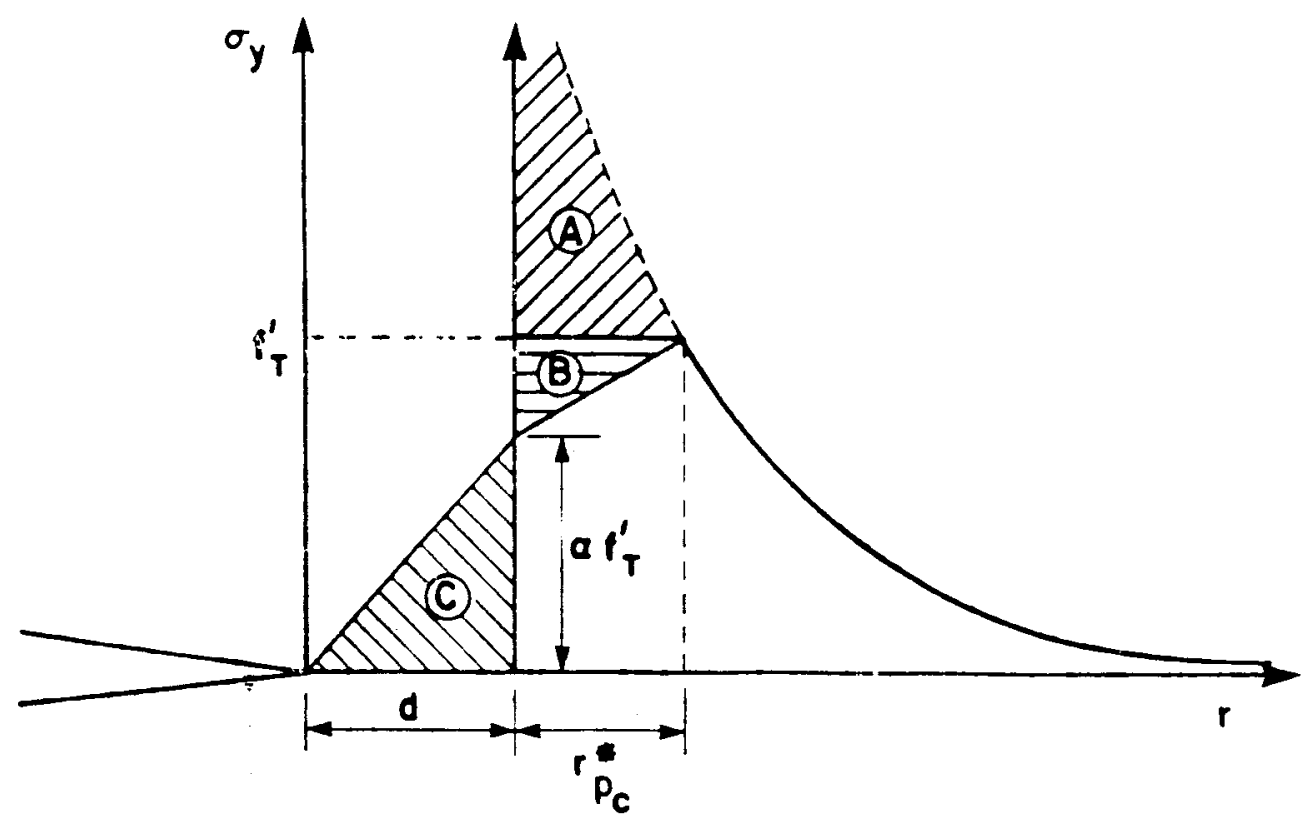

Figure 4. Hypothesized stress redistribution ahead of a true crack tip in concrete. For equilibrium, area $C$ must equal area $A$ plus area $B$.
$K_{I C}=p l a n e$ strain fracture toughness

This measure is the process zone length along the crack direction. It assumes that the effective yield stress is the uniaxial yield stress, that is, stress multiaxiality is neglected, and that approximate stress redistribution has occurred to satisfy equilibrium in the $y$-direction (see Figure 4 for coordinate system).

Focus now on Figure 4 , a simplified schematic of the region ahead of a true crack tip in concrete. The first difference which arises between this and the analogous situation in the elastic, perfectly-plastic metal is that one does not know the shape of the inelastic stress distribution in the process zone because the COD profile is problem dependent. However, to continue the analysis, we will assume a bilinear distribution as shown, with $\alpha$ as a shape parameter, and seek to find the concrete's process zone length, ${ }^{p_{c}}$, from

$$
r_{p_{C}}=d+r_{p_{C}}^{\star}
$$

where,

$$
r_{p_{C}}^{*}=\frac{1}{2 \pi}\left(\frac{K_{I C}}{f_{T}^{\prime}}\right)^{2}
$$

It can be easily shown (11) that $r_{p_{c}}^{*}$ is a first-order measure of process zone length which does not account for any stress redistribution. To satisfy equilibrium in the $y$-direction it is necessary that stress redistribution occur such that,

$$
\frac{1}{2} d \alpha f_{T}^{\prime}=\int_{0}^{r_{c}^{*}} \frac{k_{I}}{\sqrt{2 \pi r}} d r-f T_{T}^{\prime} r_{p_{C}}^{*}+\frac{1}{2}(1-\alpha) f_{T}^{\prime} r_{p_{c}}^{*}
$$

Solving Equation (2) for d yields,

$$
d=r_{p_{C}}^{\star}\left(\frac{3}{\alpha}-1\right)
$$

It is interesting to compare now the second order process zone size estimates for the two materials using Equations (1) and (2) and (5). The comparison is done in Table 1 and it reveals the second 


\section{Table 1}

Comparison of Process Zone Size Measures for Concrete, $r_{p_{c}}$, and an Elastic, Perfectly-Plastic Metal, $r p_{m}$

\begin{tabular}{lrrr}
\hline$\alpha$ & $d / r_{p_{c}}^{*}$ & $r_{p} / r_{p_{c}}^{*}$ & $r_{p_{c}} / r_{p_{m}}$ \\
\hline 0.05 & 59 & 60 & 30 \\
0.20 & 14 & 15 & 7.5 \\
0.50 & 5 & 6 & 3 \\
0.75 & 3 & 4 & 2 \\
1.00 & 2 & 3 & 1.5 \\
\hline
\end{tabular}

difference in process zone characteristics of the two materials: when the y-stress is allowed to decay as the true crack tip is approached, $r_{p_{c}}$ becomes significantly larger than $r_{p_{m}}$. Some representative inelastic stress distributions are plotted in Figure 5 in terms of $\alpha$. Again, it is important to emphasize that the rate of decay, as indicated by $\alpha$, will depend on the shape of the constitutive curve and on the COD profile characteristic of the particular structural geometry and boundary conditions under consideration.

As an example of the interaction of COD profile and constitutive model, consider the following example. Assume the process zone material model shown in Figure 6 . Let us now solve for the COD profile in the inelastic zone. First, write the COD profile in terms of the stress distribution using Figure 6 ,

$$
\operatorname{COD}(\sigma)=\delta_{C}-\frac{\delta_{c}}{f_{T}^{\prime}} \sigma(r)
$$

Next, using the bilinear stress representation shown in Figure 4 , solve for the $C O D$ in terms of the r-coordinate,

$$
\begin{aligned}
& \text { For } 0<\bar{r} d \text {, } \\
& \sigma(r)=\frac{\alpha f_{T}^{\prime}}{\left(\frac{3}{\alpha}-1\right) r_{p_{C}}^{k}} r
\end{aligned}
$$

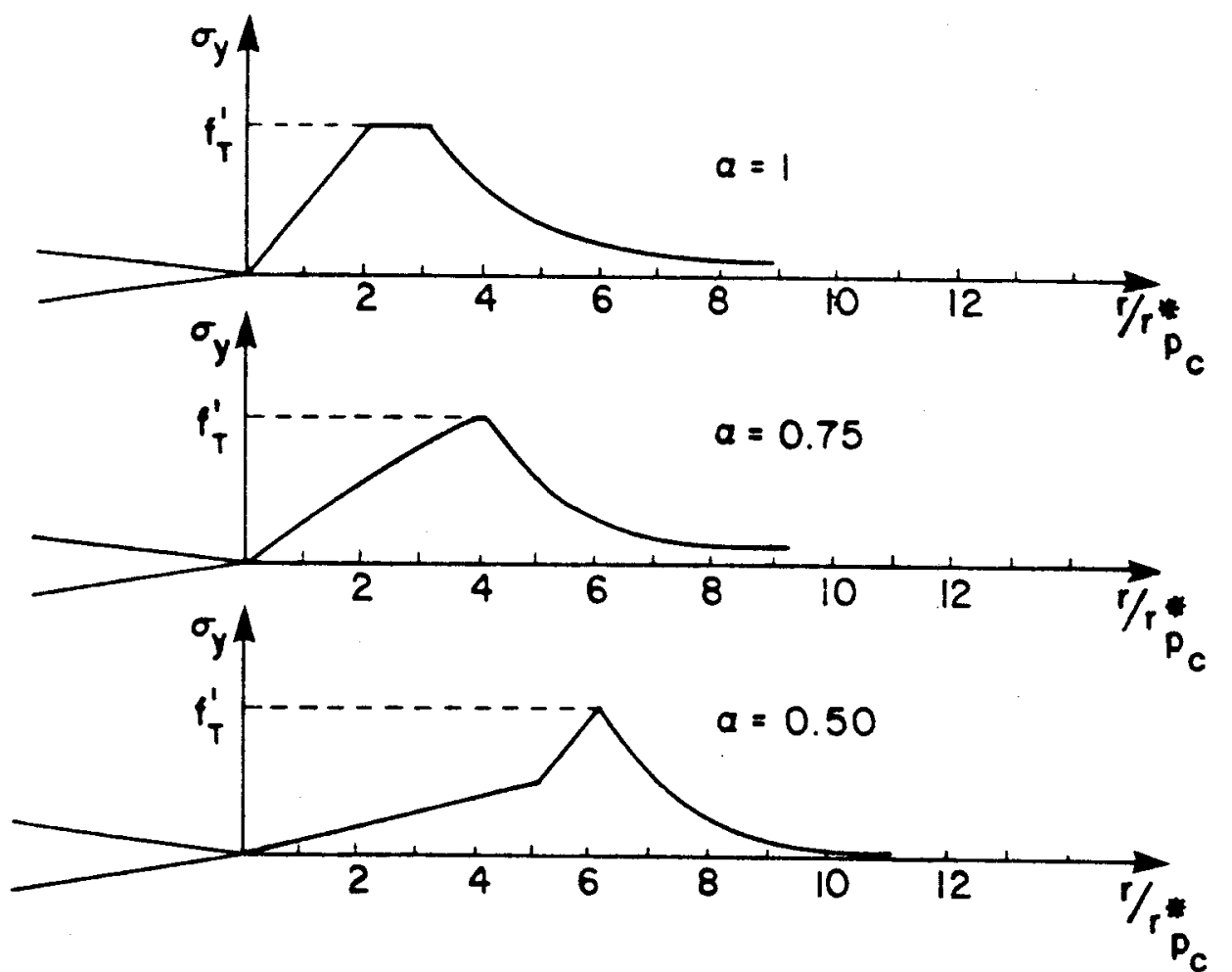

Figure 5. Representative stress distributions ahead of the true crack tip for various values of $\alpha$.

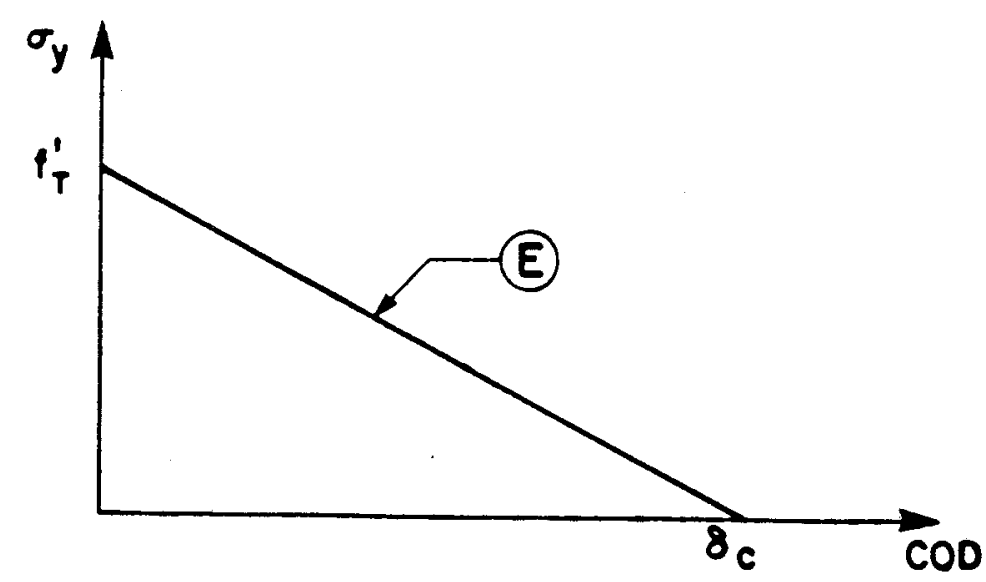

Figure 6. A simple constitutive model for the discrete process zone. 


$$
\operatorname{COD}(r)=\delta_{c}\left[1-\frac{\alpha}{\left(\frac{3}{\alpha}-1\right)}\left(\frac{r}{r_{p_{c}}^{\hbar}}\right)\right]
$$

For $d \leq r \leq r p_{c}$,

$$
\sigma(r)=f_{T}^{\prime}\left(4-\frac{3}{\alpha}\right)+(1-\alpha) f_{T}^{\prime}\left(\frac{r}{r_{p_{C}}^{\star}}\right)
$$

and,

$$
\operatorname{coD}(r)={ }_{c}\left[\frac{3}{\alpha}-3+(\alpha-1)\left(\frac{r}{r_{p_{c}}^{t}}\right)\right]
$$

Equations (8) and (10) are plotted in Figure 7 for inelastic stress distributions previously seen in Figure 5. Using Table 1, one can see that the COD-profiles of Figure 7 would correspond to process zone lengths significantly larger than those in the metal with the same order of approximations.

The inescapable conclusion to be drawn from these simple calculations is that the size restriction for valid fracture toughness measurement in metals (12), written in terms of multiples of $r_{p_{m}}$,

$$
a, w-a>2.5\left(\frac{K_{I c}}{f_{Y}}\right)^{2}
$$

where,

$$
a=\text { crack length, }
$$

$W-a=$ remaining ligament

is unconservative for materials which exhibit tensile strain softening. That is, crack lengths and ligaments longer than would be indicated by simple substitution of $f_{T}^{\prime}$ for $f_{y}$ in Equation (11)

will be necessary to measure a valid fracture toughness. Further, and a bit more subtly, the simple models used here indicate that there is a strong dependence of process zone size on specimen type. For example; assume the constitutive model of figure 6 . For a specimen that would tend to produce a linear COD-profile, such as a wedge loaded center-cracked plate, Figure 7 and Table 1 show that specimen size restrictions would more nearly be,

a, $W-a>5\left(\frac{K_{I C}}{f_{i}}\right)^{2}$

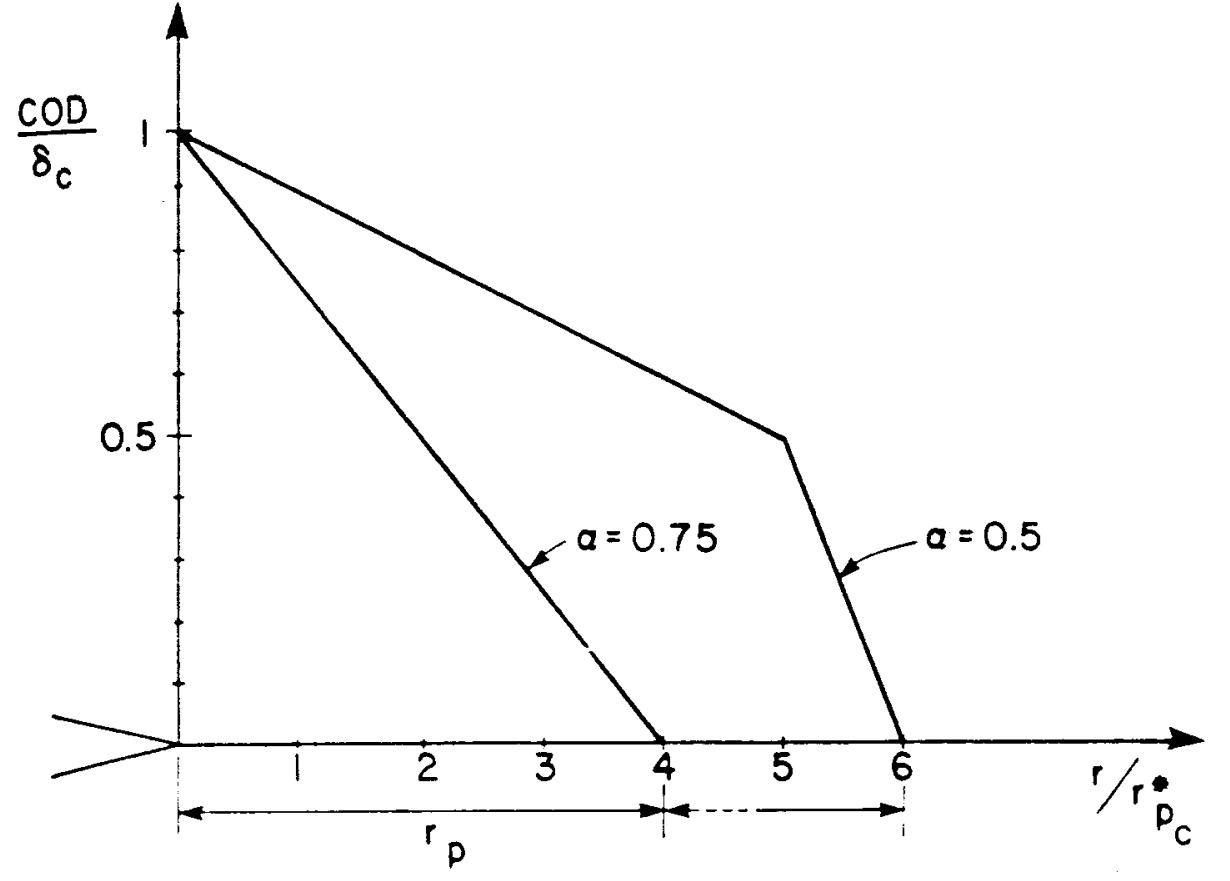

Figure 7. COD profiles for the constitutive model of Figure 6 and the stress distributions shown in Figure 5.

If the COD profile were closer to the elliptical shape exhibited by, say, a center cracked plate loaded in remote tension, the restriction would become,

$$
a, w-a>7.5 \frac{K_{I c}}{f_{T}}
$$

At this point five material characteristics have been introduced: $E$, the Young's modulus, $K_{I C}$, the fracture toughness, and the $f_{T}^{\prime}$ and $\hat{\delta}_{c}$ pair which, together with its shape, define the $\sigma-C O D$ curve. In fact, not all of these parameters are independent. Assume again the constitutive model of Figure 6 . Since every material element in the process zone must ride down this curve before it cracks, in the LEFM sense, the critical energy absorption rate is the area under this curve,

$$
G_{I C}=\frac{1}{2} \delta_{c} f^{\prime} T
$$


If a test on a large enough specimen were performed, it would yield a critical stress intensity factor related to $G_{I C}$ by the familiar expression,

$$
G_{I C}=\frac{K_{I C}{ }^{2}}{E}
$$

with plane stress assumed. It follows from Equations (14) and (15) that,

$$
\delta_{c}=\frac{2 K_{I C}{ }^{2}}{E f_{T}^{\prime}}
$$

It is interesting to note that if a value of critical stress intensity typical of the largest concrete specimens tested to date (13, 14), about $2.5 \mathrm{ksi} \sqrt{\text { in }}(2.75 \mathrm{MNm}-3 / 2)$, is used in Equation (16), the predicted characteristic $\mathrm{COO},{ }^{f} \mathrm{c}$, is about 0.01 inch $(0.25 \mathrm{~mm})$. This value is surprisingly close, considering the approximations employed here, to values measured experimentally $(2,10)$, about 0.005 to 0.010 inch $(.13$ to $.25 \mathrm{~mm}$ ).

In the next section we investigate the implications of one of these approximations on the assumption that the process zone width can be viewed, from the numerical modeling standpoint, as no more than $\delta_{c}$.

\subsection{Stress Biaxiality Effects}

Recall that the calculations of the previous section neglected stréss multiaxiality in the process zone. Equation (1), for example, is based on a uniaxial yield criterion despite the fact that tensile stress triaxiality theoretically occurs ahead of a crack tip. A third-order measure of process zone length directly ahead of the crack, and an estimate of the shape of the process zone can be obtained by admitting stress multiaxiality into the yield criterion (11).

The same process will be used here to make qualitative assessments of the influence of stress multiaxiality on process zone shape in geomaterials. In what follows no stress redistribution is performed. Rather, we seek only the implications of stress biaxiality on the tensile strength parameter, $f_{T}^{\prime}$, in the process zone constitutive model.

Consider the family of curves shown in Figure 8 . They are analogous to yield surfaces in plasticity and indicate, from

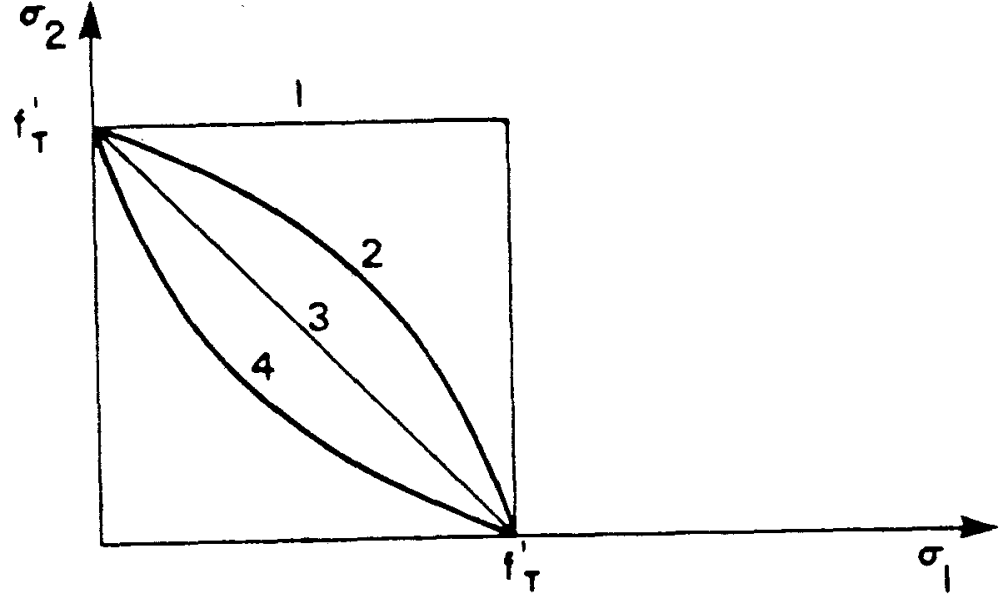

Figure 8. A family of tensile strength interaction curves.

numbers 1 to 4 , an increasing degree of principal stress interaction efect on tensile strength according to,

$$
\begin{array}{ll}
1 & \sigma_{1} \text { or } \sigma_{2}=f_{T}^{\prime} \\
2 & \sigma_{1}^{1.5}+\sigma_{2}^{1.5}=f_{T}^{1} 1.5 \\
3 & \sigma_{1}+\sigma_{2}=f_{T}^{\prime} \\
4 & \sigma_{1}^{0.7}+\sigma_{2}^{0.7}=f_{T}^{\prime}
\end{array}
$$

where,

$$
\begin{aligned}
& \sigma_{1}, \sigma_{2}=\text { principal stresses in the plane } \\
& \text { normal to the crack plane }
\end{aligned}
$$

Note that the third principal stress has been neglected for simplicity, although its influence is probably minimal because of the relatively low value of Poisson's ratio for concrete (see assumption 4 in the INTRODUCTION). It can easily be shown that substitution of Equations (14) into the well known expressions substitution of Equations (14) into the weresses near a true crack tip (11) leads directly to the envelop curves of Figure 9.

The conclusion we wish to draw from figure 9 is that, as the degree of biaxial stress influence on tensile strength increases, 


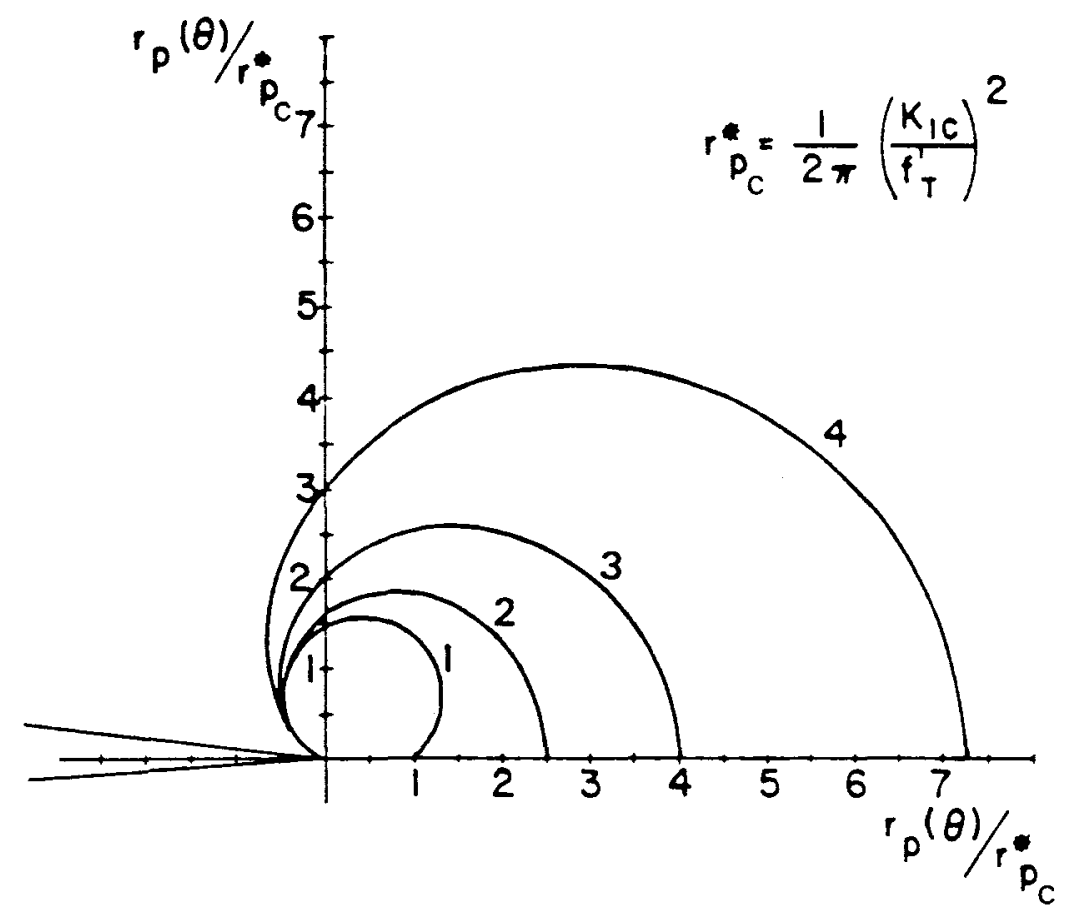

Figure 9. Process zone shapes predicted by LEFM assumptions, no stress redistribution, and the tensile strength interaction curves of Figure 8.

the length of the process zone along the crack direction grows faster than on any other radius. The qualitative implication here is quite different from what one sees in a plastic zone at a crack tip in a metal. It is generally assumed in elasto-plastic fracture mechanics that post-yield, distortional strain energy absorption accounts for the inelastic behavior in the process zone. This energy is absorbed in zones of high shear, well off the crack axis, and produces the familiar kidney-shaped plastic zones ahead of a crack tip in Mode I.

When, however, we posit that the inelastic energy absorption mechanism is a function of the normal stresses, as implied by the constitutive models of Figures 2 and 8 , the process zone localizes along the crack axis. This observation is supported experimentally $(13,14,15)$. Attempts to observe process zone shape in mortar and concrete using interferometry (14) and scanning electron microscopy (15), and in rock (13) using epoxy impregnation, have all indicated that the width of the process zone, if at all measurable, is less than its length. In the computer simulations to follow we will take the approach that the process zone width is zero, that the process zone is the "fictitious crack" (18) shown in Figure 2. The inelastic energy sink is the normal traction on this "crack" moving through its COD: every point in this zone rides down a curve like one of those in Figure 1 on its way to becoming part of a true crack surface. For each unit of crack advance, the area under such a curve is the energy absorbed in the cracking process per unit of crack front length.

\section{EXAMPLE PROBLEMS}

In this section a series of three fracture tests on concrete specimens will be simulated using the discrete cracking, finite element approach and the constitutive models previously described. There are some characteristics common to these tests. These are:

1. Unless otherwise noted, it is assumed that,

$$
\begin{aligned}
& E=3 \times 10^{3} \mathrm{ksi}(20.7 \mathrm{MPa}) \\
& v \text {, Poisson's ratio }=0.2
\end{aligned}
$$

2. Plane stress is assumed.

3. Simulations are performed with the Finite Element Fracture Analysis Program (FEFAP) $(8,9,19)$. All elements are isoparametric and of quadratic displacement order.

4. The symbol $r_{P_{C}}$ is replaced by $r_{p}$ as it is understood that we refer only to concrete hereafter.

\subsection{Example 1: A Very Large Center-Cracked Plate}

The first example problem is shown in figure 10. The structure simulates an infinite plate with a central crack normal to a remote tensile stress, the problem whose stability was first investigated by Griffith (20) in formulating the basis for LEFM. Here, however, we shall assume at first that LEFM is not appli-

cable and perform a non-linear fracture analysis using constitutive model $D$, shown in Figure 1 . The objectives of this simulation are:

1. Obtain the relationship between applied load and the COD at the plate's center to investigate structural stability.

2. Compute $C 00$ profiles at various load levels to investigate the relationship among total crack length, $a+r$, visible crack length (based on an assumed minimum, visible crack width of $0.001 \mathrm{in} .(0.025 \mathrm{~mm}))$, and process zone length, $r_{p}$. 


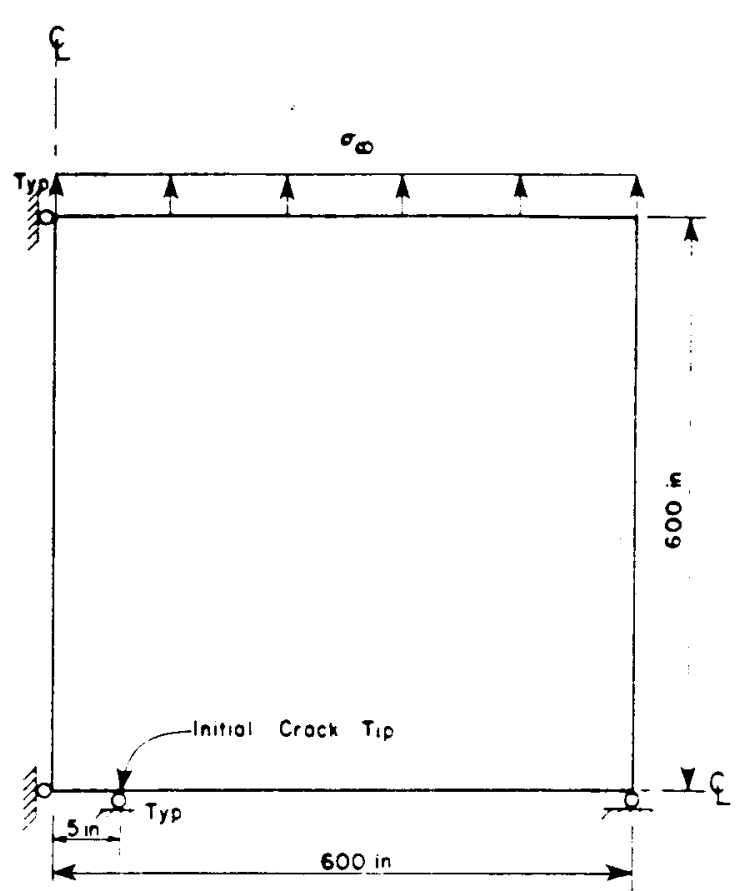

Figure 10. Example Problem \#1.

3. Investigate the evolution of $r_{p}$, and ascertain whether it reaches a steady state length.

The meshes used in this simulation are shown in figures 11 and 12. Figure 11b, a detail of the initial crack region, shows guarter-point singular elements arrayed around the initial, true crack tip, the only place they were employed. A typical global displacement pattern is shown in Figure 13, with the darkened area indicating the process zone.

Results of this simulation are shown in Figures 14 through 16 , and they should be studied together. For example, Figures 14 and 15 show that at the peak load, 142 psi $(0.98 \mathrm{MPa})$, softening had occurred for about 5 inches $(127 \mathrm{~mm})$ ahead of the initial, true crack tip. Additional visible cracking began to occur between the peak load and the next analysis step at 127 psi $(0.88 \mathrm{MPa})$. The true crack tip did not begin to extend, however, until the load had dropped to about $84 \mathrm{psi}(0.58 \mathrm{MPa})$. True crack length had increased to about 120 inches $(3.05 \mathrm{~m})$ by the last analys is step. Simulation was halted at this point because it was felt that, with additional fracturing, the structure would cease to represent an infinite plate to the crack.

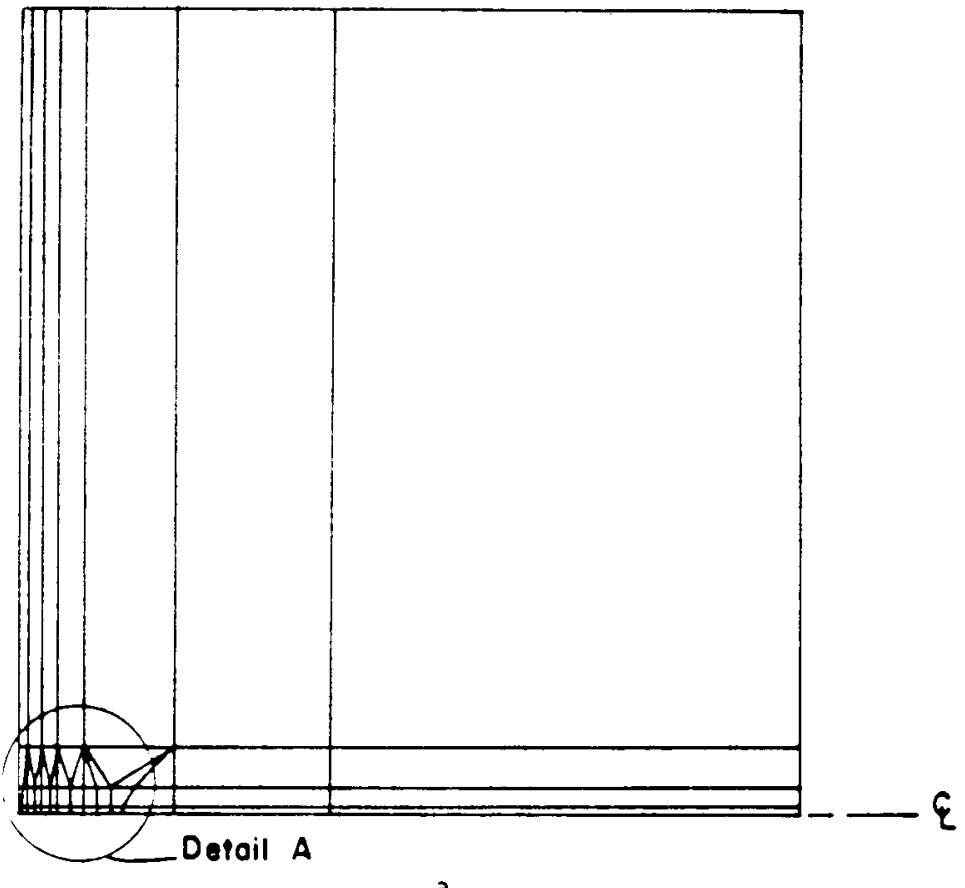

a.

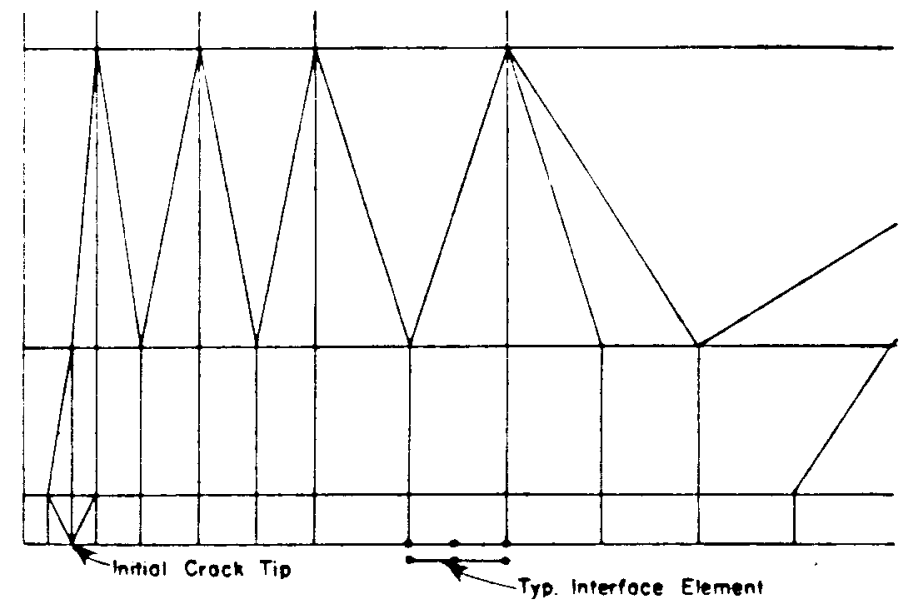

b.

Figure 11. a. First mesh used in Example Problem \#1. b. Detail A of Figure lla. 


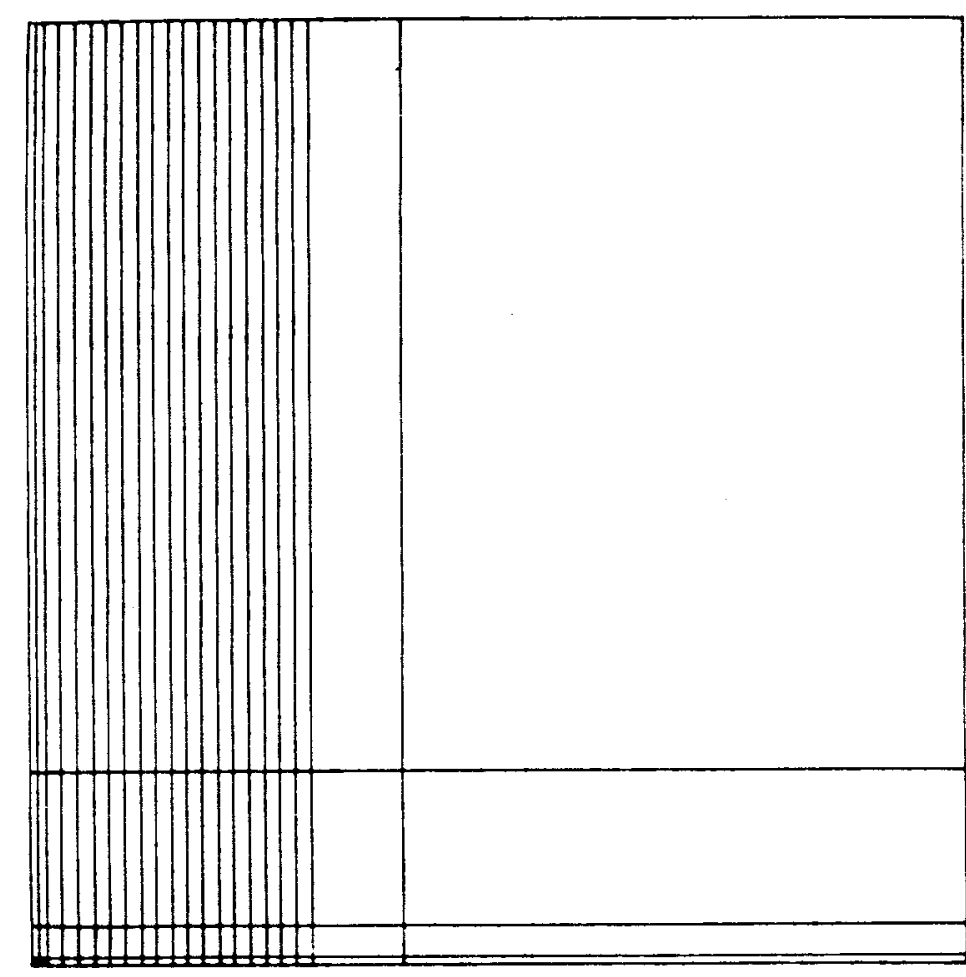

Figure 12. Second mesh used in Example Problem $\# 1$.

The information shown in Figure 15 is replotted in a most interesting form in Figure 16. Here the process zone length, $r$, is plotted against true crack length. It is clear that r first grows rapidly, reaching a peak value of about 60 inches $(\{.52 \mathrm{~m})$, and then decays asymptotically to a steady-state value of no more than 36 inches $(914 \mathrm{~mm})$.

We are now in a position to make some direct comparisons of the behavior of this simulation with the qualitative predictions of the previous section and with the implications of LEFM. First, is the steady-state $r$ of 36 inches reasonable? To answer this question, we must first estimate $K_{I c}$ for this material. The area under the Model $D$ curve, Figure 1, yields a $G$ IC of about $0.23 \mathrm{lb} /$ in. $(0.04 \mathrm{~N} / \mathrm{mm})$. This translates, using Equation (15), into a $K_{I C}$ of about 830 psi $\sqrt{i n}\left(914 \mathrm{MNm}^{-3 / 2}\right)$. Now, it was previously shown that

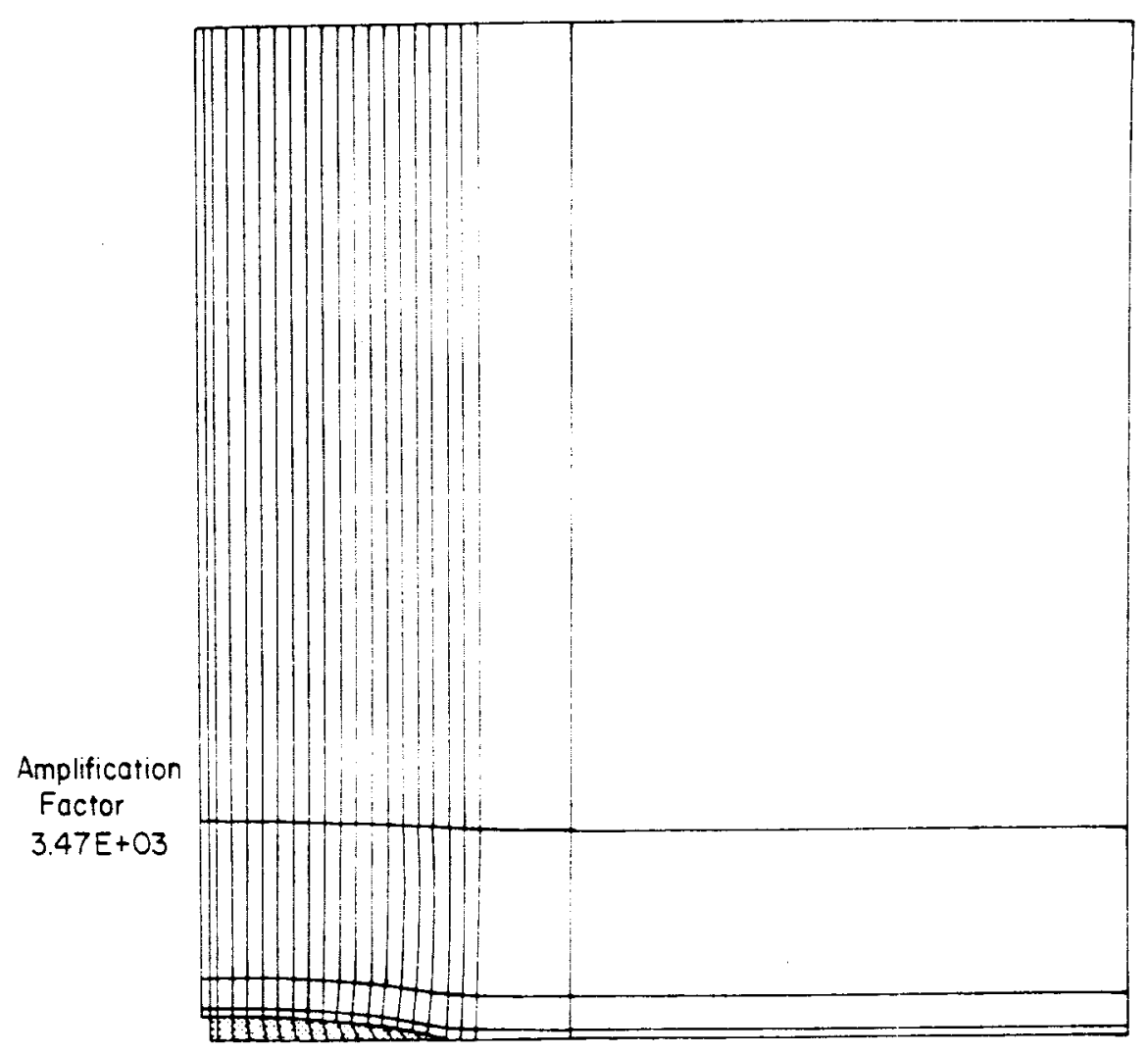

Figure 13. Amplified displaced shape of second mesh at a load level of $\sigma_{\infty}=54$ psi $(0.38 \mathrm{MPa})$. Amplication factor $3.47 \mathrm{E}+03$.

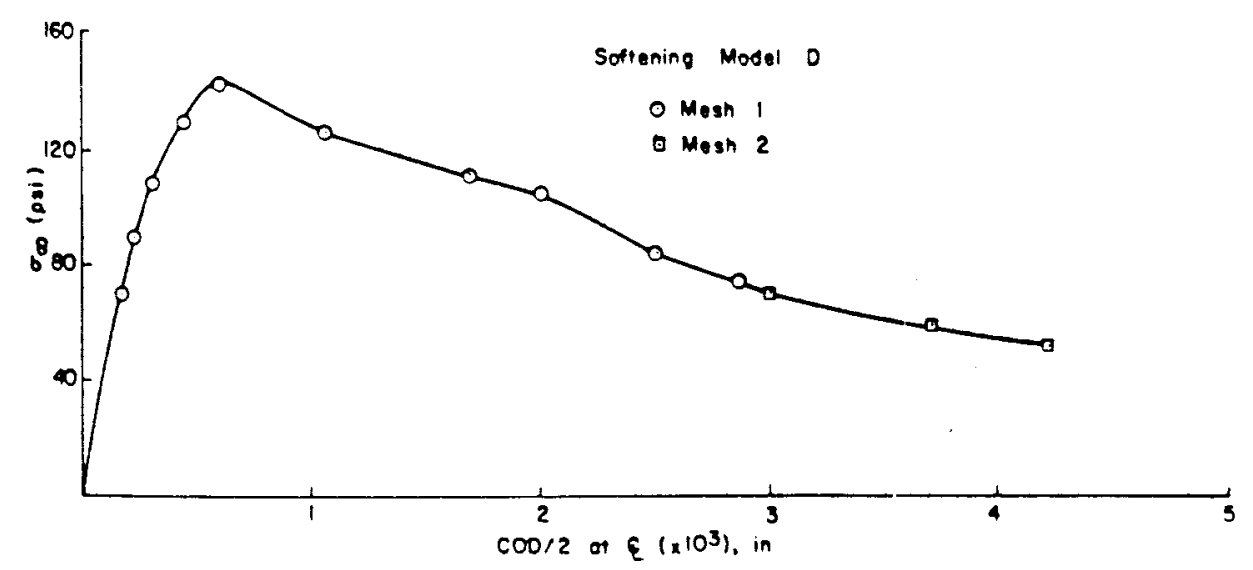

Figure 14. Predicted load versus displacement curve for Example Problem \#i. 

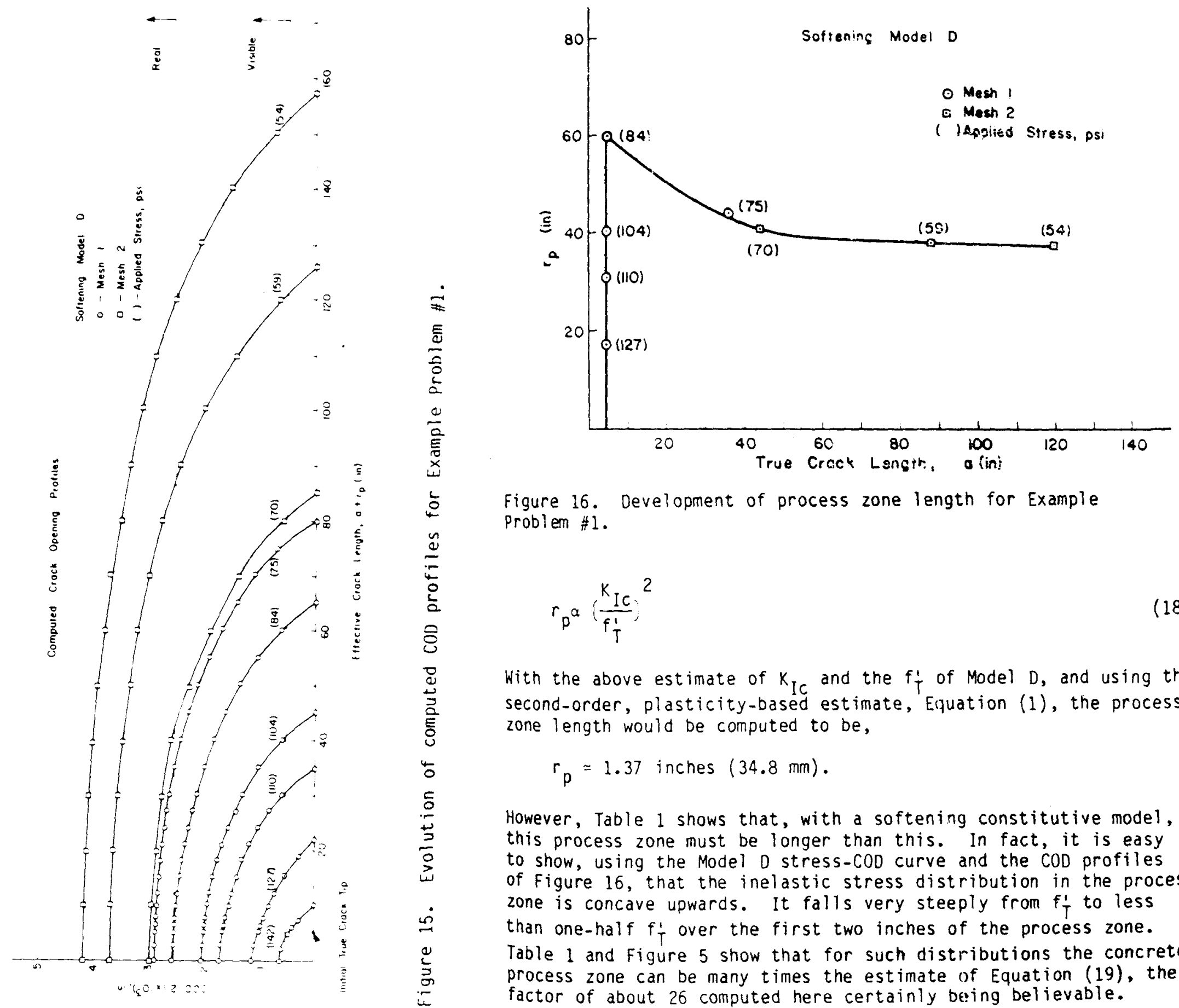

Figure 16. Development of process zone length for Example Problem \#1.

$$
r_{p^{\alpha}}\left(\frac{K_{I C}}{f_{T}^{\prime}}\right)^{2}
$$

With the above estimate of $K_{I C}$ and the $f_{T}$ of Model $D$, and using the second-order, plasticity-based estimate, Equation (1), the process zone length would be computed to be,

$$
r_{p}=1.37 \text { inches }(34.8 \mathrm{~mm}) \text {. }
$$

However, Table 1 shows that, with a softening constitutive model, this process zone must be longer than this. In fact, it is easy to show, using the Model D stress-COD curve and the COD profiles of Figure 16, that the inelastic stress distribution in the process zone is concave upwards. It falls very steeply from fi to less

than one-half $f$ ' over the first two inches of the process zone. Table 1 and Figure 5 show that for such distributions the concrete process zone can be many times the estimate of Equation (19), the factor of about 26 computed here certainly being believable. 
A second question to ask concerning this simulation is: to how long would the true crack have to have grown for LEFM to be acceptable? Assuming a steady-state $r_{p}$ of 36 inches $(914 \mathrm{~mm}$ ), and a ratio of $r_{p}$ to true crack length of 25 for acceptability, a growth to about 900 inches $(22.9 \mathrm{~m})$ would have been required with Model D. At that point, LEFM would predict a critical load on an infinite plate of only about $16 \mathrm{psi}(0.11 \mathrm{MPa})$.

The key conclusion to be drawn from this simulation is this despite the fact that concrete seems more "brittle" than, say, an elastic-perfectly plastic structural steel, in the sense that there is a rapid drop in stress carrying capability past the tensile strength, its process zone can be much larger than the steel's. It is neither accurate nor sufficient to use Equation (3) to assess the applicability of LEFM to concrete. Further implications of this conclusion are pursued in the next example problem.

\subsection{Example 2: A Finite, Center-Cracked Plate}

The experiments of Kesler, Naus, and Lott $(21,22)$ have stirred much debate in the concrete fracture literature. They tested a large number of hardened paste, mortar, and concrete specimens in the configuration shown in Figure 17, and analyzed the results using an approximate stress-intensity factor calibration. Since all their results indicated a strong dependence of apparent toughness, $K_{Q}$, on specimen size, they concluded that LEFM is not applicable to these materials.

Recently, however, the first author re-analyzed their test results (23) with a more accurate stress-intensity factor calibration and reached the opposite conclusion, with $k_{0}$ being fairly independent of specimen size.

These tests, however, will just not go away. Bazant and on (24) have more recently shown that strain readings made near the initial true crack tip during the tests could not be explained using LEFM. What then is the explanation for this contradictory behavior?

One of the concrete test specimens (Test 12, Series LC-2-AD-C of (22)), the same one analyzed by Bazant and Oh (24), is analyzed here with the hope of explaining this contradiction. Further, this example problem seeks these additional objectives:

1. To investigate the difference in response to two constitutive moclels, $D$ of Figure 1 , and $E$ of Figure 6 , fi and $\delta_{c}$ remaining the same.

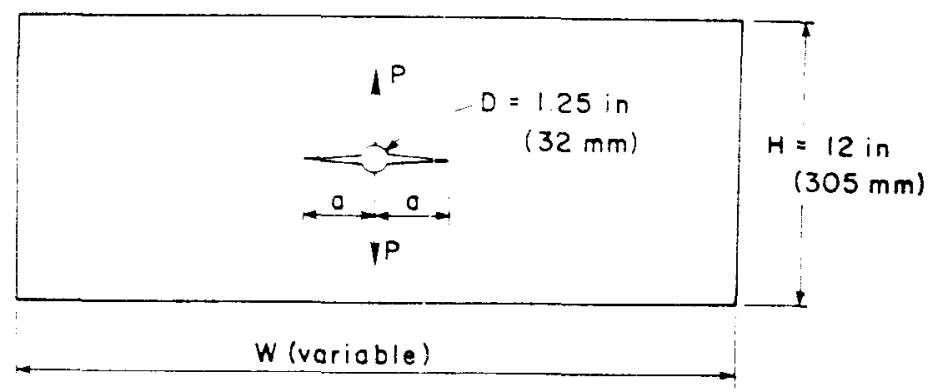

Figure 17. Specimen configuration used in the tests of References 21 and 22. For Example Problem $\# 2, W=18$ inches $(457 \mathrm{~mm}), a=$ 2.5 inches $(63.5 \mathrm{~mm})$.

2. To investigate the shape of the inelastic stress distributions in the process zone on a problem for which the COD profile is theoretically linear, and compare to the previous example in which it was theoretically elliptical.

The mesh used for this simulation is shown, in one of its deflected states, in Figure 18. The linear strain interface (LSI) elements used to model the process zone inelastic stress distribution are clearly seen.

The first result to be shown is the load-displacement response, shown in Figure 19. To interpret this result properly, it is necessary to understand the constitutive models used in the simulations. The o-COD relationship for the material used in the test is not known. The only material property reported in (22) is the splitting tensile strength, about $620 \mathrm{psi}(4.28 \mathrm{MPa})$ at the age of testing. It is well known that the direct tensile strength is less than the splitting strength, so an $f_{T}^{\prime}$ of $400 \mathrm{psi}$ ( $2.76 \mathrm{MPa}$ ) is low but not unreasonable. Tests by petersson (2) show a strong dependence of both $\delta_{c}$ and the shape of the $\sigma-C O D$ curve on maximum aggregate size, Figure 20 . The shape and $\delta_{c}$ of Model $D$ are close to the curve in Figure 20 corresponding to a maximum aggregate size of $2 \mathrm{~mm}$. The maximum aggregate size used in the specimen under consideration, however, was $3 / 4$ inch $(19 \mathrm{~mm})$. It is probable that ${ }_{c} c$ for such a size is at least 0.008 inch $(200 \mu \mathrm{m})$, assuming the same bond strength and aggregate angularity as in Petersson's tests. Also, the shape of the post-peak $\sigma-C O D$ curve would be expected to be straighter than the curves shown in Figure 20. Therefore, the $\delta$ for both models is probably too small, and the shape for Model $D$ much too steep. 


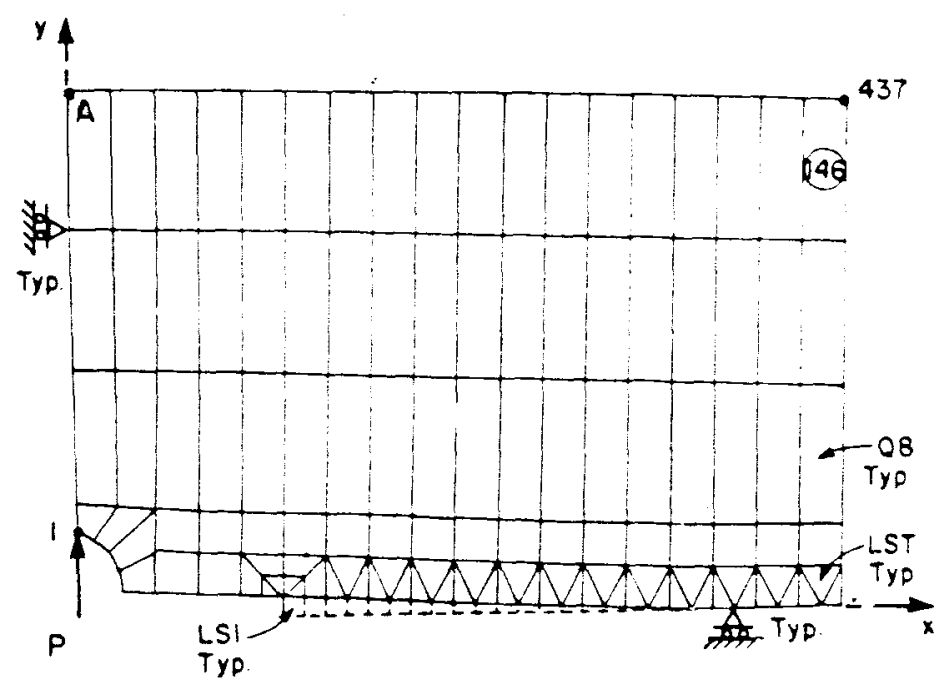

Figure 18. Amplified deflected shape of mesh used in Example Problen $\# 2$.

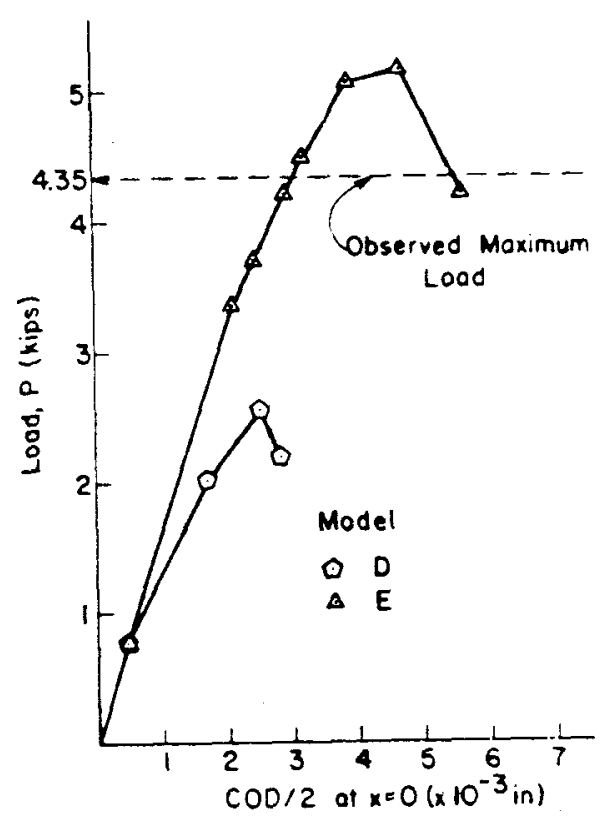

Figure 19. Predicted load-displacement responses for Example Problem \#2.

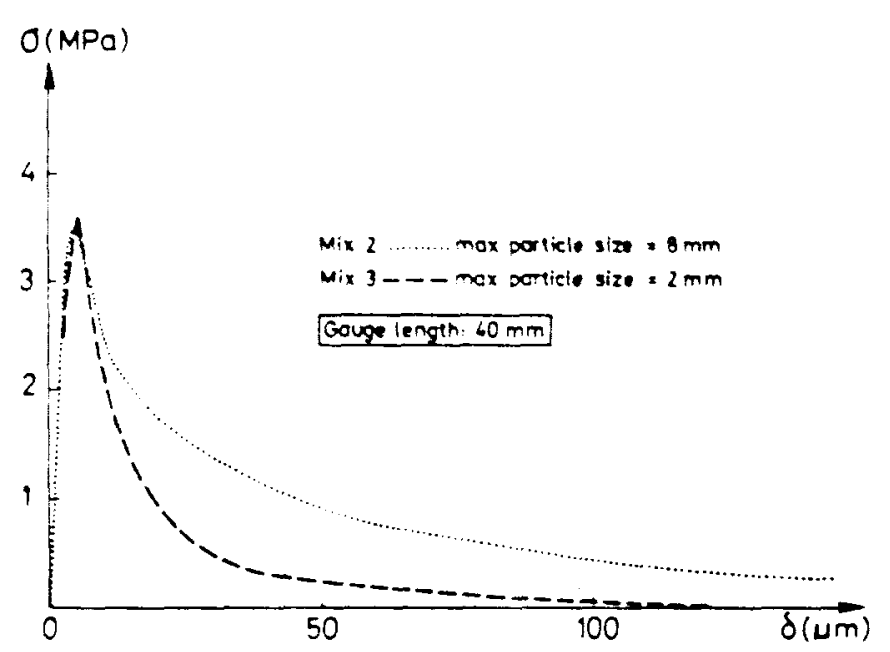

Figure 20. Measured $\sigma-C O D$ relationships for two maximum aggregate sizes. From Ref.?

Given these observations, the results shown in Figure 19 are not surprising. With Model $D$, the process zone unloads much too rapidly, and the peak load is underestimated by over 40 percent. Model $E$, underestimating toughness because of too small a $\hat{i} c$, but overestimating because of its linear shape, yields a peak load prediction about 18 percent too high. Note, however, that the ratio of the two peak load predictions is about 2, while the G Ic ratio is about 4. This is exactly what would be expected from an LEFM point of view. But is the specimen actually behaving according to LEFM? Let us next investigate process zone length.

The process zone is described by Figures 21 and 22 for Model $D$, and 23 and 24 for Model E. Comparisons of Figures 21 with 23 and 22 with 24 show the effect of the shape of the constitutive model for the process zone on its COD profile and inelastic stress distribution, respectively. Under LEFM assumptions, the COD profile for this structure is linear except for the very near crack tip region. For Model $D$, it is slightly concave downwards, Figure 22, while for Model $E$ it progresses from slightly concave upwards to nearly linear with progressive fracturing, Figure 24. Comparison of Figures 22 and 24 with figure 15 clearly shows how different specimen loading arrangements can produce markedly different COD profiles even for the same process zone constitutive models. This rigorous numerical observation was predicted by the approximate techniques used earlier in this paper, as in Figure 7 . 


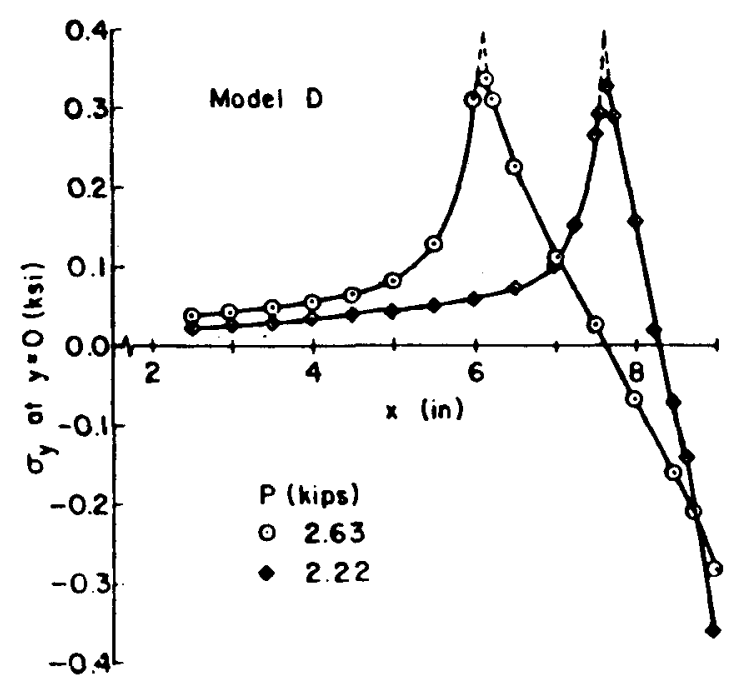

Figure 21. Evolution of normal stress distribution on remaining ligament for Example Problem \#2, constitutive Model

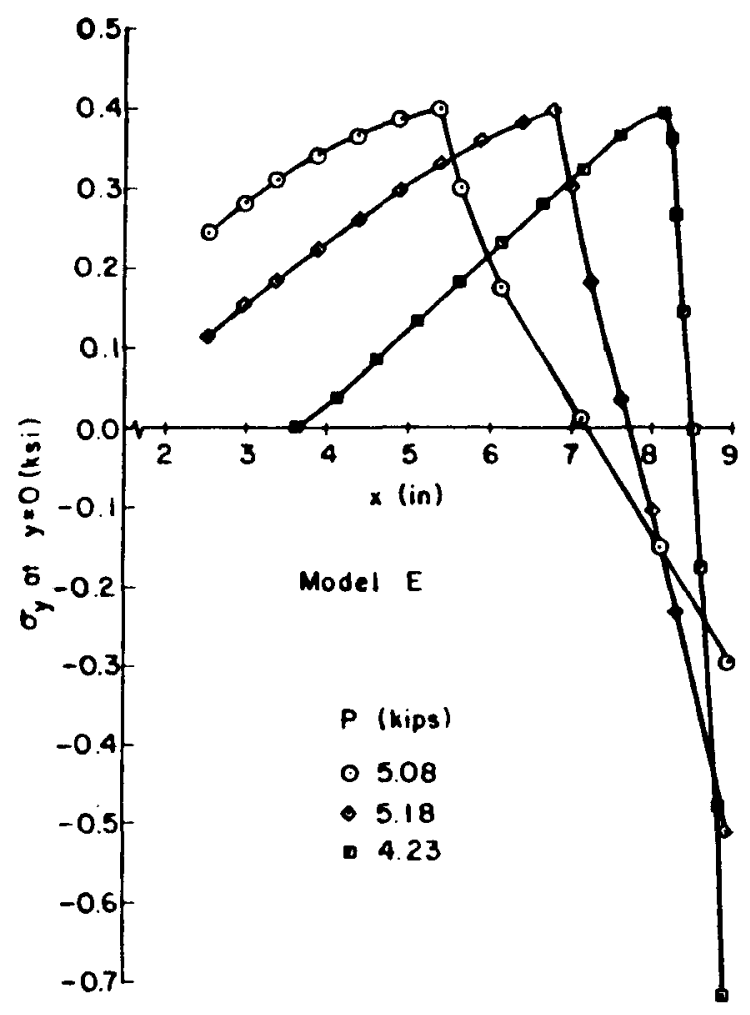

Figure 23. Evolution of normal stress distribution on remaining ligament for Example Problem \#2, constitutive Model E.

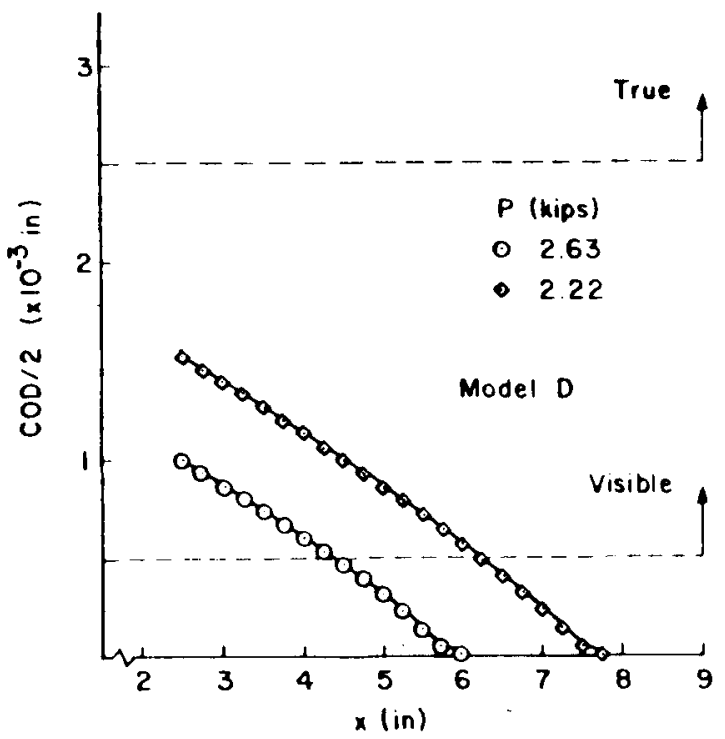

Figure 22. Evolution of COD-profiles for Example Problem \#2, constitutive Model D.

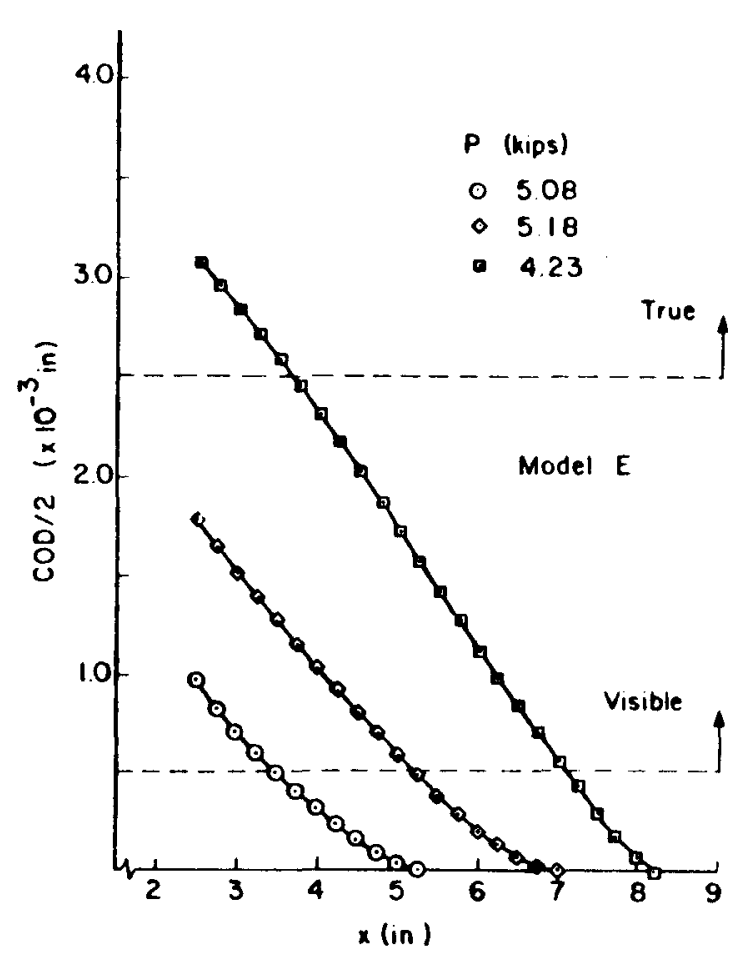

Figure 24. Evolution of COD-profiles for Example Problem \#2, constitutive Model E. 
The direct result of these $C O D$ profile differences is the shape of the inelastic stress distribution in the process zone. The distributions for Model D, Figure 21, and Model E, Figure 23 mirror the shapes of these corstitutive mdoels since the COD profiles both deviate only moderately from straight lines.

The differences in these stress distributions, however, are significant. The true crack tip actually advanced during the simulation with Model E. No true crack advance occurred with Model $D$ even though the process zone tip was pushed nearly as far. Instead, a long "tail" of relatively low stress evolved.

It is clear from Figures 22 and 24 that no steady-state process zone length had developed in these simulations. In both cases the zone had extended about 5 inches $(127 \mathrm{~mm}$ ) ahead of the true crack tip. The tip of the process zone had arrived about 1 inch $(25 \mathrm{~mm})$ from the edge of the plate. This observation suggests an important question: Why did the process zone become so long in the previous example?

The answer is that the effectively infinite extent of the plate in that problem allowed virtually uninhibited stress redistribution ahead of the advancing true crack tip. In the present example, boundary effects are felt almost immediately. Consider the stress distributions shown in figure 23. The first distribution, for $P=5.08 \mathrm{kips}(22.6 \mathrm{kPa})$, shows 3 regimes of stress behavior. Beginning at the initial, true crack tip and extending to about $x=5.5$ inches $(140 \mathrm{~mm})$ is the inelastic stress distribution of the process zone. Starting from the edge of the plate and proceeding in a direction toward the crack to about $x=6.5$ inches $(165 \mathrm{~mm})$ is a linear distribution arising from the bending moment which must exist across the ligament. Between these two distributions is a stress-concentration-like rise, not unlike what one would expect in approaching a true crack tip, as the process zone tip is approached.

However, the distribution corresponding to the last, post-peak load level, $P=4.23 \mathrm{kips}(18.8 \mathrm{kPa})$, is considerably different. At this stage in the simulation, only about one inch $(25.4 \mathrm{~mm})$ of ligament remains to try to accommodate the latter two regimes just described. The distribution in the ligament has become essentially linear, except for a small distance close to the edge of the plate wherein the compressive stress rises precipitously. In the previous example $e^{\prime}$ no bending moment distribution, with its compressive stress region, needs to exist. As the process zone tip extends there is no need to rapidly unload the process zone as in the present example. Further manifestations of the non-LEFM behavior of this specimen are revealed in the following discussion.

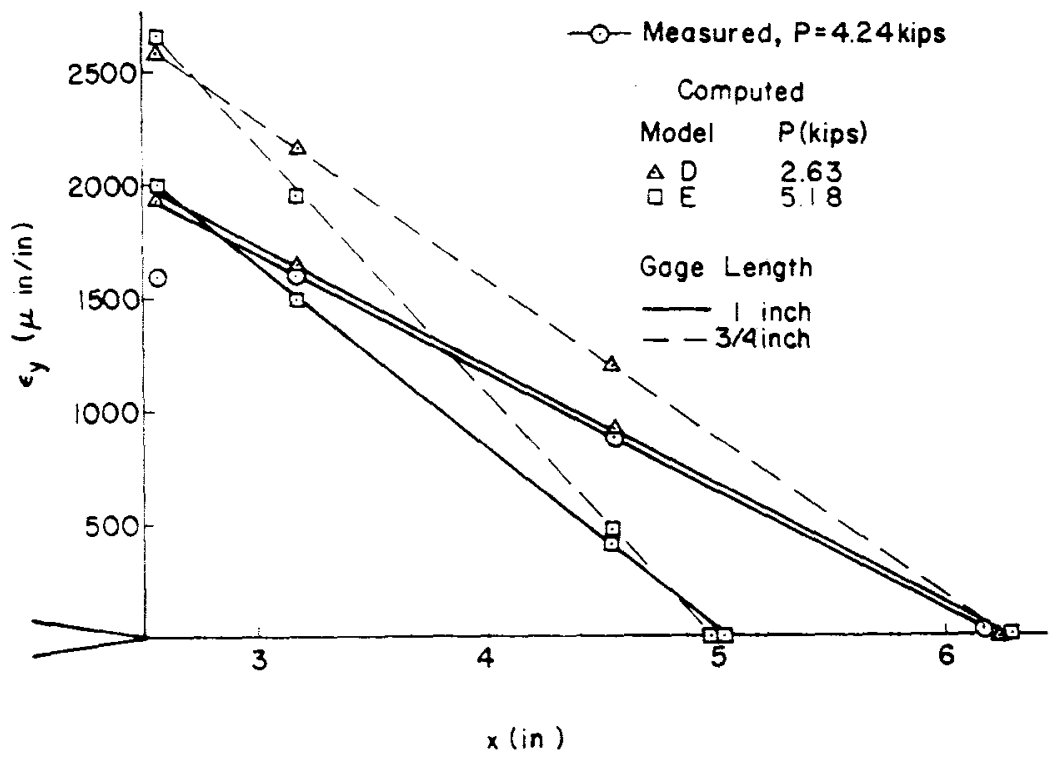

Figure 25. Comparison of measured and computed strain for Example Problem \#2.

As mentioned above, Naus (22) made strain measurements during his tests. Wire strain gages oriented to measure $\varepsilon_{y}$ were arrayed ahead of the initial, true crack tip. Strains measured just before specimen failure are shown in Figure 25. Strain is seen to be very high compared to the expected tensile failure value of about $200 \mu$ in/in. Further, it is seen to increase linearly except for the last reading close to the initial true crack tip.

Comparison of these observations with predictions from the present simulations, Figures 22 and 24 , is encumbered by the fact that gage length was not reported in $(21,22)$. Figure 25 shows the COD-profiles for peak load from Figures 22 and 24 converted to strain profiles via assumed gage lengths. The predicted profiles bracket the measured profile, except for the reading close to the initial crack tip, and are nearly linear. It is likely that the gage closest to the crack tip began to slip at this very high strain; measurements from this gage location on other specimens also showed this anomalous behavior.

Figure 25 shows that Bazant and on (24) are correct. The measured strains can only be explained by considerable extension of a process zone before peak load. From the perspective of the methods of the present simulation, the gages were reading highly localized strain: a crack-opening-displacement. 


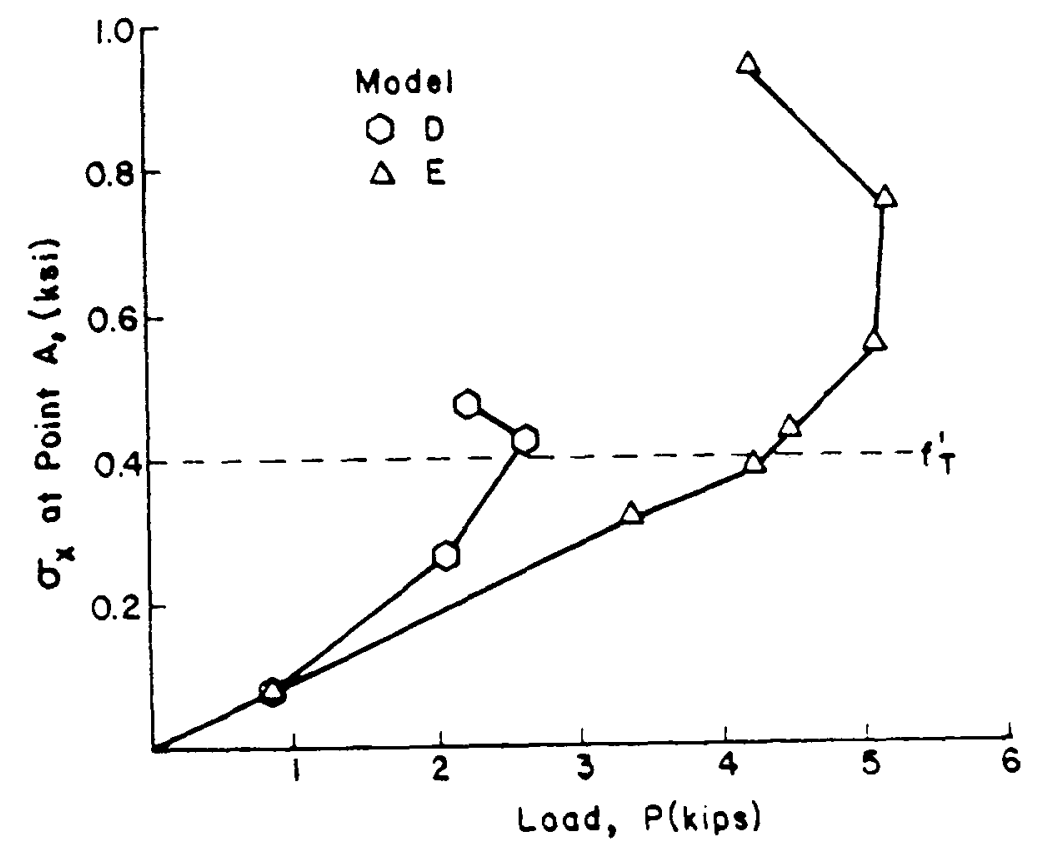

Figure 26. Predicted variation of tensile stress at point $A$, Figure 18, with applied load, Example Problem \#2.

All of the previous discussion concerning the process zone in this example points decidedly towards this being a non-LEFM test, and yet an enigma remains: why the apparently LEFM response of this and companion tests when viewed on the basis of $K_{0}$ independence from specimen size and crack length (23)? A very plausible explanation, one that in fact requires our attention to be shifted away from the initial crack and its propagation, proceeds as follows.

Consider the location of point A, Figure 18, and the displaced shape shown in the same figure. This shape shows that the top and bottom halves of this specimen behave like deep beams with partial moment restraint at their ends produced by remaining ligament.

point A lies; at the location of highest fiber stress in tension of such a beam. The writers find it more than just coincidental that the $x$-direction tensile stress at point $A$ for the specimen analyzed in this example varies as shown in Figure 26: as the computed peak load is approached, the concrete tensile strength is exceeded at point A! Consistency in application of the constitutive model would dictate that a second set of cracks would initiate at points $A$ at approximately the peak load. This phenomenon was not includec in the present simulations. Note that it is not obvious that these cracks would have been visible after specimen failure, but their existence would certainly have caused stress redistribution in the specimen. Is it possible that the apparently LEFM response of the tests was the result of two obscuring non-linear effects? This question could be definitively answered and these tests finally put to rest by a study which included both nonlinearities and a range of specimen sizes and crack lengths.

In the next example problem we relax another assumption by extending our non-linear fracture modeling technique to a problem in which crack growth is not self-similar.

\subsection{Example 3: Mixed-Mode Fracture of a Plain Concrete Beam}

The last example problem is the structure shown in figure 27. Mortar and concrete beams in this configuration were tested by Arrea and Ingraffea (25). The antisymmetric loading produces mixed-mode, $K_{I}-K_{I I}$, stress-intensity at the tip of the initial, true crack tip.

The purpose of this example is to show that the techniques used in the previous examples can be extended to curvilinear crack propagation in geomaterials. Details of the algorithms necessary for this extension can be found in References 4 and 19.

Because this example involves both crack sliding and crack opening displacements, CSD and COD, respectively, there exists not only normal stress transfer across the process zone but shear stress as well. Consequently, the so-called "aggregate interlock" model of Fenwick and Pauley (26) in which shear transfer across a crack is related to the COD was employed in this simulation.

Two analysis phases were employed. The first was a parameter study in which the crack trajectory observed in testing was modeled in the mesh, as shown in Figure 28. The $\sigma-C O D$ constitutive model was then varied in an attempt to reproduce the observed load versus crack-mouth-sliding-displacement, CMSD. This approach is the same as the "fictitious crack" method (18), except that the crack is discretely modeled.

The results of this parameter study are shown in Figure 29 , with the lettered models shown in Figure 1. The experimental results shown in this figure and from two different tests on mortar beams (25) with a maximum aggregate size of about 0.375 inch $(9.5 \mathrm{~mm})$ and a compressive strength $\mathrm{f}^{\prime}$, of about $6.6 \mathrm{ksi}(45.5$ $\mathrm{MPa}$ ). These results indicate a trend ${ }^{c}$ towards a constitutive model with a $\delta$ much less than that used in the previous example. This is to be expected since the maximum aggregate size is much less in this case. A typical displaced shape of the structure is show in Figure 30 . 


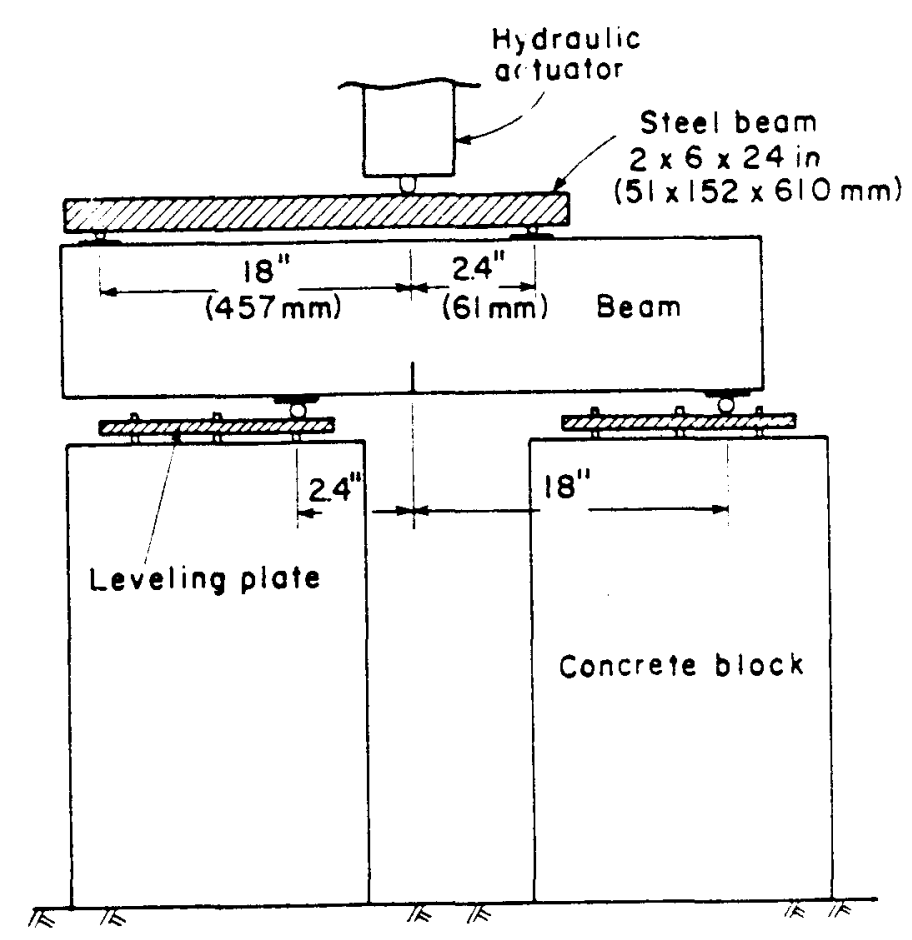

Figure 27. Test specimen and loading arrangement for Example Problem \#3. From Ref. 25.

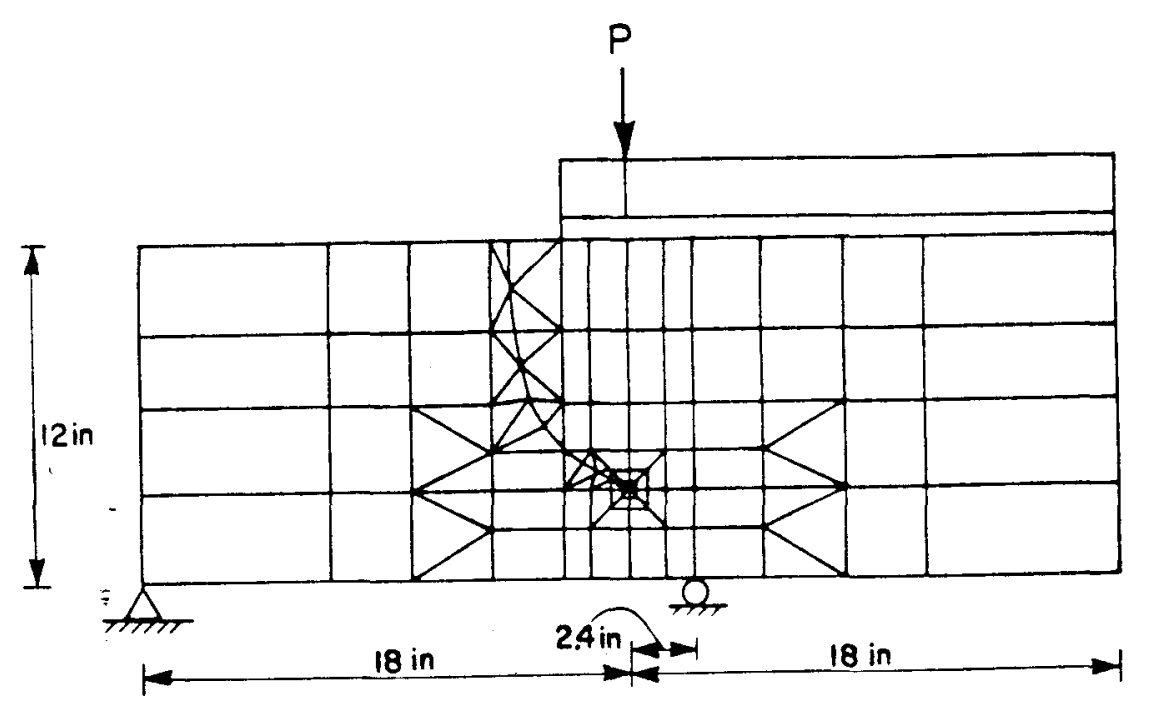

Figure 28. Mesh used for first phase, parameter study for Example Problem \#3.

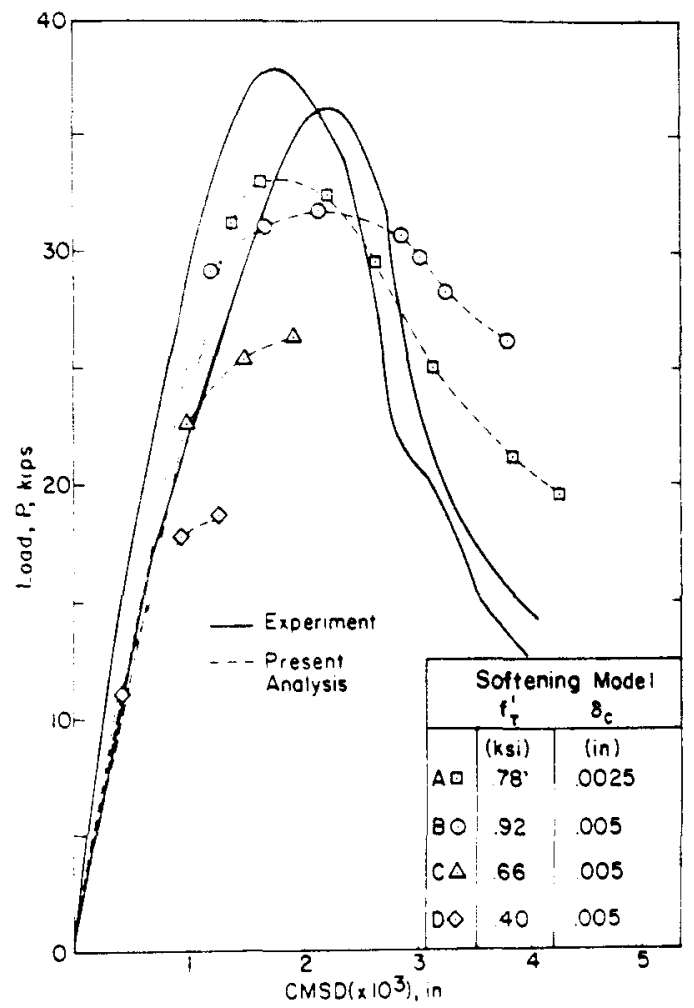

Figure 29. Results of parameter study for first phase of Example Problem $\# 3$.

Although none of the models used proved completely satisfactory, Model A was chosen for the second phase of this simulation. In this phase only the cast-in starter crack was modeled in the initial mesh, Figure 31. A discrete propagation analysis was performed with automatic remeshing occurring at each crack increment. The final mesh configuration and displaced shape are shown in Figure 32.

The predicted trajectory of the crack was very close to the observed, and the computed load versus CMOD response, Figure 33 , was very similar to that obtained during the parameter study phase.

Experience with this simulation strongly suggests that the response is sensitive to the shear transfer model across the process zone and across the true crack itself. Although the shear and normal stress transfer models used in these simulations were uncoupled, some degree of coupling through dilatency is certain. These are fertile areas for further research. 


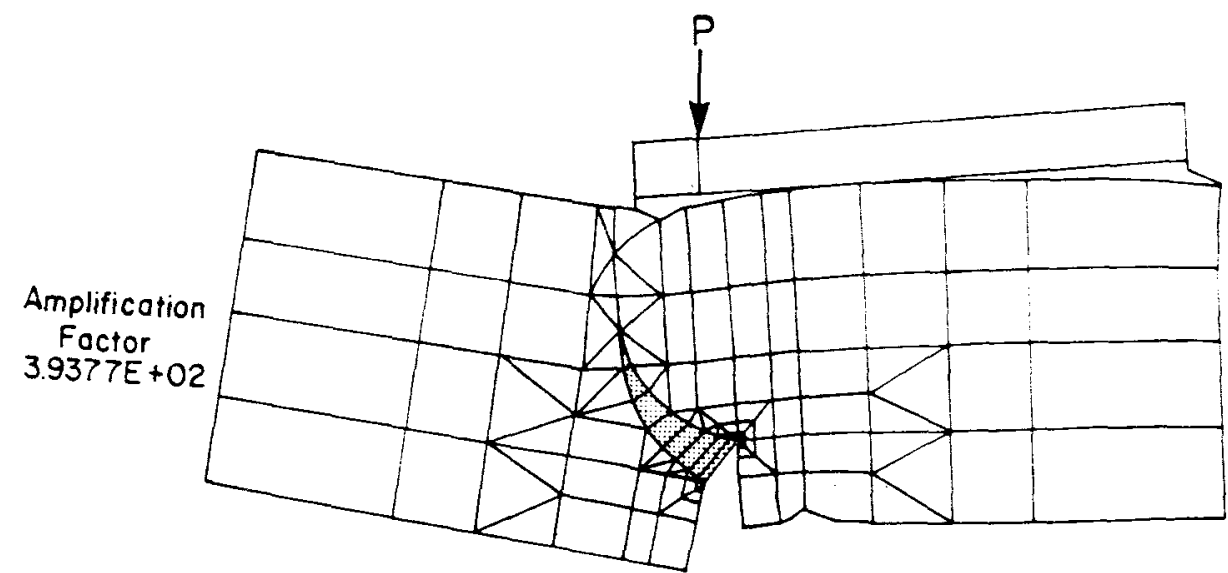

Figure 30. Amplified displaced shape of mesh shown in figure 28. Amplification factor $=394$.

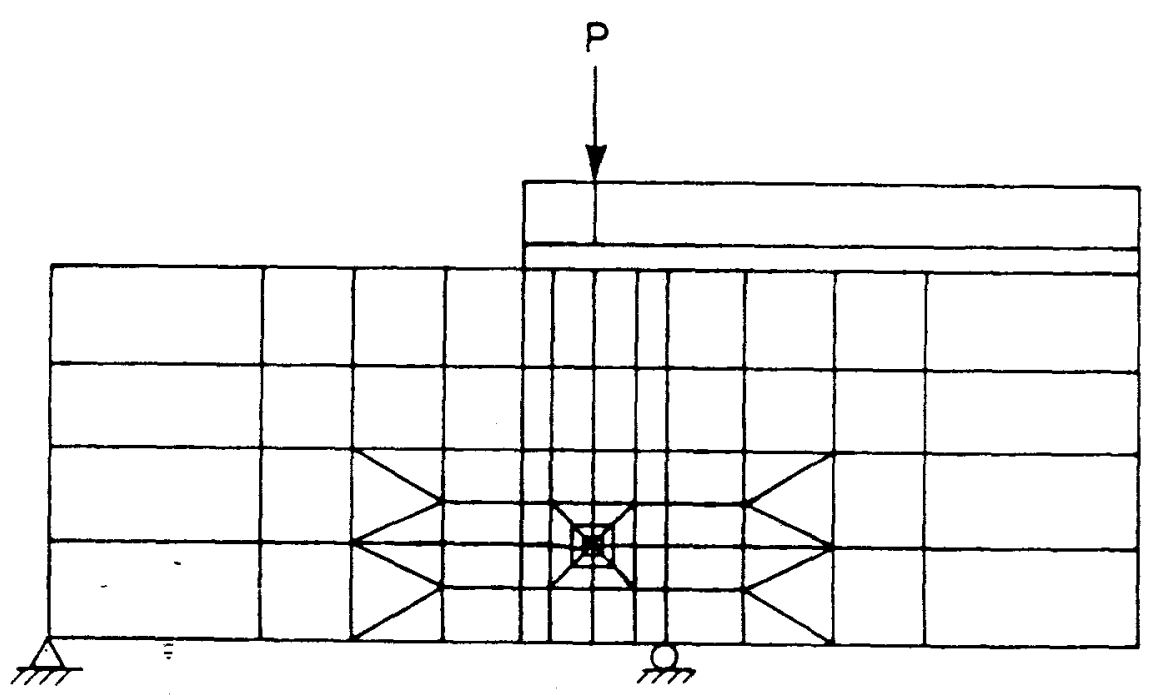

Figure 31. Initial mesh for second-phase, crack propagation study of Example Problem \#3.

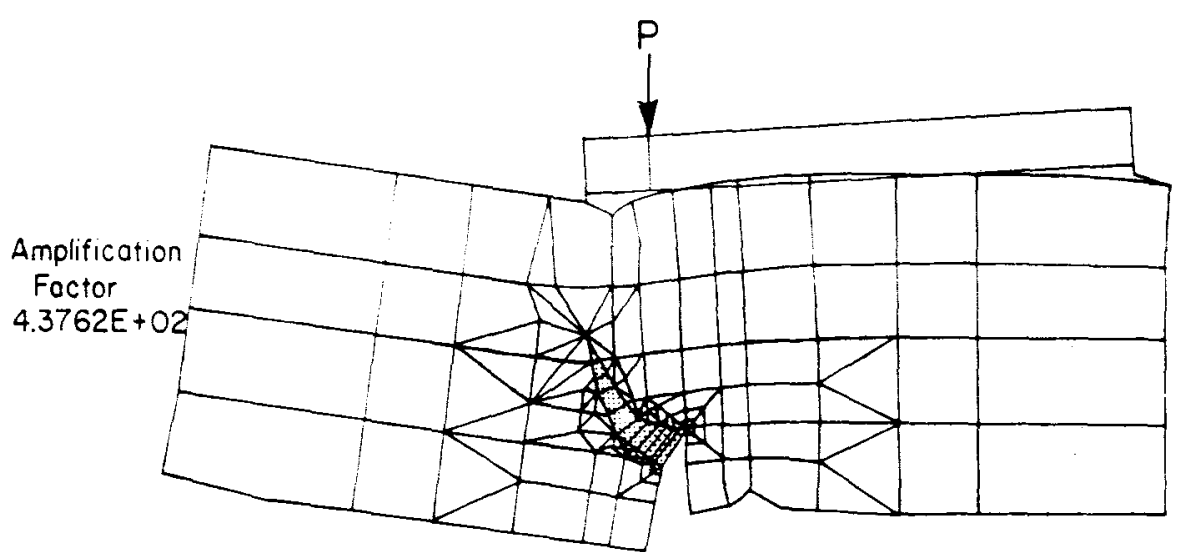

Figure 32. Amplified displaced shape after 5 crack increments through the mesh shown in Figure 31. Amplification factor $=438$.

\section{CONCLUSIONS}

This paper has shown how non-linear fracture processes can be modeled in finite element simulations involving discrete crack representations. The most important assumption involved is that the process zone is no more than an extension of the true crack itself: the zone is not an area, it is a length.

The constitutive modelling for such a zone is then considerably simplified. For Mode I'propagation, one needs only a relationship between the normal tensile stress transmitted across the process zone and the opening-displacement of that part of the crack in this length.

We first showed how, with these simplifications, one could arrive at quantitative assessments of process zone length in geomaterials using only hand calculations. It was quickly seen that the strain softening character of such materials produces process zone lengths much larger than those in more ductile materials.

These simple calculations were then supported by finite element analyses of three example problems. In the first, hypothetical problem, the growth of the process zone ahead of a true crack was studied in a very large structure. It was concluded that, as predicted by hand calculation and LEFM considerations, the process zone grew to a steady state length and that this length was far in excess of that predicted by models based on elasticperfectly plastic constitutive models. 


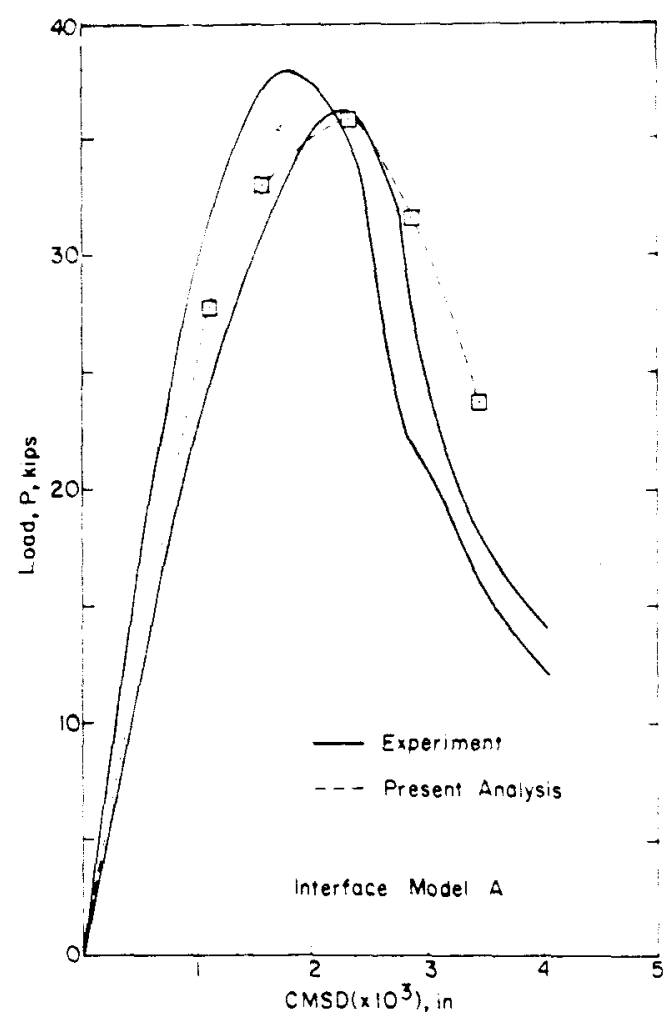

Figure 33. Comparison of crack propagation model prediction with experimental results for Example Problem \#3.

The next two problems involved simulations of actual experiments. The tests of Kesler, Naus, and Lott (21) were again analyzed, but for the first time using a non-linear fracture model in a discrete crack representation. It was concluded that these tests were not valid measurements of $\mathrm{K}_{\mathrm{IC}}$. Moreover, it was furthe shown that they still have not been properly analyzed.

The final analysis involved curvilinear crack propagation. The process zone constitutive modeling was extended to include shear transfer across the zone as a function of its openingdisplacement. The automatic rezoning feature of FEFAP (19) was employed here to permit cracking to evolve as predicted by the non-linear stress transfer models without being constrained by meshing considerations.

Parameter studies performed during these simulations clearly show the dependence of process zone length on the crack opening profiles characteristic of the structure, and on the $\sigma-C O D$ relationship characteristic of the geomaterial.
Using the modeling tools described here, it is now possible to make a rigorous, a priori assessment of the applicability of LEFM to the fracture process occurring over a wide range of structure scale.

\section{ACKNOWLEDGEMENTS}

The work reported here was sponsored by the National Science Foundation under Grants PFR-7900711 and CME80-20925.

The authors would like to thank Mr. Walid Najjar for performing some of the analyses, and Mrs. Oneita Weeks for typing the manuscript.

\section{REFERENCES}

1. Irwin, G.R. Plastic Zone Near a Crack and Fracture Toughness. Proceedings 7 th Sagamore Conference (1960) IV-63.

2. Petersson, P-E. Crack Growth and Development of Fracture Zones in Plain Concrete and Similar Materials. Report TVBM-1006, Division of Building Materials, Lund Institute of Technology, Lund, Sweden (1981).

3. Catalano, D. and A.R. Ingraffea. Concrete Fracture: A Linear Elastic Fracture Mechanics Approach. Department of Structural Engineering Report 82-1, School of Civil and Environmental Engineering, Cornell University, Ithaca, NY (1982).

4. Ingraffea, A.R., W. Gerstle, P. Gergely, and V. Saouma. Fracture Mechanics of Bond in Reinforced Concrete. Journal of the Structural Dtvision, American Society of Civil Engineers, Vol. 110, No. 4 (April 1984) 871-890.

5. Mindess, S. and J.S. Nadeau. Effect of Notch Width on KIC for Mortar and Concrete. Cement and Concrete Research, vol. 6 (1976) 529-534.

6. Schmidt, R. and T. Lutz. $K_{I C}$ and $J_{I C}$ of Westerly Granite Effects of Thickness and In-Plane Dimensions. American Society for Testing and Materials, STP 678 (1979) 166-182.

7. Rashid, Y.R. Analys is of Prestressed Concrete Pressure Vessels. Nuclear Engineering and Design, Vol. 7, No. 4 (April 1968) 334-344. 
8. Saouma, V., A.R. Ingraffea, P. Gergely, and R.N. White. Interactive Finite Element Analysis of Reinforced Concrete: A Fracture Mechanics Approach. Department of Structural Engineering Report 81-5, School of Civil and Environmental Engineering, Cornell University, Ithaca, NY (1981).

9. Saouma, V.E. and A.R. Ingraffea. Fracture Mechanics Analysis of Discrete Cracking. Proceedings, IABSE Colloquium on Advanced Mechanics of Reinforced Concrete, Delft (June 1981) 393-416.

10. Evans, R.H. and M.S. Marathe. Microcracking and Stress-Strain Curves for Concrete in Tension. Materiaux et Constructions, Vol. 1, No. 1 (1968) 61-64.

11. Broek, D. Elementary Engineering Fracture Mechanics (The Hague, Martinus Nijhoff Publishers, 1982).

12. Annual Book of Standards, American Society for Testing and Materials, Section 3, E399-83 (1983) 518-553.

13. Sok, C., J. Baron, and D. Francois. Fracture Mechanics Applied to Concrete. Cement and Concrete Research, Vol. 9, No. 5 (1979) 641-648 [In French].

14. Entow, V. and V. Yagust. Experimental Investigation of Laws Governing Quasi-Static Development of Macrocracks in Concrete. Mekhanika Trerdogo Tela, Vol. 10 (1975) 93-103.

15. Cedolin, L., S. Dei Poli, and I. Iori. Experimental Analysis of the Process of Fracture Formation in Concrete. Studi $e$ Ricerche, No. 3, Politecnico di Milano, Italia (1981) [In Italian].

16. Mindess, S. and S. Diamond. The Cracking and Fracture of Mortar. In Fracture in Concrete, W.F. Chen and E.C. Ting, eds. American Society of Civil Engineers (1980) 15-27.

17. Hoaglund, R., G. Mahn, and A. Rosenfield. Influence of Microstructure on Fracture Propagation in Rock. In Rock Mechanics, Vol. 5 (1973) 77-106.

18. Hillerborg, A. M. Modeer, and P-E. Petersson. Analysis of Crack Formation and Crack Growth in Concrete by Means of Fracture Mechanics and Finite Elements. Cement and Concrete Research, Vol. 6, No. 6 (1976) 773-782.
19. Ingraffea, A.R. and V. Saouma, Numerical Modeling of Discrete Crack Propagation in Reinforced and Plain Concrete. To appear in Application of Fracture Mechanics to Concrete Structures, G.C. Sih and A. DiTommaso, eds. (The Hague, Martinus Nijhoff Publishers, 1984).

20. Griffith, A.A. The Phenomena of Rupture and Flow in Solids. Phil. Trans. Royal Soc. of London, A221 (1921) 163-197.

21. Kesler, C., D. Naus, and J. Lott. Fracture Mechanics - Its Applicability to Concrete. Proceedings of the 1971 International Conference on Mechanical Behavior of Materials, Vol. IV, Japan (1972) 113-124.

22. Naus, D. Applicability of Linear-Elastic Fracture Mechanics to Portland Cement Concrete. Ph.D. thesis, University of Illinois at Urbana-Champaign (1971).

23. Saouma, V., A.R. Ingraffea, and D. Catalano. Fracture Toughness of Concrete: K Ic Revisited. Journal of the Engineering Mechanics Division, ASCE, Vol. 108, No. EM6 (1982) 1152-1166.

24. Bazant, Z. and B.H. Oh. Crack Band Theory for Fracture of Concrete. Materiaux et Constructions, Vol. 16, No. 93 (1983) 155-177.

25. Arrea, M. and A.R. Ingraffea. Mixed-Mode Crack Propagation in Mortar and Concrete. Department of Structural Engineering Report 81-13, School of Civil and Environmental Engineering, Cornell University, Ithaca, NY (1981).

26. Fenwick, R.C. and T. Paulay. Mechanics of Shear Resistance of Concrete Beams. Journal of the Structural Division, American Society of Civil Engineers, Vol. 94, No. STIO' (1968)
2325-2350. 